\title{
Sistema evolutivo eficiente para aprendizagem estrutural de redes Bayesianas
}

\author{
Edwin Rafael Villanueva Talavera
}

Tese apresentada à Escola de Engenharia de São Carlos da Universidade de São Paulo, como parte dos requisitos para obtenção do título de Doutor em Ciências, Programa de Engenharia Elétrica

ORIENTADOR: Prof. Dr. Carlos Dias Maciel ÁREA DE CONCENTRAÇÃO: Sistemas Dinâmicos 
AUTORIZO A REPRODUÇÃO TOTAL OU PARCIAL DESTE TRABALHO, POR QUALQUER MEIO CONVENCIONAL OU ELETRONNICO, PARA FINS DE ESTUDO E PESQUISA, DESDE QUE CITADA A FONTE.

Villanueva Talavera, Edwin Rafael

Sistema evolutivo eficiente para aprendizagem

estrutural de redes Bayesianas. / Edwin Rafael

Villanueva Talavera; orientador Carlos Dias Maciel.

São Carlos, 2012

Tese (Doutorado) - Programa de Pós-Graduação em Engenharia Elétrica e Área de Concentração em Sistemas Dinâmicos -- Escola de Engenharia de São Carlos da Universidade de São Paulo, 2012.

1. Redes Bayesianas. 2. Aprendizagem estrutural. 3. Computação evolutiva. I. Título. 


\section{FOLHA DE JULGAMENTO}

Candidato: Bacharel EDWIN RAFAEL VILLANUEVA TALAVERA.

Título da tese: "Sistema evolutivo eficiente para aprendizagem estrutural de redes Bayesianas".

Data da defesa: 21/09/2012

\section{Comissão Julgadora:}

Prof. Associado Carlos Dias Maciel (Orientador) (Escola de Engenharia de São Carlos/EESC)

Prof. Dr. Carlos Henrique Costa Ribeiro (Instituto Tecnológico de Aeronáutica/ITA)

Prof. Dr. Estevam Rafael Hruschka Júnior (Universidade Federal de São Carlos/UFSCar)

Prof. Dr. Ricardo Zorzetto Nicoliello Vêncio (Faculdade de Filosofia, Ciências e Letras de Ribeirão Preto/USP)

Prof. Titular Francisco Javier Ramirez Fernandez (Escola Politécnica/USP)
Resultado:
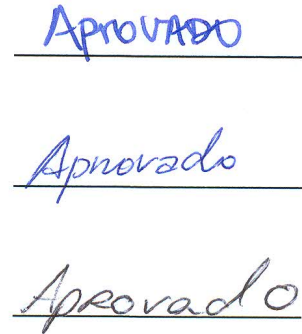

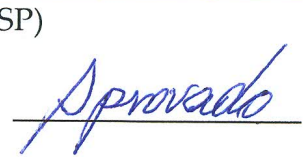

Coordenador do Programa de Pós-Graduação em Engenharia Elétrica e Presidente da Comissão de Pós-Graduação:

Prof. Titular Denis Vinicius Coury 
Dedicatória

Aos meus pais, Aidee e José, que desde cedo me impulsionaram na senda do conhecimento. A minha esposa Soledad e a meu filho Gabriel por seu amor, apoio e paciência nesta longa caminhada. 
Ao meu orientador Prof. Dr. Carlos Dias Maciel, por dar-me a oportunidade, confiança e liberdade para desenvolver o presente trabalho.

A minha esposa Soledad, que me apoiou e energizou nos momentos decisivos. Sem você tenho certeza que não conseguiria.

Aos membros da banca de qualificação, professores Ricardo Vêncio e Carlos Henrique Costa Ribeiro, pelas críticas para enriquecer o trabalho.

À professora Vilma Alves de Oliveira, por facilitar-me a concessão parcial da bolsa através do seu projeto CAPES/PROCAD.

Aos meus amigos do LPS que alguma vez compartilhamos dias memoráveis e também dias cinzentos.

À CAPES, pelo apoio financeiro outorgado em vinte meses de bolsa. 
"Transportai um punhado de terra todos os dias e fareis uma montanha." Confúcio 


\section{Conteúdo}

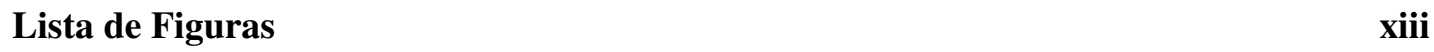

$\begin{array}{lll}\text { Lista de Tabelas } & \text { xv }\end{array}$

$\begin{array}{ll}\text { Lista de Símbolos } & \text { xvii }\end{array}$

Lista de Siglas

Resumo $\quad$ xxi

$\begin{array}{lll}\text { Abstract } & \text { xxiii }\end{array}$

1 Introdução 1

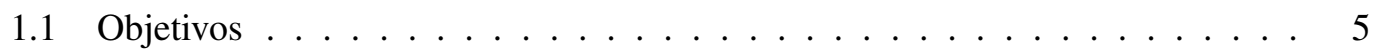

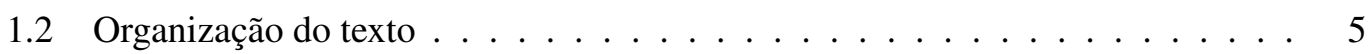

2 Fundamentos Teóricos $\quad 7$

2.1 Teoria de probabilidades . . . . . . . . . . . . . 7

2.2 Teoria de grafos $\ldots \ldots \ldots \ldots \ldots \ldots$

2.3 Redes Bayesianas . . . . . . . . . . . . . . . . . . . . . . . . . 14

2.4 Fundamentos da aprendizagem estrutural de redes Bayesianas . . . . . . . . 17

2.4.1 Propriedades estruturais usadas na aprendizagem de redes Bayesianas . 17

2.4.2 Avaliação de redes Bayesianas . . . . . . . . . . . . . . . 21

3 Revisão Bibliográfica $\quad 23$

3.1 Aprendizagem estrutural de RBs baseada em testes de independência condicional 23

3.2 Aprendizagem estrutural baseada em busca e pontuação . . . . . . . . . . . . 26

3.3 Métodos híbridos . . . . . . . . . . . . . . . . . . . . . . . . 28

3.4 Métodos evolutivos . . . . . . . . . . . . . . . . . . . . . . 30

3.4 .1 Paradigma Evolutivo . . . . . . . . . . . . . . . 30

3.4 .2 Espaço de busca . . . . . . . . . . . . . . . 32 
3.4 .3 Codificação das soluções $\ldots \ldots \ldots$. . . . . . . . . . . . . 33

3.4 .4 Operadores de busca . . . . . . . . . . . . . . . . . . . . . . . . 34

3.4 .5 Redução do espaço de busca . . . . . . . . . . . . . . . . . . . 35

3.4.6 Eficiência Computacional . . . . . . . . . . . . . . . 36

3.4 .7 Ajuste de Parametros . . . . . . . . . . . . . . . . 36

4 Sistema Evolutivo Eficiente para Aprendizagem de Estruturas de Redes Bayesianas - EES-BN 39

4.1 Arquitetura do sistema . . . . . . . . . . . . . . . . . . . . . . . . . . 39

4.2 Redução do espaço de busca . . . . . . . . . . . . . . . . . . . . . . . . 41

4.2.1 Método de estimação de superestruturas: Opt01SS . . . . . . . . . . 42

4.2.2 Método de estimação de superestruturas: OptHPC . . . . . . . . . . . 50

4.3 Representação de soluções em EES-BN . . . . . . . . . . . . . . . . . . 58

4.4 Recombinação em EES-BN: operador MergePop . . . . . . . . . . . . . . . . 59

4.5 Mutação e Substituição em EES-BN . . . . . . . . . . . . . . . . . . . . . . 62

4.6 Injeção de Diversidade em EES-BN . . . . . . . . . . . . . . . . . . . . . 64

4.7 Autorregulação em EES-BN . . . . . . . . . . . . . . . . . . . . . . . 66

5 Avaliação Experimental

$5.1 \quad$ Dados . . . . . . . . . . . . . . . . . . . . . . . . . . . 69

5.2 Avaliação de Opt01SS e OptHPC . . . . . . . . . . . . . . . . . . 71

5.2.1 Resultados de sensibilidade e especificidade . . . . . . . . . . . 73

5.2.2 Resultados de custo computacional . . . . . . . . . . . . . . . . 78

5.3 Avaliação do operador de recombinação MergePop . . . . . . . . . . . . . . 80

5.4 Avaliação dos blocos de recombinação, mutação e injeção de diversidade . . . 82

5.5 Avaliação da inicialização em EES-BN . . . . . . . . . . . . . . . . 86

5.6 Comparação de EES-BN contra outros algoritmos representativos . . . . . . 87

6 Aplicações $\quad 93$

6.1 Aplicação na modelagem da rede gênica do sistema de regulação do ciclo celular da levadura (Saccharomyces cerevisiae) . . . . . . . . . . . . 93

6.2 Aplicação na modelagem de desequilíbrio de ligação . . . . . . . . . . . . . 100

7 Conclusões 111

7.1 Contribuições e Publicações . . . . . . . . . . . . . . . . . . . . . . 113

7.2 Limitações e sugestões de trabalhos futuros . . . . . . . . . . . . . . 115

$\begin{array}{ll}\text { Bibliografia } & 117\end{array}$ 


\section{Lista de Figuras}

FIGURA 2.1 Exemplo de grafo dirigido e grafo não dirigido $\ldots$. . . . . . . . . . 12

FIGURA 2.2 Exemplo de rede Bayesiana $\ldots \ldots \ldots$

FIGURA 4.1 Arquitetura de EES-BN f . . . . . . . . . . . . . . . . 40

FIGURA 4.2 Exemplo de aprendizagem estrutural com ADR . . . . . . . . . . . . 43

FIGURA 4.3 Exemplo de aprendizagem estrutural com inconsistências nos testes de independência . . . . . . . . . . . . . . . . . . . . 44 44

FIGURA 4.4 Exemplo de partição da adjacência em Opt01SS . . . . . . . . . . . 47

FIGURA 4.5 Pseudocódigo do operador de recombinação MergePop . . . . . . . 60

FIGURA 5.1 Resultados de sensibilidade e especificidade de vários métodos de aprendizagem de superestruturas $\ldots \ldots \ldots \ldots 75$

FIGURA 5.2 Resultados de custo computacional de vários métodos de aprendizagem de superestruturas $\ldots \ldots \ldots \ldots \ldots \ldots$

FIGURA 5.3 Resultados do operador de recombinação MergePop _ . . . . . . 81

FIGURA 5.4 Evolução típica do escore populacional em três configurações de

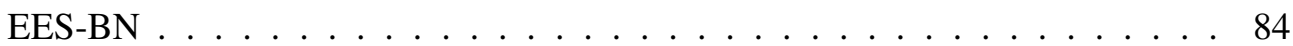

FIGURA 6.1 Estrutura robusta obtida com EES-BN num banco de dados de expressão gênica do ciclo celular de levedura . . . . . . . . . . . . . . . . . . . . 98

FIGURA 6.2 Marcadores genéticos SNPs escolhidos para a modelagem de LD . . 104 
FIGURA 6.3 Estruturas de LD obtidas com a ferramenta Haploview nos bancos de haplótipos analisados . . . . . . . . . . . . . . . . . . . . 106

FIGURA 6.4 Estruturas robustas aprendidas com EES-BN num banco de dados de haplótipos . . . . . . . . . . . . . . . . . . . . . 107

FIGURA 6.5 Distribuição do número de relações aprendidas nas estruturas robustas em relação ao coeficiente $D^{\prime} \ldots \ldots$. . . . . . . . . . . . . . . . 109 


\section{Lista de Tabelas}

TABELA 4.1 Funções auxiliares usadas em Opt01SS e OptHPC. . . . . . . . . . . 48

TABELA 5.1 Redes Bayesianas usadas na avaliação experimental $\ldots$. . . . . . . 71

TABELA 5.2 Percentagem de não-arestas presentes na estrutura verdadeira que são detectadas como arestas na superestrutura estimada . . . . . . . . . . . . . 77

TABELA 5.3 Estimativa da escalabilidade dos métodos de aprendizagem de supe-

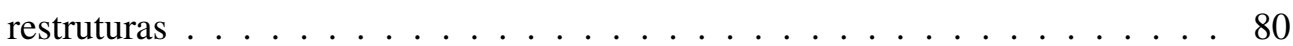

TABELA 5.4 Resultados da avaliação experimental do operador MergePop . . . . 82

TABELA 5.5 Resultados da avaliação de escore e distância estrutural de EES-BN com diferentes blocos ativados $\ldots \ldots \ldots$. . . . . . . . . . 85

TABELA 5.6 Resultados da avaliação de EES-BN com duas formas de inicialização 87

TABELA 5.7 Comparação de escores obtidos por EES-BN e outros métodos de aprendizagem estrutural . . . . . . . . . . . . . . . . . . . . . . 90

TABELA 5.8 Comparação de distância estrutural obtida por EES-BN e outros métodos de aprendizagem estrutural . . . . . . . . . . . . . . . . . . . 91

TABELA 5.9 Comparação de tempo computacional obtido por EES-BN e outros métodos de aprendizagem estrutural _ . . . . . . . . . . . . . . . 92

TABELA 6.1 Lista de genes dominantes obtidos com EES-BN do banco de expressão gênica do ciclo celular da levedura . . . . . . . . . . . . . . . . . . 100

TABELA 6.2 Exemplo de genótipos e haplótipos para dois marcadores bi-alélicos de um organismo diploide . . . . . . . . . . . . . . . . . . . . 101 
TABELA 6.3 Bancos de dados de haplotipos usados na aplicação de EES-BN para modelar LD . . . . . . . . . . . . . . . . . . . . . . . . . . . . . 103

TABELA 6.4 Lista de marcadores genéticos dominantes obtidos com EES-BN num banco de dados de haplótipos . . . . . . . . . . . . . . . . . . . . 110 


\section{Lista de Símbolos}

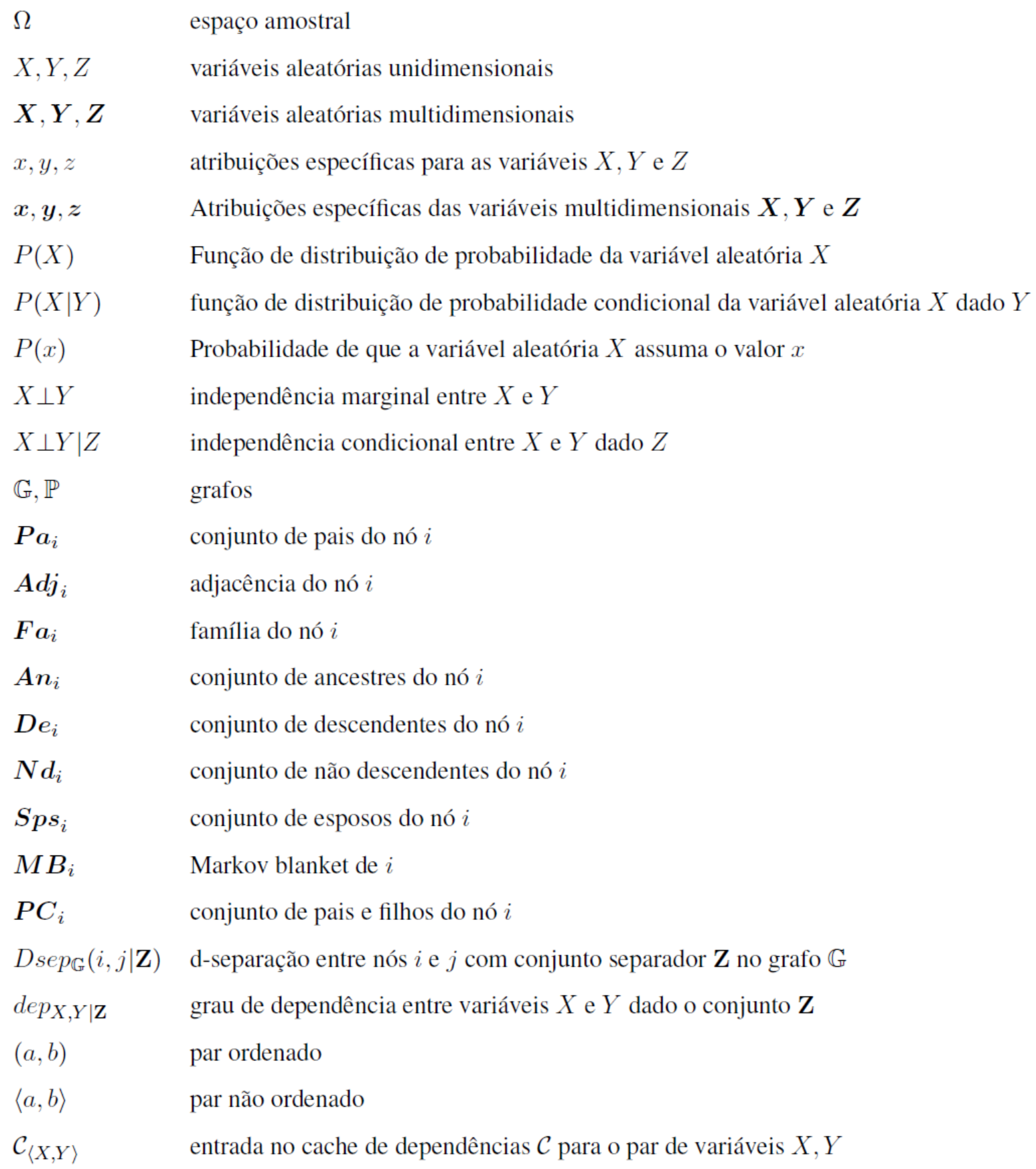




\title{
Lista de Siglas
}

\author{
RB (BN) Rede Bayesiana (Bayesian Network) \\ EES-BN Efficient Evolutionary System for learning BN structures \\ CCGA Cooperative Coevolutionary Genetic Algorithm \\ MMHC Max-Min Hill-Climbing \\ GS Greedy hill-climbing Search \\ HeuPC Heuristic Parents and Children \\ CE Computação Evolutiva \\ SNP Single Nucleotide Polimorphism \\ LD Linkage Disequilibrium \\ DAG Directed Acyclic Graph \\ (C)PDAG (Completed) Partially DAG \\ CM Condição de Markov \\ BDe(u) Bayesian Dirichlet likelihood equivalent (uniform) \\ ADR Approximate Deterministic Relationship \\ CIDS Conditional Independence and Dependence Statements \\ PNM Path Number Matrix \\ NPC Necessary Path Condition \\ Opt01SS Optimized Zero-First-Order Superstructure \\ OptHPC Optimized Hybrid Parents and Children \\ NSC Number of Statistical Calls
}




\section{Resumo}

Villanueva Talavera, Edwin. Sistema evolutivo eficiente para aprendizagem estrutural de redes Bayesianas. 2012. 130 f. Tese de doutorado. Escola de Engenharia de São Carlos, Universidade de São Paulo, São Carlos, 2012.

Redes Bayesianas (RB) são ferramentas probabilísticas amplamente aceitas para modelar e fazer inferências em domínios sob incertezas. Uma das maiores dificuldades na construção de uma RB é determinar a sua estrutura de modelo, a qual representa a estrutura de interdependências entre as variáveis modeladas. A estimativa exata da estrutura de modelo a partir de dados observados é, de forma geral, impraticável já que o número de estruturas possíveis cresce de forma super-exponencial com o número de variáveis. Métodos eficientes de aprendizagem aproximada tornam-se, portanto, essenciais para a construção de RBs verossímeis. O presente trabalho apresenta o Sistema Evolutivo Eficiente para Aprendizagem Estrutural de RBs, ou abreviadamente, EES-BN. Duas etapas de aprendizagem compõem EES-BN. A primeira etapa é encarregada de reduzir o espaço de busca mediante a aprendizagem de uma superestrutura. Para tal fim foram desenvolvidos dois métodos efetivos: Opt01SS e OptHPC, ambos baseados em testes de independência. A segunda etapa de EES-BN é um esquema de busca evolutiva que aproxima a estrutura do modelo respeitando as restrições estruturais aprendidas na superestrutura. Três blocos principais integram esta etapa: recombinação, mutação e injeção de diversidade. Para recombinação foi desenvolvido um novo operador (MergePop) visando ganhar eficiência de busca, o qual melhora o operador Merge de Wong e Leung (2004). Os operadores nos blocos de mutação e injeção de diversidade foram também escolhidos procurando um adequado equilíbrio entre exploração e utilização de soluções. Todos os blocos de EES-BN foram estruturados para operar colaborativamente e de forma auto-ajustável. Em uma serie de avaliações experimentais em RBs conhecidas de variado tamanho foi encontrado que 
EES-BN consegue aprender estruturas de RBs significativamente mais próximas às estruturas verdadeiras do que vários outros métodos representativos estudados (dois evolutivos: CCGA e GAK2, e dois não evolutivos: GS e MMHC). EES-BN tem mostrado também tempos computacionais competitivos, melhorando marcadamente os tempos dos outros métodos evolutivos e superando também ao GS nas redes de grande porte. A efetividade de EES-BN foi também comprovada em dois problemas relevantes em Bioinformática: i) reconstrução da rede de interações intergênicas a partir de dados de expressão gênica, e ii) modelagem do chamado desequilíbrio de ligação a partir de dados genotipados de marcadores genéticos de populações humanas. Em ambas as aplicações, EES-BN mostrou-se capaz de capturar relações interessantes de significância biológica estabelecida.

Palavras-chaves: redes Bayesianas, aprendizagem estrutural, computação evolutiva. 


\section{Abstract}

Villanueva Talavera, Edwin. Efficient evolutionary system for learning BN structures. 2012. 130 p. Thesis Doctoral. Escola de Engenharia de São Carlos, Universidade de São Paulo, São Carlos, 2012.

Bayesian networks $(B N)$ are probabilistic tools widely accepted for modeling and reasoning in domains under uncertainty. One of the most difficult tasks in the construction of a BN is the determination of its model structure, which is the inter-dependence structure of the problem variables. The exact estimation of the model structure from observed data is generally infeasible, since the number of possible structures grows super-exponentially with the number of variables. Efficient approximate methods are therefore essential for the construction of credible BN. In this work we present the Efficient Evolutionary System for learning BN structures (EES-BN). This system is composed by two learning phases. The first phase is responsible for the reduction of the search space by estimating a superstructure. For this task were developed two methods (OptO1SS and OptHPC), both based in independence tests. The second phase of EES-BN is an evolutionary design for finding the optimal model structure using the superstructure as the search space. Three main blocks compose this phase: recombination, mutation and diversity injection. With the aim to gain search efficiency was developed a new recombination operator (MergePop), which improves the Merge operator of Wong e Leung (2004). The operators for mutation and recombination blocks were also selected aiming to have an appropriate balance between exploitation and exploration of the solutions. All blocks in EES-BN were structured to operate in a collaborative and self-regulated fashion. Through a series of experiments and comparisons on benchmark BNs of varied dimensionality was found that EES-BN is able to learn BN structures markedly closer to the gold standard networks than various other representative methods (two evolutionary: CCGA and GAK2, and two non-evolutionary methods: 
GS and MMHC). The computational times of EES-BN were also found competitive, improving notably the times of the evolutionary methods and also the GS in the larger networks. The effectiveness of EES-BN was also verified in two real problems in bioinformatics: i) the reconstruction of a gene regulatory network from gene-expression data, and ii) the modeling of the linkage disequilibrium structures from genetic marker genotyped data of human populations. In both applications EES-BN proved to be able to recover interesting relationships with proven biological meaning.

Keywords: Bayesian networks, structure learning, evolutionary computation. 


\section{Capítulo 1}

\section{Introdução}

As redes Bayesianas (RBs) são ferramentas muito úteis para modelar e realizar inferências em domínios complexos e sob incertezas. Desde a sua formalização por Judea Pearl (Pearl, 1988), a literatura tem mostrado um crescente e sustentado interesse por RBs, tanto no seu desenvolvimento teórico quanto na aplicação das mesmas em uma grande diversidade de problemas. É possível encontrar, por exemplo, aplicações em medicina humana (Nikovski, 2000; Lucas et al., 2004; Charitos et al., 2009), bioinformática (Friedman et al., 2000; Jansen et al., 2003; Ben-Gal et al., 2005), marketing (Cooper, 2000), economia (Segal et al., 2005), finanças (Kirkos et al., 2007), gestão de risco (Lee et al., 2009), ecologia (Marcot et al., 2001; Uusitalo, 2007), ciências do comportamento (Lee et al., 2008), entre outras (Pourret et al., 2008). Esta elevada popularidade das RBs tem sido originada em grande medida por sua capacidade de poder representar de forma intuitiva e simultânea complexas relações de dependência e independência entre as diversas variáveis do problema estudado.

Um componente central das RBs, e que dá a expressividade às mesmas, é a chamada estrutura do modelo, a qual é definida por um grafo acíclico direcionado ou DAG (do inglês directed acyclic graph) que modela as variáveis aleatórias do problema como nós e as dependências diretas entre variáveis como arestas dirigidas (Pearl, 1988; Neapolitan, 2003). Em adição à estrutura do modelo é necessário especificar os parâmetros do modelo para definir completamente uma RB. Os parâmetros do modelo são um conjunto de distribuições de probabilidades condicionais associadas a cada nó da estrutura do modelo e definem a força das dependências representadas pelas arestas. Uma vez definida uma RB, esta constitui uma ferramenta eficiente de codificação da probabilidade conjunta do problema modelado, a qual pode ser usada para realizar inferências e previsões de situações não observadas ou como sistema de 
suporte à tomada de decisões (Neapolitan, 2003; Gross e Yellen, 2005; Ash, 2008).

A tarefa mais difícil na construção de uma RB é a determinação da sua estrutura do modelo. Em algumas situações é possível construir a estrutura do modelo usando conhecimento do especialista do domínio (Kjaerulff e Madsen, 2008). No entanto, é frequente encontrar situações onde o conhecimento do domínio é muito limitado ou inexistente. Nesses casos, torna-se necessário recorrer a métodos computacionais (conhecidos como métodos de aprendizagem estrutural) para estimar a estrutura de modelo a partir de conjuntos de dados ou observações disponíveis das variáveis modeladas. Contudo, estimar a estrutura do modelo mais provável a partir de uma amostra de dados é em geral um problema NP-difícil (Chickering et al., 2004) devido a que o número de DAGs cresce de maneira super-exponencial com o número de variáveis (Robinson, 1977). Por exemplo, para 3 variáveis existem 25 DAGs possíveis, enquanto que para 6 variáveis existem cerca de quatro milhões de estruturas possíveis.

Dada a intratabilidade geral do problema de aprendizagem estrutural exata, as pesquisas têm-se focado majoritariamente em desenvolver métodos aproximados de aprendizagem estrutural. Nesse sentido, métodos de busca gananciosa como Greedy Search with tabu lists (GS) (Aliferis et al., 2003) e Max-Min Hill-Climbing search (MMHC) (Tsamardinos et al., 2006a) têm mostrado precisões e custos computacionais difíceis de ser superados (Teyssier e Koller, 2005), razão pela qual eles têm sido incluídos como métodos de aprendizagem padrão em vários pacotes de software de RBs (tal como o Bayes Net Toolbox de Murphy (2001) e o Causal Explorer Toolkit de Aliferis et al. (2003)) e usados frequentemente em várias aplicações (Friedman et al., 2000; Yu et al., 2004).

Na última década tem-se observado um considerável interesse na literatura por métodos de aprendizagem estrutural baseados em computação evolutiva (CE) (por exemplo, Larranaga et al. (1996a); Hsu et al. (2002); Cotta e Muruzabal (2002); Wong e Leung (2004); Kim et al. (2005); Faulkner (2007); Delaplace et al. (2007); Tian et al. (2007); Jia et al. (2008); Stefano et al. (2010); Carvalho (2011); Park e Cho (2012)). A razão desse interesse pode ser explicada pelo sucesso que a CE tem mostrado em uma ampla variedade de problemas, tanto na área industrial como científica (Dasgupta e Michalewicz, 1997). Grande parte das publicações sobre aprendizagem estrutural evolutiva têm-se focado no desenvolvimento de operadores evolutivos para a busca da melhor estrutura (em relação a uma função de escore) e na adaptação de diversos paradigmas evolutivos para realizar a busca da estrutura. As vantagens dessas propostas têm sido maiormente evidenciadas em relação a outros métodos ou configurações evolutivas. 
No entanto, apesar dessa relativamente alta disponibilidade de ideias evolutivas, é difícil encontrar até agora sistemas de aprendizagem que integrem ou adaptem de forma eficiente o melhor dessas propostas e que mostrem uma clara superioridade em relação aos métodos tradicionais de aprendizagem estrutural como o GS e o MMHC.

Seguindo essa direção, o presente trabalho apresenta o Sistema Evolutivo Eficiente para Aprendizagem Estrutural de RBs ou abreviadamente, EES-BN (do inglês Efficient Evolutionary System for Bayesian Network structure learning). Para o desenvolvimento deste sistema foi realizada uma revisão extensiva da literatura recente, na qual se objetivou a identificação de operadores e componentes com grande potencialidade de aumentar a eficiência e precisão da aprendizagem estrutural. O sistema resultante é constituído por um hibrido de duas etapas de aprendizagem: uma primeira etapa de redução do espaço de busca mediante a aprendizagem de uma superestrutura (grafo não dirigido que somente contêm arestas com alguma chance de pertencer à RB verdadeira, Perrier et al. (2008)), e uma segunda etapa de otimização com algoritmo genético para refinar a busca do DAG final com base na superestrutura aprendida na primeira etapa.

Para o aprendizado da superestrutura foram desenvolvidos dois métodos alternativos baseados em testes de independência condicional: o método Opt01SS (do inglês Optimized Zero-First-order Super-Structure learning method) e o método OptHPC (do inglês, Optimized Hybrid Parents and Children learning method). O primeiro método foi construído sob o requerimento de aproximar rapidamente uma superestrutura em cenários de pouca amostra, razão pela qual somente testes de independência condicional de ordem 0 e 1 são executados em uma forma que as inconsistências encontradas nos testes sejam resolvidas de forma efetiva e segura. O segundo método desenvolvido, OptHPC, é uma otimização do recente método HPC (do inglês Hybrid Parents and Children) (De Morais e Aussem, 2010), um método que tem mostrado alta precisão em estimar a estrutura local (pais e filhos) em torno de uma variável alvo, mas que se torna computacionalmente ineficiente ao ser aplicado na recuperação da superestrutura completa. As otimizações em OptHPC foram realizadas, portanto, com a finalidade de melhorar a eficiência computacional de HPC mantendo sua precisão.

Para a etapa de otimização evolutiva de EES-BN foi adotado um esquema de representação de soluções que evita a codificação de soluções ilegais (não DAGs) e que integra implicitamente as restrições aprendidas na superestrutura. Também foi desenvolvido um novo operador de recombinação, chamado de MergePop, que generaliza o operador binário Merge (Wong e 
Leung, 2004) para permitir uma quantidade arbitraria de progenitores na criação de novas soluções, o que facilita a rápida localização de melhores soluções e portanto a diminuição do tempo de convergência. Os operadores de mutação foram escolhidos para agir de maneira local (nas famílias dos nós) com o propósito de maximizar a reutilização de computações da função de escore previamente realizadas. EES-BN controla também a retrogressão da evolução, mantendo para isso uma memória das últimas operações realizadas. A convergência prematura é outro aspecto controlado por EES-BN, para o qual foi desenvolvido um efetivo bloco de injeção de diversidade, baseado nas recentes ideias de Chang et al. (2010). Finalmente, a estruturação das operações de recombinação, mutação e injeção de diversidade em EES-BN tem sido realizada a fim de agir de forma colaborativa e autorregulada conforme as necessidades do processo evolutivo, evitando assim a configuração manual dos parâmetros evolutivos, tarefa que normalmente leva a configurações sub-ótimas.

O desempenho de EES-BN é avaliado experimentalmente em uma coleção pública de bancos de dados de variados tamanhos, amostrados de RBs referenciais com diversas dimensionalidades. Quatro métodos representativos de aprendizagem estrutural foram escolhidos para tal avaliação, dois deles não evolutivos (GS e MMHC) e dois evolutivos (o recente Cooperative Co-evolutionary Genetic Algorithm (CCGA) (Carvalho, 2011) e o tradicional GAK2 de Larranaga et al. (1996a)). Os resultados obtidos mostram uma notável vantagem de EES-BN sobre os outros métodos em termos de precisão de recuperação da estrutura verdadeira. Também, os custos computacionais são encontrados claramente melhores que os outros métodos evolutivos analisados e competitivos em relação aos métodos não evolutivos.

Finalmente, os benefícios de EES-BN são testados em duas aplicações reais de modelagem de processos biológicos. A primeira aplicação é na recuperação da rede de interações gênicas do sistema de regulação do ciclo celular da levedura (Saccharomyces cerevisiae) a partir de um banco de dados público de expressão gênica com limitada quantidade de amostras e dados faltantes. A segunda aplicação é na modelagem da estrutura de iterações entre marcadores genéticos SNPs em trechos cromossômicos de populações humanas (problema conhecido em genética como desequilibrio de ligação). Os dados usados nesta aplicação são também de origem pública. Nas duas aplicações, EES-BN mostrou-se capaz de capturar relações com significância biológica em tempos computacionais razoáveis. 


\subsection{Objetivos}

O propósito geral do presente trabalho foi contribuir com o avanço do estado da arte da aprendizagem estrutural de redes Bayesianas mediante o desenvolvimento de um sistema de aprendizagem evolutivo que consiga melhorar a precisão e eficiência computacional de métodos de aprendizagem estabelecidos.

Os seguintes foram os objetivos específicos perseguidos ao longo do desenvolvimento do presente trabalho:

- Identificar componentes de sistemas de aprendizagem existentes com potencial ganho em precisão ou eficiência computacional;

- Propor melhorias dos componentes identificados, ou novos componentes, visando sua integração de forma eficaz e colaborativa a fim de aumentar o desempenho da aprendizagem estrutural;

- Avaliar experimentalmente o desempenho dos diversos componentes integrantes do sistema desenvolvido;

- Comparar experimentalmente o desempenho do sistema desenvolvido em relação a métodos relevantes de aprendizagem estrutural da literatura; e

- Aplicar o método desenvolvido em problemas reais e testar sua capacidade de recuperar relações de interesse para o problema modelado;

\subsection{Organização do texto}

O Capitulo 2 apresenta uma revisão dos fundamentos teóricos relacionados às redes Bayesianas e seu aprendizagem estrutural, incluindo conceitos importantes da teoria de probabilidades e teoria de grafos. O Capitulo 3 apresenta uma revisão bibliográfica da literatura relevante de aprendizagem estrutural, colocando um ênfase especial nas contribuições evolutivas propostas para essa tarefa. No Capítulo 4 é descrito EES-BN, o sistema evolutivo proposto da presente tese com todas suas contribuições correlatas. A avaliação experimental de EES-BN é relatada no Capitulo 5, apresentando os dados usados para tal fim assim como a configuração dos experimentos, métricas analisadas, resultados obtidos e uma discussão dos mesmos. No Capitulo 6 são apresentadas as duas aplicações em que EES-BN foi usado, dando uma breve descrição do 
contexto dos problemas abordados e dos dados usados. O capítulo descreve também a forma como o sistema proposto foi usado, junto com a metodologia de pré-processamento dos dados, pós-processamento dos resultados e validação dos mesmos. Finalmente, o Capítulo 7 apresenta as conclusões do presente trabalho, uma revisão das contribuições do mesmo e sugestões de trabalhos futuros. 


\section{Capítulo 2}

\section{Fundamentos Teóricos}

Neste capítulo, apresenta-se uma revisão dos fundamentos teóricos usados ao longo da tese. O capítulo inicia introduzindo conceitos básicos da teoria de probabilidades na Secção 2.1. Logo, na Secção 2.2, são apresentados os conceitos relativos à teoria de grafos. Na seção 2.3 é introduzida a teoria das redes Bayesianas. Finalmente, na Seção 2.4 são revisados os fundamentos de aprendizagem de redes Bayesianas.

As referências usadas para a construção desta seção foram: Peña (2001); Neapolitan (2003); Gross e Yellen (2005); Ash (2008).

\subsection{Teoria de probabilidades}

A teoria de probabilidades está relacionada com a noção de experimento aleatório. Um experimento aleatório é aquele que quando repetido em condições idênticas, pode fornecer resultados diferentes e imprevisíveis. O conjunto de todos os resultados possíveis de um experimento aleatório definem seu espaço amostral (denotado com $\Omega$ neste texto). Cada subconjunto desse espaço amostral é chamado de evento. Os eventos com exatamente um elemento são chamados de eventos elementares. Um espaço amostral é chamado de discreto quando este é formado por um conjunto contável de elementos, caso contrário ele é chamado de contínuo. Diz-se que um evento $E$ tem uma ocorrência quando o resultado do experimento aleatório subjacente é algum elemento de $E$. O lançamento de um dado seria um típico exemplo de experimento aleatório, no qual o espaço amostral é $\Omega=\{1,2,3,4,5,6\}$. Um evento possível nesse exemplo poderia ser "obter um número par", assim $E=\{2,4,6\}$. 
Com o espaço amostral identificado podemos definir a função de probabilidade:

Definição 1 (Probabilidade). Dado um espaço amostral $\Omega$, a função de probabilidade (ou simplesmente probabilidade) é uma função $P$ que atribui um número real $P(E)$ a cada evento $E \subseteq \Omega$ e que satisfaz as seguintes condições (axiomas de Kolmogórov) (Ash, 2008):

1. $0 \leq P(E) \leq 1$, para todo $E \subseteq \Omega$;

2. $P(\Omega)=1$;

3. Para eventos mutuamente exclusivos $\left\{E_{i} \subseteq \Omega\right\}, E_{i} \cap E_{j}=\emptyset$, a probabilidade do evento união é a soma das probabilidades dos eventos integrantes, $P\left(\cup E_{i}\right)=\sum_{i} P\left(E_{i}\right)$.

O par $(\Omega, P)$ define o que é frequentemente conhecido como o espaço de probabilidades. A seguir são definidos os conceitos de probabilidade condicional, independência e independência condicional, conceitos centrais na teoria de probabilidades e de redes Bayesianas.

Definição 2 (Probabilidade condicional). Dados dois eventos $E$ e $F$, tal que $P(F) \neq 0 . A$ probabilidade condicional de E dado $F$, denotada como $P(E \mid F)$, é definida como:

$$
P(E \mid F)=P(E \cap F) / P(F)
$$

Definição 3 (Independência). Dois eventos E e F são independentes se:

1. $P(E \mid F)=P(E)$, tal que $P(E), P(F) \neq 0$; ou

2. $P(E)=0$ ou $P(F)=0$.

Definição 4 (Independência condicional). Dois eventos E e F são condicionalmente independentes $(C I)$ dado um terceiro evento $G$ com $P(G)>0$ (condicionante) se:

1. $P(E \mid F \cap G)=P(E \mid G)$, tal que $P(E \mid G), P(F \mid G) \neq 0$; ou

2. $P(E \mid G)=0$ ou $P(F \mid G)=0$.

A definição de independência é simétrica, ou seja, $P(E \mid F)=P(E)$ implica $P(F \mid E)=P(F)$. A partir da definição de independência é possível mostrar (Ash, 2008) que para $n$ eventos independentes $\left\{E_{i}\right\}_{i=1}^{n}$, a probabilidade do evento interseção é o produto das probabilidades 
dos eventos integrantes, $P\left(\cap E_{i}\right)=\prod_{i} P\left(E_{i}\right)$. A mesma propriedade se verifica para $n$ eventos condicionalmente independentes (dado um evento comum $G$ ) substituindo $E_{i}$ é por $E_{i} \mid G$.

Uma regra importante pode ser derivada a partir das definições anteriores. Suponha $n$ eventos $\left\{E_{i}\right\}_{i=1}^{n}$ mutuamente exclusivos e exaustivos, isto é, $E_{i} \cap E_{j}=\emptyset$ para todo $i \neq j$ e $\cup E_{i}=\Omega$. A probabilidade de qualquer evento $F$ pode ser expressa em termos desses eventos da seguinte maneira (lei da probabilidade total) (Ash, 2008): $P(F)=\sum_{i} P\left(F \cap E_{i}\right)$. Se todo evento $E_{i}$ tem probabilidade não nula então segue que $P\left(F \cap E_{i}\right)=P\left(F \mid E_{i}\right) P\left(E_{i}\right)$ (Definição 2), o qual permite reescrever a lei da probabilidade total como:

$$
P(F)=\sum_{i} P\left(F \mid E_{i}\right) P\left(E_{i}\right)
$$

Um resultado amplamente usado na teoria de probabilidades e de redes Bayesianas é o teorema de Bayes (Neapolitan, 2003):

Teorema 1 (Bayes). Dados dois eventos E e F com probabilidades não nulas, verifica-se que:

$$
P(E \mid F)=P(F \mid E) P(E) / P(F) .
$$

Este resultado pode ser verificado escrevendo $P(E \mid F)$ e $P(F \mid E)$ segundo a Definição 2, assim: $P(E \mid F)=P(E \cap F) / P(F)$ e $P(F \mid E)=P(F \cap E) / P(E)$. Logo, ao isolar $P(E \cap F)$ e igualar ambas as equações se obtém $P(E \mid F) P(F)=P(F \mid E) P(E)$, o qual mostra o teorema.

O teorema de Bayes é muito importante para realizar inferência probabilística, já que ela constitui uma regra útil para determinar ou atualizar a probabilidade de alguma hipótese $E$ quando se consegue ou se observa alguma evidência nova $F$. Neste caso, $P(E)$ e $P(F)$ são as probabilidades (a priori) da hipótese e da evidência, isto é, antes de observar $F ; P(F \mid E)$ é a probabilidade da evidência $F$ sob a hipótese $E$; e $P(E \mid F)$ é a probabilidade atualizada da hipótese $E$ após observar $F$ (probabilidade posterior). Um exemplo ilustrativo disso é mostrado no Exemplo 1. O processo de realizar inferência probabilística mediante o uso do teorema de Bayes é chamado de inferência Bayesiana.

Exemplo 1 Considere uma hipótese E denotando "existência de gripe"e uma evidência F sendo "presença de dor de cabeça". Então mediante o teorema de Bayes é possível calcular a probabilidade de ter gripe após observar a presença de dor de cabeça $(P(E \mid F))$, sempre que se conheça a probabilidade de ter gripe $(P(E))$, ter dor de cabeça $(P(F))$ e ter dor de cabeça 
quando se tem gripe $(P(F \mid E))$.

É apresentado a seguir o conceito de variável aleatória e algumas das suas propriedades mais importantes para a conceituação de redes Bayesianas (Neapolitan, 2003).

Definição 6 (Variável aleatória). Uma variável aleatória é uma função $X$ que atribui um valor a cada elemento do espaço amostral $\Omega$.

O conjunto de valores que pode assumir $X$ é chamado de espaço de $X$. Quando esse espaço é enumerável e finito diz-se que a variável aleatória é discreta.

A expressão $X=x$ é usada para denotar o conjunto de elementos em $\Omega$ que a variável aleatória $X$ mapeia para o valor $x$, ou seja, $X=x$ denota o evento $\{e \mid e \in \Omega, X(e)=x\}$. No exemplo do lançamento de um dado, uma variável aleatória $X$ poderia ser "ocorrência 'par' ou 'impar'. O espaço de $X$ seria nesse caso $\{$ par, impar $\}$, e a atribuição $X=i m p a r$ representaria ao evento $\{2,4,6\}$.

Em algumas situações, as variáveis aleatórias são entendidas simplesmente como símbolos matemáticos $X$ representando algum valor dentro de um conjunto de valores (espaço de $X$ ), ao invés de como funções de algum espaço amostral $\Omega$ (Neapolitan, 2003). Isto porque as vezes é desnecessário definir $\Omega$ já que o espaço de $X$ é tão atômico quanto o espaço amostral $\Omega$ (existe um mapeamento um a um). Um exemplo disso é apresentado no Exemplo 2. As definições restantes desta seção são igualmente aplicáveis para qualquer um dos dois entendimentos citados para variáveis aleatórias.

Exemplo 2 Considere uma variável aleatória "estado de saúde do paciente"que possui um espaço tão elementar quanto o espaço amostral \{"saudável", "doente"\}. Neste entendimento de variável aleatória o evento $X=x$ representa uma primitiva matemática para o cálculo de probabilidades, a qual não está definida em termos de alguma outra definição.

A função $P$ que atribui um valor de probabilidade aos eventos de tipo $X=x$ (para todo valor $x$ ) é comumente chamada de função de distribuição de probabilidade da variável aleatória $X$ ou simplesmente distribuição de $X$, a qual é usualmente denotada como $P(X)$. Quando $X$ toma uma atribuição particular $X=x$ é comum representar tal evento simplesmente por $x$ (é sobre-entendido o nome da variável aleatória) e a sua probabilidade por $P(x)$.

As definições e notações anteriores podem ser estendidas naturalmente para mais de uma variável aleatória (Neapolitan, 2003). Suponha um conjunto de $n$ variáveis aleatórias $X_{1}, \ldots, X_{n}$. 
Este conjunto pode ser representado por uma única variável $n$-dimensional $\boldsymbol{X}$ cujas dimensões são as variáveis aleatórias integrantes, assim $\boldsymbol{X}=\left(X_{1}, \ldots, X_{n}\right)$. O espaço dessa variável aleatória $n$-dimensional é então o produto cartesiano dos espaços das variáveis aleatórias integrantes. A expressão $X_{1}=x_{1}, \ldots, X_{n}=x_{n}$ representa ao evento ou estado nesse espaço conjunto onde cada variável $X_{i}$ toma um valor particular $x_{i}$, para todo $i=1, \ldots, n$. A função $P$ que atribui um valor de probabilidade a cada evento $\left\{X_{1}=x_{1}, \ldots, X_{n}=x_{n}\right\}$, para todo valor de $x_{i}$, é conhecida como função de distribuição de probabilidade conjunta de $\boldsymbol{X}$, ou simplesmente distribuição conjunta de $\boldsymbol{X}$ e é denotada por $P(\boldsymbol{X})$. Um evento particular $X_{1}=x_{1}, \ldots, X_{n}=x_{n}$ é vetorialmente denotado como $\boldsymbol{X}=\boldsymbol{x}$ (onde $\boldsymbol{x}=\left(x_{1}, \ldots, x_{n}\right)$ ) ou simplificadamente por $\boldsymbol{x}$. A probabilidade desse evento específico é consequentemente denotado por $P(\boldsymbol{x})$.

As definições de independência e independência condicional também podem ser estendidas para variáveis aleatórias, como mostrado a seguir (Neapolitan, 2003):

Definição 7 (Independência de variáveis aleatórias). Duas variáveis aleatórias multidimensionais $\boldsymbol{X}$ e $\boldsymbol{Y}$ são independentes, denotado como $\boldsymbol{X} \perp \boldsymbol{Y}$, se para todo valor $\boldsymbol{x}$ e $\boldsymbol{y}$ se verifica que os eventos $\boldsymbol{X}=\boldsymbol{x}$ e $\boldsymbol{Y}=\boldsymbol{y}$ são independentes.

Definição 8 (Independência condicional de variáveis aleatórias). Duas variáveis aleatórias multidimensionais $\boldsymbol{X}$ e $\boldsymbol{Y}$ são condicionalmente independentes dado uma terceira variável aleatória multidimensional $\boldsymbol{Z}$, denotado como $\boldsymbol{X} \perp \boldsymbol{Y} \mid \boldsymbol{Z}$, se para todo valor $\boldsymbol{x}$, $\boldsymbol{y}$ e $\boldsymbol{z}$, e quando quer que $P(\boldsymbol{z})>0$, se verifica que os eventos $\boldsymbol{X}=\boldsymbol{x}$ e $\boldsymbol{Y}=\boldsymbol{y}$ são condicionalmente independentes dado o evento $\boldsymbol{Z}=\boldsymbol{z}$.

Esta definição de independência condicional implica que, uma vez conhecido o valor de $\boldsymbol{Z}$, a informação que se tenha de alguma das duas variáveis aleatórias $X, Y$ não fornece nehuma informação sobre o valor da outra variável aleatória. A dimensão da variável condicionante $Z$ é conhecida como ordem da independência condicional.

\subsection{Teoria de grafos}

Junto com a teoria de probabilidade, a teoria de grafos é um dos formalismos matemáticos fundamentais para a formalização dos modelos gráficos probabilísticos (Peña, 2001; Neapoli$\tan , 2003)$ 
Um grafo é uma tupla $\mathbb{G}=(\boldsymbol{V}, \boldsymbol{E})$, na qual $\boldsymbol{V}$ representa um conjunto não vazio e finito de objetos, chamados de nós (ou vértices), e $\boldsymbol{E}$ denota um conjunto de pares ordenados formados de elementos de $\boldsymbol{V}$, assim, $\boldsymbol{E} \subseteq \boldsymbol{V} \times \boldsymbol{V}$. Os elementos de $\boldsymbol{E}$ são chamados de arestas ou arcos. Se $\left(V_{i}, V_{j}\right) \in \boldsymbol{E}$, diz-se que há uma aresta de $V_{i}$ a $V_{j}$ e que $V_{i}$ e $V_{j}$ são incidentes na aresta. Quando as duas arestas $\left(V_{i}, V_{j}\right)$ e $\left(V_{j}, V_{i}\right)$ pertencem a $\boldsymbol{E}$, diz-se que elas são arestas não dirigidas e são denotadas por $V_{i}-V_{j}$. Se a aresta $\left(V_{i}, V_{j}\right)$ pertence a $\boldsymbol{E}$, mas $\left(V_{j}, V_{i}\right)$ não pertence a $\boldsymbol{E}$, então $\left(V_{i}, V_{j}\right)$ é chamada de aresta dirigida e denotada por $V_{i} \rightarrow V_{j}$. Se há uma aresta entre $V_{i}$ e $V_{j}$ (dirigida ou não), diz-se que $V_{i}$ e $V_{j}$ são nós adjacentes.

A representação gráfica dos grafos é usualmente realizada usando círculos para os nós, linhas para as arestas não dirigidas e setas para arestas dirigidas (no sentido da aresta). $\mathrm{Na}$ Figura 2.1(a) é mostrado um grafo com somente arestas dirigidas (também chamado de grafo dirigido) e na Figura 2.1(b) é mostrado um grafo com somente arestas não dirigidas (chamado de grafo não dirigido). Em uma aresta dirigida $V_{i} \rightarrow V_{j}$, o nó $V_{i}$ é chamado de pai de $V_{j}$, e este último de filho de $V_{i}$. O conjunto de todos os nós pais de um nó $V_{i}$ num grafo $\mathbb{G}$ é denotado neste texto como $\boldsymbol{P} \boldsymbol{a}_{i}$. O conjunto de todos os nós adjacentes a um nó $V_{i}$ num grafo $\mathbb{G}$ é chamado de adjacência de $V_{i}$ e denotado como $\boldsymbol{A} \boldsymbol{d} \boldsymbol{j}_{i}$. A família de um nó $V_{i}$ num grafo $\mathbb{G}$ é o conjunto formado pelos pais de $V_{i}$ e o próprio $V_{i}$ e denotado como $\boldsymbol{F} \boldsymbol{a}_{i}$. No exemplo da Figura 2.1(a), o conjunto de pais do nó 3 é $\boldsymbol{P a _ { 3 }}=\{2\}$, a adjacência é $\boldsymbol{A d j _ { 3 }}=\{2\}$ e a família é $\boldsymbol{F a}_{3}=\{3,2\}$.

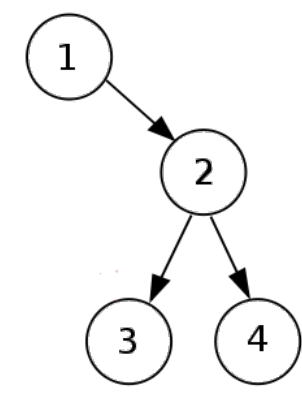

(a) Grafo dirigido

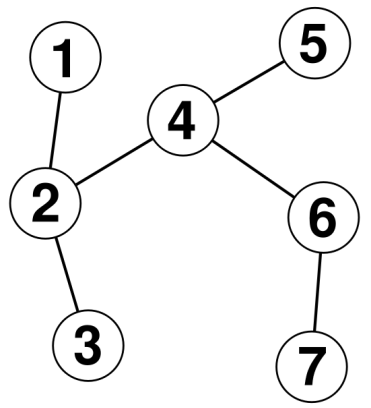

(b) grafo não dirigido

Figura 2.1: Exemplo de grafo dirigido (a) e grafo não dirigido (b)

Em um grafo $\mathbb{G}$ com nós $\boldsymbol{V}=\left\{V_{1}, \ldots, V_{n}\right\}$, um caminho de $V_{i}$ para $V_{j}$ é uma sequência de nós $\left[c_{0}=V_{i}, c_{1}, \ldots, c_{r-1}, c_{r}=V_{j}\right], r>0$, tal que existe uma aresta entre nós consecutivos $c_{k}, c_{k+1}$. Quando $V_{i}=V_{j}$, o caminho é chamado de ciclo. Um grafo dirigido que não contém ciclos é chamado de grafo acíclico dirigido ou DAG (do inglês directed acyclic graph). O grafo da Figura 2.1(a) é um exemplo de DAG. O grafo resultante de substituir as arestas dirigidas por 
não dirigidas a um DAG $\mathbb{G}$ é chamado de grafo esqueleto de $\mathbb{G}$.

Em um DAG $\mathbb{G}$ com nós $\boldsymbol{V}=\left\{V_{1}, \ldots, V_{n}\right\}$, se existir um caminho do nó $V_{i}$ para $V_{j}$ então $V_{i}$ é chamado de ancestral de $V_{j}$ e este último de descendente de $V_{i}$. O conjunto de todos os nós ancestrais de um nó $V_{i}$ em $\mathbb{G}$ é chamado de conjunto ancestral de $V_{i}$ e denotado como $\boldsymbol{A} \boldsymbol{n}_{i}$. O conjunto de todos os nós descendentes de um nó $V_{i}$ em $\mathbb{G}$ é chamado de descendentes de $V_{i}$ e denotado como $\boldsymbol{D} \boldsymbol{e}_{i}$. O conjunto de todos os nós que não são descendentes de $V_{i} \mathrm{em}$ $\mathbb{G}$, ou seja $\left\{\boldsymbol{V} \backslash \boldsymbol{D} \boldsymbol{e}_{i}\right\}$, é chamado de não descendentes de $V_{i}$ e denotado como $\boldsymbol{N} \boldsymbol{d}_{i}$.

Exemplo 3 No exemplo da Figura 2.1(a) o conjunto ancestral do nó 4 é $\boldsymbol{A} \boldsymbol{n}_{4}=\{1,2\}$, os descendentes do nó 1 são $\mathbf{D} \boldsymbol{e}_{1}=\{2,3,4\}$ e os não descendentes do nó 3 são $\mathbf{N} \boldsymbol{d}_{3}=\{1,2,4\}$.

Diz-se que um caminho $l$ de $V_{i}$ para $V_{j}$ em um DAG $\mathbb{G}$ é bloqueado por um conjunto de nós $\mathbf{Z}\left(V_{i}, V_{j} \notin \mathbf{Z}\right)$ se são satisfeitas as seguintes condições:

1. $\mathbf{Z}$ contém nós $V_{k}$ que estão em $l$ na forma $\rightarrow V_{k} \rightarrow$ ou na forma $\leftarrow V_{k} \rightarrow$;

2. $\mathbf{Z}$ não contém nós $V_{k}$, ou descendentes dele, que estão em $l$ na forma $\rightarrow V_{k} \leftarrow$ (forma conhecida como colisor).

Um colisor $V_{i} \rightarrow V_{k} \leftarrow V_{j}$ num DAG $\mathbb{G}$ é chamado de v-estructura se $V_{i}$ e $V_{j}$ são não adjacentes em $\mathbb{G}$. Neste caso, $V_{i}$ e $V_{j}$ são chamados de esposos com filho comum $V_{k}$. O conjunto de todos os esposos de um nó $V_{i}$ é denotado com $\mathbf{S p s}_{i}$.

Um conceito importante em DAGs que é de bastante utilidade em RBs é a $d$-separação (Pearl, 1988; Neapolitan, 2003):

Definição 9 (D-separação). Dado um DAG $\mathbb{G}$ com nós $\boldsymbol{V}=\left\{V_{1}, \ldots, V_{n}\right\}$. Diz-se que dois nós $V_{i}$ e $V_{j}$ estão d-separados por um subconjunto $\mathbf{Z} \subset \boldsymbol{V}\left(V_{i}, V_{j} \notin \mathbf{Z}\right)$, denotado como $\operatorname{Dsep}_{\mathbb{G}}\left(V_{i}, V_{j} \mid \mathbf{Z}\right)$, se todos os caminhos de $V_{i}$ para $V_{j}$ são bloqueados por $\mathbf{Z}$ em $\mathbb{G}$. $\mathbf{Z} e ́$ chamado de conjunto separador.

A definição de d-separação pode ser generalizada para subconjuntos disjuntos de variáveis $\boldsymbol{A}, \boldsymbol{B}, \mathbf{Z}$ em $\boldsymbol{V}$. Nesse caso, $D \operatorname{sep}_{\mathbb{G}}(\boldsymbol{A}, \boldsymbol{B} \mid \mathbf{Z})$ denota que $\mathbf{Z} d$-separa cada membro $V_{i} \in \boldsymbol{A}$ de cada membro $V_{j} \in \boldsymbol{B}$.

Exemplo 4 No exemplo da Figura 2.1(a) podem ser encontradas as d-separações: Dsep $\mathbb{G}_{\mathbb{G}}(1,3 \mid\{2\})$, $\operatorname{Dsep}_{\mathbb{G}}(1,4 \mid\{2\}) e \operatorname{Dsep}_{\mathbb{G}}(3,4 \mid\{2\})$. 
Uma ordem ancestral de um DAG $\mathbb{G}$ com nós $\boldsymbol{V}=\left\{V_{1}, \ldots, V_{n}\right\}$ é um ordenamento de $\boldsymbol{V}$ tal que, para todo $V_{i}, V_{j}$ nesse ordenamento, $V_{i}$ aparece primeiro que $V_{j}$ se $V_{i}$ é um ancestral de $V_{j}$. Todo DAG admite ao menos uma ordem ancestral.

Exemplo 5 As ordens ancestrais admitidas pelo grafo da Figura 2.1(a) são: $(1,2,3,4)$ e $(1,2,4,3)$.

\subsection{Redes Bayesianas}

A seguir é introduzido o conceito de condição de Markov, necessário para a conceituação de redes Bayesianas (Peña, 2001; Neapolitan, 2003):

Definição 10 (Condição de Markov). Suponha uma variável aleatória n-dimensional $\boldsymbol{U}=$ $\left(X_{1}, \ldots, X_{n}\right)$ com uma função de distribuição de probabilidade conjunta $P$ definida sobre ela. Suponha também um DAG $\mathbb{G}$ com nós representando um a um as variáveis aleatórias de $\boldsymbol{U}$, ou seja, $\mathbb{G}=(\boldsymbol{U}, \boldsymbol{E})$. Diz-se que P satisfaz a condição de Markov $(C M)$ com o DAG $\mathbb{G}$ se para cada variável aleatória $X_{i} \in U$ verifica-se que $X_{i}$ é independente de seus não descendentes $\boldsymbol{N} \boldsymbol{d}_{i}$ dados seus pais $\boldsymbol{P a} \boldsymbol{a}_{i}$ em $\mathbb{G}$, ou seja, $X_{i} \perp \boldsymbol{N} \boldsymbol{d}_{i} \mid \boldsymbol{P} \boldsymbol{a}_{i}$.

Quando $P$ satisfaz a CM com o DAG $\mathbb{G}$ então diz-se que o par $(\mathbb{G}, P)$ satisfaz a CM. A CM implica também que toda variável $X_{i} \in U$ é condicionalmente independente de qualquer

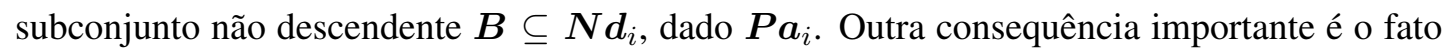
de que se $(\mathbb{G}, P)$ satisfaz a $C M$ então $P$ é equivalente ao produto das distribuições condicionais de cada variável $X_{i}$ dados seus pais $\boldsymbol{P} \boldsymbol{a}_{i}$, sempre que essas distribuições existam (Teorema 1.4 em Neapolitan (2003)).

Uma outra relação derivada da $\mathrm{CM}$ estabelece que se temos um DAG $\mathbb{G}$ com nós representando variáveis aleatórias $\boldsymbol{U}=\left(X_{1}, \ldots, X_{n}\right)$, e tendo atribuída uma distribuição de probabilidades condicional para cada nó $X_{i}$ (condicionada nos pais do nó, $\boldsymbol{P} \boldsymbol{a}_{i}$ ), o produto destas distribuições condicionais gera uma distribuição conjunta $P$ sobre as variáveis aleatórias $\boldsymbol{U}$ e também o par $(\mathbb{G}, P)$ satisfaz a CM (Teorema 1.5 em Neapolitan (2003)).

Definição 11 (Rede Bayesiana). Suponha uma distribuição de probabilidade conjunta $P$ definida num conjunto de variáveis aleatórias $\boldsymbol{U}=\left(X_{1}, \ldots, X_{n}\right)$ e um DAG $\mathbb{G}$ com nós representando essas variáveis, $\mathbb{G}=(\boldsymbol{U}, \boldsymbol{E})$. Então, a tupla $(\mathbb{G}, P)$ é uma rede Bayesiana $(R B)$ se ela satisfaz a condição de Markov. 
Uma RB é então uma forma de representar a distribuição de probabilidade conjunta $P$ sobre um conjunto de variáveis aleatórias $\boldsymbol{U}$ mediante uma estrutura de grafo $\mathbb{G}$. Esta estrutura, conhecida também como estrutura do modelo, é a que permite uma eficiente fatoração de $P$ em termos que somente dependem de um reduzido número de variáveis (famílias dos nós), como segue (Pearl, 1988; Neapolitan, 2003):

$$
P(\boldsymbol{U})=P\left(X_{1}, \ldots, X_{n}\right)=\prod_{i=1}^{n} P\left(X_{i} \mid \boldsymbol{P} \boldsymbol{a}_{i}\right) .
$$

A fatoração que uma RB induz na probabilidade conjunta $P$ é geralmente vantajosa em termos de redução de parâmetros. Em particular, se cada variável aleatória é binária e o número de pais por nó é ao máximo $k<<n$, então o número necessário de parâmetros a serem especificados na RB para representar $P$ seria $2^{k} n$ ao invés de $2^{n}-1$ na especificação direta de $P$. Por exemplo, para uma rede de 20 variáveis, o numero de parâmetros da RB seria de 640 com $k=5$ (um valor realista), enquanto que a especificação direta de $P$ precisaria de mais de um milhão de parâmetros.

Exemplo 6 Na Figura 2.2 é mostrado um exemplo de rede Bayesiana hipotética (Neapolitan, 2003) que modela iterações entre duas doenças respiratórias (bronquite (B) e câncer de pulmão (L)), uma possível causa (histórico de fumante $(H)$ ) e duas possíveis consequências (Fadiga $(F)$ e resultado de raios $X$ no peito $(C)$ ). Todas as variáveis aleatórias são discretas e binárias. São especificadas também as distribuições de probabilidades condicionais de cada nó. De acordo com a Equação 2.4, a probabilidade conjunta $P$ de qualquer evento $H=h, B=b, L=l, F=f, C=c$, onde $h, b, l, f, c$ denotam valores específicos das variáveis aleatórias, pode ser calculada como $P(h, b, l, f, c)=P(h) P(b \mid h) P(l \mid h) P(f \mid b, l) P(c \mid l)$.

Além de poder representar de forma compacta a distribuição conjunta de um conjunto de variáveis aleatórias, uma RB pode ser usada para realizar inferências Bayesianas complexas. De fato, muitas vezes esse é o motivo principal para construir uma RB. Na RB da Figura 2.2 por exemplo, poderia ser requerido o cálculo da probabilidade posterior de ter câncer de pulmão após conhecer que: o indivíduo tem um histórico de fumante, tem um resultado positivo no raio-X do peito e apresenta fadiga. Tal cálculo não poderia ser feito com uma aplicação simples do teorema de Bayes. Existem vários métodos eficientes para realizar inferência probabilística em RBs, tais como: métodos de propagação de evidências, métodos de Monte Carlos e métodos variacionais (Neapolitan, 2003). 


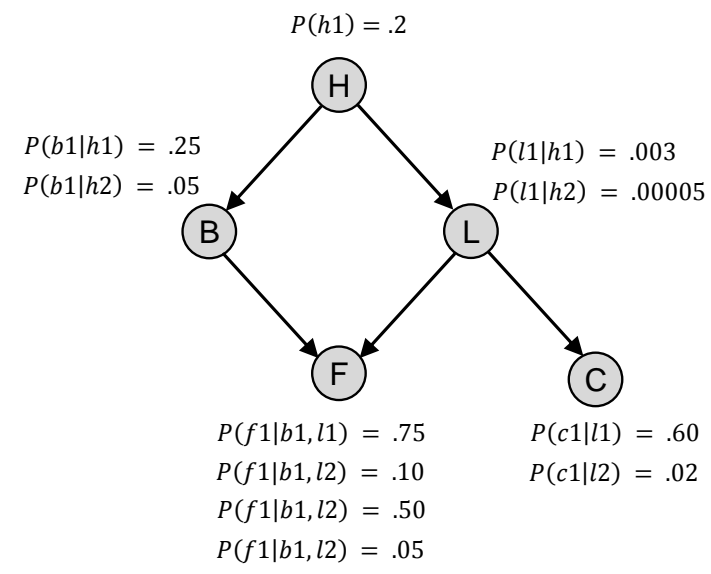

\begin{tabular}{|l|c|l|}
\hline Variável Aleatória & Valor & Descrição \\
\hline \hline H: histórico de fumante & $h 1$ & Há histórico \\
& $h 2$ & Não há histórico \\
\hline B: Bronquite & $b 1$ & Bronquite presente \\
& $b 2$ & Bronquite ausente \\
\hline L: Câncer de pulmão & $I 1$ & Câncer presente \\
& $I 2$ & Câncer ausente \\
\hline F: Fadiga & $f 1$ & Fadiga presente \\
& $f 2$ & Fadiga ausente \\
\hline C: Raios X no peito & $c 1$ & Teste positivo \\
& $c 2$ & Teste negativo \\
\hline
\end{tabular}

Figura 2.2: Rede Bayesiana exemplo (Neapolitan, 2003). As distribuições de probabilidades condicionais de cada nó são especificados ao lado dos mesmos. Observe que para o nó raiz $H$ essa distribuição corresponde a uma distribuição marginal. A tabela da direita descreve as variáveis aleatórias e seus valores.

Uma outra vantagem pela qual as RBs são frequentemente usadas é que é possível atribuir uma interpretação causal ou construir elas a partir de relações causais conhecidas. Isto é possível fazendo a consideração de que toda aresta $X \rightarrow Y$ representa uma relação de causa-efeito, onde $X$ é a causa e $Y$ é o efeito. O exemplo da Figura 2.2 foi construído a partir de relações causais conhecidas. Quando um DAG é construído a partir de relações causais ele é chamado de DAG causal. A construção de RBs com DAG causais tem sido uma prática bastante empregada. Isto porque a $\mathrm{CM}$ é frequentemente satisfeita para distribuições conjuntas $P$ sobre varáveis aleatórias $\boldsymbol{U}$ com DAG causais $\mathbb{G}$ que refletem relações autênticas em $\boldsymbol{U}$, e portanto tais modelos $(\mathbb{G}, P)$ constituem RBs válidas (Neapolitan, 2003). Contudo, a interpretação causal de RBs tem gerado certa controvérsia, já que não existe uma definição amplamente aceita de causalidade (Neapolitan, 2003), e também porque desde o ponto de vista puramente estatístico não seria possível atribuir uma interpretação causal a um modelo se ele não for aprendido mediante manipulações (isto é, forçar que umas variáveis tomem determinados estados para observar a consequência nas outras variáveis) (Daly et al., 2011). A aprendizagem de RB causais apresenta maiores desafios que aprender RBs para modelar somente probabilidades conjuntas. Entre esses desafios encontram-se: i) presença de causas comuns não modeladas (nós ocultos), e ii) relações cíclicas (Daly et al., 2011). Na literatura podem ser encontrados vários trabalhos sobre redes Bayesianas causais, sendo que os livros de Spirtes et al. (2000) e Pearl (2009) abordam esse tópico de forma exaustiva. 


\subsection{Fundamentos da aprendizagem estrutural de redes Bayesianas}

Dado que a presente tese centra-se na estimação da estrutura de modelo de redes Bayesianas, nesta seção é apresentada uma revisão dos fundamentos teóricos que estão por traz dos principais sistemas de aprendizagem estrutural (uma revisão bibliográfica destes sistemas é introduzida no Capitulo 2). A seção está dividida em duas partes. A primeira parte apresenta definições e propriedades importantes no contexto de aprendizagem estrutural de RBs. A segunda parte discorre sobre funções para avaliar RBs e suas propriedades.

\subsubsection{Propriedades estruturais usadas na aprendizagem de redes Bayesianas}

A condição de Markov relaciona a estrutura de modelo de uma RB com certas independências condicionais na distribuição conjunta $P$ que ela codifica. Na seção anterior for dito que tais independências condicionais têm a forma geral: $V_{i} \perp \boldsymbol{B} \mid \boldsymbol{P \boldsymbol { a } _ { i }}$, para todo $i$ e $\boldsymbol{B} \subseteq \boldsymbol{N} \boldsymbol{d}_{i}$. A seguir, apresenta-se uma nova consequência da CM que tem sido muito explorada na aprendizagem estrutural de RB, a qual relaciona d-separações no DAG da RB com independências condicionais na distribuição conjunta $P$ por ela modelada (Lema 2.1, Neapolitan (2003)):

Teorema 2 (Independência e D-separação). Dada uma rede Bayesiana $(\mathbb{G}, P)$ sobre um conjunto de variáveis aleatórias $\boldsymbol{U}=\left(X_{1}, \ldots, X_{n}\right)$, verifica-se que toda d-separação em $\mathbb{G}$, $\operatorname{Dsep}_{\mathbb{G}}(\boldsymbol{A}, \boldsymbol{B} \mid \mathbf{Z})$, onde $\boldsymbol{A}, \boldsymbol{B}, \mathbf{Z} \subset \boldsymbol{U}$ são subconjuntos mutuamente disjuntos, implica uma relação de independência condicional em P na forma $\boldsymbol{A} \perp \boldsymbol{B} \mid \boldsymbol{Z}$.

De forma complementar ao teorema 2, existe um outro resultado que estabelece que toda independência condicional $V_{i} \perp \boldsymbol{B} \mid \boldsymbol{P} \boldsymbol{a}_{i}$ implicada pela $\mathrm{CM}$ numa rede Bayesiana $(\mathbb{G}, P)$ é identificável como d-separação na estrutura de modelo $\mathbb{G}$, nomeadamente $D \operatorname{sep}_{\mathbb{G}}\left(V_{i}, \boldsymbol{B} \mid \boldsymbol{P} \boldsymbol{a}_{i}\right)$ (Teorema 2.1 em Neapolitan (2003). Por conseguinte, todo conjunto de pais $\boldsymbol{P a}_{i}$ age em $\mathbb{G}$ como separador de todo caminho entre $V_{i}$ e qualquer subconjunto $\boldsymbol{B}$ não descendente de $V_{i}$.

Outro conceito amplamente usado na aprendizagem estrutural de RB é a equivalência de Markov:

Definição 12 (Equivalência de Markov). Dois ou mais DAGs, $\mathbb{G}_{1}, \mathbb{G}_{2}, \ldots$, definidos sobre o mesmo conjunto de variáveis aleatórias $\boldsymbol{U}=\left(X 1, \ldots, X_{n}\right)$ são Markov equivalentes entre

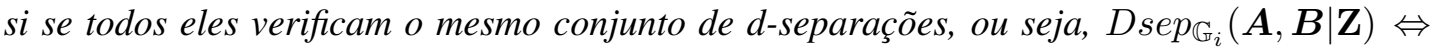
$\operatorname{Dsep}_{\mathbb{G}_{j}}(\boldsymbol{A}, \boldsymbol{B} \mid \mathbf{Z})$, para todo $i, j$ e trio de subconjuntos mutuamente disjuntos $\boldsymbol{A}, \boldsymbol{B}, \mathbf{Z} \subset \boldsymbol{U}$. 
Duas ou mais RBs, $\left(\mathbb{G}_{1}, P_{1}\right),\left(\mathbb{G}_{2}, P_{2}\right), \ldots$, formadas por DAGs Markov equivalentes representam o mesmo conjunto de independências condicionais nas respectivas - não necessariamente iguais - distribuições conjuntas $P_{i}$. Isto porque tais DAGs, por definição, contêm as mesmas d-separações. Redes Bayesianas com DAGs Markov equivalentes são chamadas de redes Bayesianas equivalentes. $\mathrm{O}$ conjunto $\mathcal{C}$ que contém todas os RBs equivalentes representando um determinado conjunto de independências condicionais é chamado de clase de equivalência.

O seguinte teorema constitui um critério bastante utilizado para determinar graficamente se um conjunto de DAGs são Markov equivalentes entre si (Teorema 2.4 em Neapolitan (2003)):

Teorema 3 (Identificação de DAGs Markov equivalentes). Dois ou mais DAGs $\mathbb{G}_{1}, \mathbb{G}_{2}, \ldots$ definidos sobre as mesmas variáveis aleatórias $\boldsymbol{U}=\left(X_{1}, \ldots, X_{n}\right)$ são Markov equivalentes se e só se possuem o mesmo grafo esqueleto e o mesmo conjunto de v-estruturas.

Este teorema implica que todas as d-separações em um DAG $\mathbb{G}$ são definidas pela estrutura de conexões do DAG e a direcionalidade de certas arestas que definem as v-estruturas.

O Teorema 3 implica também que, apesar de todos os DAGs numa mesma classe de equivalência possuir o mesmo grafo esqueleto, não todas as arestas têm que ter a mesma direcionalidade. As arestas cuja direcionalidade é igual em todos os DAGs da mesma classe de equivalência são chamadas de arestas dirigidas obrigatórias. As demais arestas são chamadas de arestas reversíveis. Toda aresta que participa de uma v-estrutura num determinado DAG $\mathbb{G}$ membro de uma classe de equivalência $\mathcal{C}$ é uma aresta dirigida obrigatória em todos os membros de $\mathcal{C}$. No entanto, nem toda aresta dirigida obrigatória em $\mathcal{C}$ participa de v-estruturas. Tais arestas são requeridas em $\mathcal{C}$ para garantir o mesmo conjunto de v-estruturas em todos os membros de $\mathcal{C}$, caso contrario alguns membros de $\mathcal{C}$ teriam novas v-estruturas e portanto $\mathcal{C}$ não seria uma classe de equivalência.

Uma classe de equivalência $\mathcal{C}$ pode ser representada inequivocamente por um grafo acíclico parcialmente dirigido completo ou CPDAG (do inglês completed partially directed acyclic graph). Um CPDAG $\mathbb{P}$ é um grafo que pode conter tanto arestas não dirigidas quanto arestas dirigidas (não formando ciclos dirigidos) e que satisfaz as seguintes propriedades (Chickering, 2002):

- o grafo esqueleto de $\mathbb{P}$ é igual ao esqueleto de qualquer membro de $\mathcal{C}$;

- toda aresta dirigida obrigatória em $\mathcal{C}$ é também dirigida em $\mathbb{P}$ com a mesma direcionali- 
dade; e

- toda aresta reversível em $\mathcal{C}$ é representada em $\mathbb{P}$ como aresta não dirigida.

Um CPDAG $\mathbb{P}$ pode ser instanciado a um DAG $\mathbb{G}$ pertencente à classe de equivalência que $\mathbb{P}$ representa, dando direcionalidade às arestas não dirigidas de tal forma que não sejam introduzidas novas v-estruturas. Um DAG instanciado de um CPDAG $\mathbb{P}$ é chamado de extensão consistente de $\mathbb{P}$ (Chickering, 2002). O CPDAG $\mathbb{P}$ que representa a classe de equivalência de um determinado DAG $\mathbb{G}$ é também conhecido como grafo essencial de $\mathbb{G}$ e denotado como $C P D A G(\mathbb{G})$ (Castelo e Kocka, 2004).

Uma outra propriedade gráfica que tem sido usada em vários sistemas de aprendizagem estrutural é a que relaciona adjacência e d-separação (Lema 2 em Neapolitan (2003)):

Teorema 4 (Adjacência e D-separação). Dado um DAG $\mathbb{G}$ definido sobre um conjunto de variáveis aleatórias $\boldsymbol{U}=\left(X_{1}, \ldots, X_{n}\right)$. Verifica-se que todo par de variáveis $X_{i}, X_{j} \in \boldsymbol{U}$ é adjacente em $\mathbb{G}$ se e só se $X_{i}$ e $X_{j}$ não estão d-separados por algum subconjunto $\mathbf{Z} \subset \boldsymbol{U}$.

O Teorema 4 implica que toda aresta na estrutura do modelo representa a ausência de dseparação (ou, equivalentemente, ausência de independência condicional na distribuição subjacente) entre as variáveis da aresta. Alguns métodos de aprendizagem baseiam-se nesta propriedade e estimam o DAG mediante a busca de separadores entre pares de variáveis; se o separador não é encontrado a aresta é mantida no DAG.

A seguir é apresentado um corolário do Teorema 4, o qual tem sido bastante usado em métodos de aprendizagem estrutural (Corolário 2.2 em Neapolitan (2003)):

Corolario 1 (Separadores e Adjacência). Dado um DAG $\mathbb{G}$ definido sobre um conjunto de variáveis aleatórias $\boldsymbol{U}=\left(X_{1}, \ldots, X_{n}\right)$. Para todo par de variáveis $X_{i}, X_{j} \in \boldsymbol{U}$, se $X_{i}$ está $d$-separado de $X_{j}$ em $\mathbb{G}$ então eles estão d-separados ou pelo conjunto de pais de $X_{i}$ ou pelo conjunto de pais de $X_{j}$.

Vários métodos de aprendizagem usam o resultado do Corolário 1 para ajudar a focalizar a busca de separadores ao conjunto de nós atualmente adjacentes da aresta (Wang et al., 2007).

A condição de Markov garante que toda d-separação numa RB codifica uma independência condicional na distribuição conjunta modelada $P$. No entanto, o caminho inverso não é necessariamente verdadeiro, ou seja, não toda independência em $P$ é representada na RB como d-separação. A seguir define-se a condição em que essa bidirecionalidade é satisfeita: 
Definição 13 (Condição de fidelidade). Suponha uma distribuição de probabilidade conjunta $P$ definida num conjunto de variáveis aleatórias $\boldsymbol{U}=\left(X_{1}, \ldots, X_{n}\right)$ e um DAG $\mathbb{G}$ com nós representando essas variáveis, $\mathbb{G}=(\boldsymbol{U}, \boldsymbol{E})$. Diz-se que a tupla $(\mathbb{G}, P)$ satisfaz a condição de fidelidade se:

- $(\mathbb{G}, P)$ satisfaz a condição de Markov (ou seja, é uma RB representando somente independências condicionais em $P$ ); $e$

- todas as independências condicionais em P são representadas com o DAG $\mathbb{G}$.

Quando uma RB $(\mathbb{G}, P)$ satisfaz a condição de fidelidade então diz-se que $\mathbb{G}$ e $P$ são fiéis entre si, e também $\mathbb{G}$ é chamado de mapa perfeito de $P$. O fato que um DAG $\mathbb{G}$ seja fiel a $P$ implica que todo DAG Markov equivalente a $\mathbb{G}$ também seja fiel a $P$ (Teorema 2.6 em Neapolitan (2003)). Além de representar todas as independências condicionais da distribuição conjunta modelada $P$, um DAG fiel a $P$ representa todas as dependências diretas em $P$ através das suas arestas. Uma dependência direta é uma relação entre um par de variáveis aleatórias $X_{i}, X_{j} \mathrm{em}$ que não existe subconjunto $\boldsymbol{Z} \in \boldsymbol{U}$ que faça $\left.X_{i} \perp X_{j} \mid \boldsymbol{Z}\right)$.

O problema da aprendizagem estrutural de RBs têm sido definido de diversas formas na literatura. Neste trabalho adota-se a definição de Perrier et al. (2008), a qual é apresentada a seguir:

Definição 14 (Aprendizagem estrutural). Dado um conjunto de observações ou instâncias $D$ amostradas de uma distribuição conjunta $P$ que admite uma representação fiel com algum DAG. A aprendizagem estrutural de RB consiste em inferir a partir de D um DAG $\mathbb{G}$, ou modelo de equivalência, que seja um mapa perfeito de $P$.

Um conceito importante em RBs, especialmente usado em vários algoritmos de aprendizagem estrutural, é a noção de Markov Blanket (Neapolitan, 2003). O Markov Blanket de uma variável $T$ numa RB $(\mathbb{G}, P)$ é o conjunto mínimo de variáveis, $\boldsymbol{M} \boldsymbol{B}_{T}$, que tornam $T$ condicionalmente independente de qualquer subconjunto de variáveis da RB (excetuando as variáveis em $\boldsymbol{M} \boldsymbol{B}_{T}$ ) dado $\boldsymbol{M} \boldsymbol{B}_{T}$. Isso significa que o Markov Blanket de uma variável $T$ carrega toda a informação que a RB fornece para determinar o valor da variáve $T$. 


\subsubsection{Avaliação de redes Bayesianas}

Uma das principais abordagens na aprendizagem estrutural de RBs trata esse problema como um de otimização. Para isso, uma função de pontuação (também chamada de função de escore) é usada para avaliar quão bom as estruturas candidatas explicam os dados observados. Formalmente, uma função de escore é uma função $S(\mathbb{G}, D)$ que atribui um valor a um DAG (ou CPDAG) $\mathbb{G}$ baseado no conjunto de dados fornecido $D$.

Uma propriedade que é frequentemente perseguida quando se constrói uma função de escore é a noção de decomposição (Chickering e Boutilier, 2002):

Definição 15 (Decomposição de função de escore). Uma função de escore $S(\mathbb{G}, D)$ é decomponível se ele pode ser escrito como uma soma de funções locais s, cada uma definida sobre uma família diferente de $\mathbb{G}$, assim, $S(\mathbb{G}, D)=\prod_{i=1}^{n} s\left(X_{i}, \mathbf{P} \mathbf{a}_{i}\right)$.

Está implícito que a função local $s$ é calculada com os dados de $D$ relativos à família fornecida. Assim, quando se escreve $s\left(X_{i}, \mathbf{P a}{ }_{i}\right)$ se entende que ela é calculada com o subconjunto de dados relativos às columnas $X_{i}$ e $\mathbf{P a}_{i}$ de $D$, denotado também como $D\left(\left\{\mathbf{P a}_{i}, X_{i}\right\}\right)$. Existem funções de escore que são escritas como produtórios de funções locais. Nesses casos, a propriedade de decomposição pode também ser aplicável, já que sempre é possível aplicar a função logaritmo para tornar o produtório em somatório. Uma implicação importante da propriedade de decomposição é que ela permite comparar dois DAGs simplesmente comparando os escores das famílias que apresentam diferencias (conjuntos de pais diferentes), não sendo necessário o computo do escore de todas as famílias da rede.

Uma outra propriedade importante que esta integrada em várias funções de escore é a equivalência:

Definição 16 (Equivalência de funções de escore). Uma função de escore $S(\mathbb{G}, D)$ é Markov equivalente se para qualquer par de DAGs Markov equivalentes $\mathbb{G}_{1}, \mathbb{G}_{2}$ se verifica que $S\left(\mathbb{G}_{1}, D\right)=S\left(\mathbb{G}_{1}, D\right)$.

O uso de funções de escore equivalentes é importante quando se pretende usar as RBs como meio para representar as independências condicionais de uma determinada distribuição, ja que tais funções não distinguem modelos que codificam o mesmo conjunto de independências.

Uma função de escore frequentemente usada em RBs e que satisfaz a propriedade de decomposição e equivalência é o critério BDe (do inglês, Bayesian Dirichlet likelihood equiva- 
lent), o qual equivale à probabilidade posterior do DAG dados os dados (Heckerman et al., 1995):

$$
\begin{gathered}
S(\mathbb{G}, D)=P(\mathbb{G} \mid D)=\prod_{i=1}^{n} s\left(X_{i}, \mathbf{P a}_{i}\right), \\
s\left(X_{i}, \mathbf{P a}_{i}\right)=\prod_{j=1}^{q_{i}} \frac{\Gamma\left(N_{i j}^{\prime}\right)}{\Gamma\left(N_{i j}^{\prime}+N_{i j}\right)} \prod_{k=1}^{r_{i}} \frac{\Gamma\left(N_{i j k}^{\prime}+N_{i j k}\right)}{\Gamma\left(N_{i j k}^{\prime}\right)}
\end{gathered}
$$

onde $\Gamma()$ é a função Gamma, $r_{i}$ é o numero de valores distintos de $X_{i} ; q_{i}$ é o numero das distintas configurações dos pais $\mathbf{P a}_{\mathbf{i}} ; N_{i j k}$ é o numero de observações em $D$ onde $X_{i}$ tem valor $k$ e seus pais $\mathbf{P a}_{\mathbf{i}}$ tem valor $j ; N_{i j}$ é a soma de $N_{i j k}$ sobre $k ; N_{i j k}^{\prime}$ é uma distribuição $a$ prior sobre $N_{i j k}$; e $N_{i j}^{\prime}$ é a soma de $N_{i j k}^{\prime}$ sobre $k$.

Uma versão de BDe que tem mostrado sucesso em vários sistemas de aprendizagem, é a BDeu (do inglês, Uniform Bayesian Dirichlet likelihood equivalent) (Daly et al., 2011), a qual usa como distribuição a priori de $N_{i j k}$ uma distribuição uniforme, assim $N_{i j k}^{\prime}=N^{\prime} / r_{i} q_{i}$, onde $N^{\prime}$ é chamado de tamanho de amostra equivalente. A uniformidade na distribuição a priori de BDeu faz com que ela não favoreça nenhuma configuração em especial (é não informativa). A força da hipótese que todas as configurações são igualmente prováveis é controlada pelo parâmetro $N^{\prime}$. Por exemplo, um valor de $N^{\prime}=1$ indica que existe uma única (pseudo) observação suportando tal uniformidade.

Dentre das funções de escore existentes, nenhum delas provou ser marcadamente superior às outras (Wang et al., 2007). Nas implementações do presente trabalho foi selecionada a função BDeu como função de escore, dada sua grande popularidade e suas propriedades de decomposição e equivalência. BDeu é calculada de forma logarítmica, assim, o produtório da Equação 2.5 torna-se em somatório, o qual ajuda em melhorar a precisão numérica quando os valores são elevados. 


\section{Capítulo 3}

\section{Revisão Bibliográfica}

Neste capítulo é apresentada uma revisão dos métodos de aprendizagem estrutural mais relevantes da literatura, com especial ênfase em métodos evolutivos, abordagem em que a presente tese está parcialmente baseada.

A literatura de aprendizagem estrutural de RBs tem sido dominada por dois grandes abordagens: os métodos baseados em detecção de independências condicionais (Spirtes et al., 2000) e os métodos baseados em busca e pontuação (?). Uma terceira abordagem que combina as duas anteriores tem também emergido na última década, os chamados métodos híbridos (Wong e Leung, 2004; Tsamardinos et al., 2006a). Na Seção 3.1 é apresentada uma revisão dos principais métodos de detecção de independências condicionais, enquanto a Seção 3.2 apresenta uma revisão dos métodos de busca e pontuação. Seção 3.3 apresenta uma revisão dos métodos híbridos. Finalmente, Seção 3.4 detalha especificamente os métodos baseados em heurísticas evolutivas na aprendizagem estrutural de RBs.

\subsection{Aprendizagem estrutural de RBs baseada em testes de inde- pendência condicional}

A característica principal desta abordagem é o uso sistemático de testes estatísticos de independência ou, de forma geral, de independência condicional para determinar a presença de arestas e sua direção. Dado um conjunto de variáveis aleatórias $\boldsymbol{U}=\left(X_{1}, \ldots, X_{n}\right)$ e um banco de dados $D$ com instâncias dessas variáveis aleatórias, os testes são aplicados normalmente entre duas variáveis $X_{i}$ e $X_{j}$, procurando um conjunto separador $\boldsymbol{Z} \subset \boldsymbol{U}$ que torne as variáveis 
condicionalmente independentes (ou seja $X_{i} \perp X_{j} \mid \boldsymbol{Z}$ ) e assim a existência de aresta entre $X_{i}$ e $X_{j}$ é descartada da estrutura sendo inferida (Teorema 4). Os métodos nesta abordagem diferem maiormente no tipo de teste estatístico usado, na heurística de busca do conjunto separador, e na forma como lidam com inconsistências ou pouca fiabilidade nos testes estatísticos (causado por conjuntos de dados ruidosos ou com poucas amostras).

Com respeito aos testes de independência, os mais frequentemente usados para aprendizagem estrutural de RBs são os testes $X^{2}$ e $G^{2}$ em dados discretos (Spirtes et al., 2000; Neapolitan, 2003; Tsamardinos et al., 2006a; Wang et al., 2007; Xie e Geng, 2008) e o teste Z-Fisher em dados contínuos (Kalisch e Bühlmann, 2007). Esses testes devolvem um valor, chamado de $p$-valor, que corresponde à probabilidade de falsamente rejeitar a hipótese nula (independência) dado que ela é verdadeira. Se o p-valor é menor que um determinado limiar $\alpha$ (conhecido como nível de significância) a hipótese nula é rejeitada, de outra forma ela é aceita. A confiabilidade do teste depende do número de amostras no banco de dados e da ordem do subconjunto condicionante. Um pequeno número de amostras ou grandes subconjuntos condicionantes produzem resultados pouco confiáveis. Essa é a razão pela qual a maioria de métodos de aprendizagem estrutural baseados em testes de independência realizam os testes em forma incremental em relação à ordem do condicionante, garantindo que os testes mais confiáveis se realizem primeiro. Além dos testes anteriores, foram propostos também testes baseados na teoria da informação, tal como a informação mútua (Cheng et al., 2002; Jia et al., 2007).

Um dos primeiros métodos propostos para recuperar DAGs a partir de testes de independência foi o SGS de Spirtes et al. (1991). No entanto, esse método é muito ineficiente computacionalmente, já que para cada par de variáveis ele testa como possível separador cada subconjunto das variáveis restantes, operação que tem um custo exponencial. Várias melhoras de SGS foram propostas posteriormente. Um dos mais populares e bem sucedidos foi o método PC de Spirtes et al. (2000), o qual busca os separadores na adjacência atual das arestas testadas numa ordem crescente (até um ordem máximo predefinido), explorando assim a frequente esparsidade das redes. A consistência de PC foi mostrada em dados de alta dimensão por Kalisch e Bühlmann (2007). Uma outra alternativa a SGS foi apresentada por Margaritis e Thrun (2000), o método Grow and Shrink, o qual reduz o número de testes estatísticos para cada par de variáveis buscando separadores no Markov blanket das variáveis, o qual é calculado antecipadamente para ganhar eficiência.

Um outro método que teve um alto impacto na literatura foi descrito por Cheng et al. (2002), 
o chamado TPDA (do inglês three-phase dependency analysis), o qual não somente testa a existência de independência condicional entre pares de variáveis mas também usa uma medida de dependência (baseado em informação mútua) no processo de busca de separadores. TPDA confia na condição de fidelidade e na condição de fidelidade monotônica (uma condição ainda mais estrita que a de fidelidade). Os autores mostraram que é possível aprender um DAG de $n$ variáveis com TPDA usando $O\left(n^{4}\right)$ testes de independência. Uma implementação paralela de TPDA foi também apresentada em (Gou et al., 2007). No entanto, apesar da aceitação de TPDA, Chickering e Meek (2006) mostraram que a consistência assintótica de TPDA não é satisfeita de forma geral devido a uma incompatibilidade entre as duas condições em que TPDA está baseado.

Seguindo uma ideia parecida à TPDA, Wang et al. (2007) apresentaram o método Heuristics $P C^{1}$ para determinar esqueletos de $\mathrm{RBs}$, o qual é baseado também nas condições de fidelidade, de fidelidade monotônica e uma medida de dependência (o p-valor do teste $G^{2}$ ). O fator chave de Heuristics $P C$ para reduzir o número de testes de independência em cada par de variáveis é selecionar um candidato a separador que tenha a maior chance de separar as variáveis (baseado nas medidas de dependência), ao invés de outros métodos como PC que testam todos os subconjuntos separadores possíveis. Os autores mostraram as vantagens do método em uma aplicação com dados de expressão gênica.

Uma outra proposta para aprender RBs com testes de independência veio de Xie e Geng (2008), na qual o conjunto total de variáveis é particionado recursivamente até que são obtidos subconjuntos atômicos (que não podem ser divididos). O método então aprende um DAG em cada subconjunto e em seguida vai combinando esses DAGs subindo na árvore de particionamento até obter o DAG do conjunto total de variáveis. A vantagem dessa ideia é que a aprendizagem dos DAGs nos subconjuntos atômicos é facilitada, já que o espaço de busca de separadores é reduzido. Por outro lado, o particionamento pode não funcionar se a rede é altamente conexa.

Os métodos anteriores assumem que os testes de independência condicional dão sempre resultados corretos. No entanto, em situações reais tais testes apresentam muitas vezes inconsistências e pouca confiabilidade, principalmente devido a tamanhos de amostra pequenos, dados ruidosos e presença de relações quase determinísticas conhecidas como $\mathrm{ADRs}^{2}$ (do inglês

\footnotetext{
${ }^{1} \mathrm{O}$ método Heuristics PC é abreviado nesta tese como HeuPC, ao invés da abreviação original AlgorithmHPC. Isto para evitar confusão com um outro método estudado nesta tese denominado HPC (De Morais e Aussem, 2010).

${ }^{2}$ De acordo com van Dijk et al. (2003), um ADR é uma relação pronunciada entre dois variáveis, onde somente
} 
approximate deterministic relationship) (van Dijk et al., 2003; De Morais e Aussem, 2010). Uma tentativa de contornar esse último problema foi descrito por Campos e Huete (2000b), propondo um esquema para manter tão baixo quanto possível a ordem do teste de independência, porém sem deixar de garantir consistência assintótica. Steck e Tresp (1999) propuseram um algoritmo para lidar com resultados de testes de independência inconsistentes (que não podem ser mapeados em um único DAG), devolvendo esqueletos alternativos para cada conjunto de testes de independência maximamente consistente. van Dijk et al. (2003) descreveram um método que consegue aprender esqueletos na presença de ADRs. Para tal fim, os testes de independência são limitados a somente ordem 0 e 1 e um pós-processamento do esqueleto é realizado ao final do processo.

Os métodos acima são frequentemente considerados como métodos "globais", já que eles aprendem a estrutura completa do DAG, do CPDAG ou do grafo esqueleto suportada pelos dados. Existem também os chamados métodos "locais", que têm por objetivo aprender somente a parte da rede envolvida com uma determinada variável alvo de interesse $T$, ou seja o conjunto de pais e filhos de $T$. A origem desses métodos é normalmente encontrada em áreas de classificação e seleção de atributos, onde a variável alvo é a variável classe. No entanto, tais métodos são relevantes na aprendizagem de RBs, desde que teoricamente eles poderiam recuperar a rede completa se aplicados interativamente em todas as variáveis da rede. Os métodos mais representativos neste tipo incluem o algoritmo IAMB (do inglês Incremental Association Markov Boundary) (Tsamardinos et al., 2003), o algoritmo BFMB (do inglês Breadth-First search of Markov Blanket) (Fu e Desmarais, 2008), o método MMPC (do inglês Max-Min Parents and Children) (Tsamardinos et al., 2006a), o método GetPC (Pena et al., 2007), e o método HPC (do inglês Hybrid Parents and Children) (De Morais e Aussem, 2010). Todos estes métodos possuem provas de exatidão assintótica sob condições ideais. No entanto, na prática o método que melhor tem mostrado diminuir a taxa de erros falso-negativos em bancos de dados com poucas amostras é o HPC (De Morais e Aussem, 2010).

\subsection{Aprendizagem estrutural baseada em busca e pontuação}

Em forma geral, os métodos baseados em busca e pontuação estão formados pelos seguintes componentes (Daly et al., 2011):

uma pequena fração de instâncias nos dados não está deterministicamente relacionada. 
- um espaço de busca que consiste de soluções admissíveis do problema;

- um mecanismo para codificar as soluções;

- uma estratégia para se deslocar entre soluções no espaço de busca; e

uma função de pontuação que atribui um valor de escore a cada solução no espaço de busca, baseado no ajuste dessa solução em relação aos dados disponíveis.

O problema de encontrar a estrutura ótima global dentro do espaço de busca é de forma geral um problema NP difícil (não pode ser resolvido em um tempo determinístico polinomial) (Chickering et al., 2004). Isto devido a que o número de DAGs no espaço de busca aumenta de forma super-exponencial com o número de variáveis (especificamente $O\left(n ! 2\left(\begin{array}{l}n \\ 2\end{array}\right)\right)$ ) (Robinson, 1977). Por exemplo, para um problema de 3 variáveis tem-se 25 DAGs possíveis, enquanto que para 6 variáveis tem-se mais de 3.7 milhões de DAGs no espaço de busca. Apesar disso, é possível encontrar na literatura alguns esforços de aprendizagem estrutural ótima para reduzidos números de variáveis (umas poucas dezenas). Os primeiros esforços vieram de Ott et al. (2004) e de Koivisto e Sood (2004), nos quais foi proposto o uso de programação dinâmica. A complexidade temporal e de memória desses algoritmos é $O\left(n 2^{n}\right)$, o que limita sua aplicação a cerca de 29 variáveis em um típico computador com memória externa de aproximadamente 100GB.

Em uma tentativa de aumentar a aplicabilidade dos métodos de busca ótima em problemas de maior dimensão, Perrier et al. (2008) propuseram o uso de superestruturas como forma de reduzir os espaço de busca. No entanto, a otimalidade não é mais garantida nesse esquema, já que as superestruturas são estimativas aproximadas de heurísticas baseadas em testes de independência. Parviainen e Koivisto (2009) propuseram um novo algoritmo de busca ótima que tenta balancear tempo computacional e memória de forma eficiente, conseguindo aprender estruturas ótimas de até 31 nós. Recentemente, Tamada et al. (2011b) descreveram uma implementação paralela do método de Ott et al. (2004) e mostraram sua aplicação em uma RB de 32 nós. Seu experimento mostrou a dificuldade atual de aprender RBs ótimas de maior dimensão, já que para aprender essa estrutura de 32 variáveis foi necessária uma semana de processamento em um computador massivamente paralelo com 256 processadores.

Dada a dificuldade de determinar a RB ótima no paradigma de busca e pontuação, vários métodos de aprendizagem aproximado (heurísticas) tem sido propostos na literatura. Um dos trabalhos iniciais mais influentes nessa área veio de Cooper e Herskovits (1992) que descreve- 
ram o método K2. Esse método usa uma estratégia greedy search para construir as famílias dos nós baseado numa predefinida ordem ancestral de variáveis e uma função de escore decomponível (a qual passou a ser conhecido também como K2). Outros métodos foram desenvolvidos posteriormente baseados em K2, tais como K3 de Bouckaert (1993) e o MRMRG (do inglês Max Relevance and Min Redundancy Greedy) de Liu et al. (2007).

O principal problema do método $\mathrm{K} 2$ e os subsequentes baseados nele é que é necessário saber com antecedência a ordem ancestral das variáveis, informação que muitas vezes não está disponível. Um dos trabalhos pioneiros e mais influentes na aprendizagem estrutural de RBs que elimina a necessidade de ordens ancestrais predefinidas veio de Heckerman et al. (1995). Eles propuseram várias funções de escore desde a perspectiva Bayesiana, algumas delas sendo usadas hoje em dia com muita frequência (por exemplo, BDe e BDeu). Os autores testaram posteriormente essas funções num método iterativo simples de busca gananciosa (descrito em (Chickering et al., 1995)) em que a cada passo uma aresta é adicionada, removida ou revertida.

A partir dos trabalhos seminais de Heckerman e Chickering, várias abordagens de busca e pontuação foram propostas tentando melhorar a velocidade e precisão da aprendizagem estrutural, a maioria dessas abordagens sendo aplicações ou adaptações de meta-heurísticas de otimização existentes. Entre as mais notáveis tem-se: busca gananciosa (Steck, 2000; Hwang et al., 2002; Campos et al., 2002; Chickering, 2002; Chickering e Boutilier, 2002; Teyssier e Koller, 2005); simulated annealing (Campos e Huete, 2000a; Wang et al., 2004; Janzura e Nielsen, 2006; Ye et al., 2008); otimização de enxame de partículas - PSO (do inglês: particle swarm optimization) (Heng et al., 2006; Xing-Chen et al., 2007; Sahin e Devasia, 2007); otimização por colônia de formigas - ACO (do inglês: ant colony optimization) (de Campos et al., 2002; Daly e Shen, 2009) e algoritmos evolutivos (discutido na Seção 3.4 em detalhe).

\subsection{Métodos híbridos}

Tanto os métodos baseados em independências condicionais quanto os métodos baseados somente em busca e pontuação apresentam limitações. Os testes estatísticos são o ponto frágil dos primeiros métodos, já que a confiabilidade dos testes estatísticos cai rapidamente a medida que a ordem do conjunto condicionante aumenta (é necessário um aumento exponencial do número de amostras para manter a mesma confiabilidade). Isso provoca que as estruturas aprendidas sejam de baixa precisão em situações em que se tem poucas amostras ou a estrutura 
a aprender é densamente conectada (Spirtes et al., 2000; Yehezkel e Lerner, 2009). Por outro lado, os métodos baseados em busca e pontuação produzem normalmente resultados de melhor precisão com as mesmas quantidades de dados, mas apresentam maiores dificuldades em escalar a problemas de alta dimensão, dado o crescimento super-exponencial do espaço de busca (Wang et al., 2007).

Vários métodos híbridos têm sido propostos na literatura tentando aproveitar as vantagens dos dois paradigmas de aprendizagem estrutural existentes. Um dos primeiros métodos nessa linha de pesquisa veio de Singh e Valtorta (1995), no qual são usados testes de independência para inferir uma ordem ancestral das variáveis e que serve depois como entrada do método K2 que determina o DAG final baseado nessa ordem e na função de escore.

Acid e De Campos (2000) propuseram um método, chamado de BENEDICT, o qual mede as divergências entre as independências condicionais codificadas por um DAG candidato e as encontradas nos dados. Uma hibridização mais direta foi descrita por Dash e Druzdzel (1999), no qual usa-se o tradicional método de independências condicionais PC para obter uma estrutura inicial, o qual constitui o ponto inicial de um método de busca gananciosa que determina o DAG final. de Campos et al. (2003) apresentaram uma ideia oposta à anterior, o algoritmo IMAPR, em que primeiro é obtido um DAG mediante busca gananciosa (com reinicializações aleatórios) e logo são aplicados testes de independência para determinar a adição ou eliminação de arestas nesse DAG.

Friedman et al. (1999) apresentaram um esquema híbrido (chamado de Sparce Candidate - SC) que itera entre duas etapas: i) determinação de conjuntos de candidatos a pais para as variáveis, usando uma medida de dependência (informação mútua); e ii) otimização da estrutura sujeito aos conjuntos anteriores e uma função de escore (BDeu). Os autores mostraram uma redução de tempo computacional significativa com esse esquema. Posteriormente, Tsamardinos et al. (2006a) construíram sobre a ideia de SC, propondo o algoritmo MMHC (do inglês Max-Min Hill-Climbing). A diferença principal sobre SC é que MMHC restringe o espaço de busca somente uma vez por médio de um algoritmo sofisticado proposto também pelos autores, o algoritmo MMPC (do ingles Max-Min Parents and Children). MMPC determina mediante testes de independência e medidas de dependência a adjacência (pais e filhos) de cada variável, ou seja, determina um grafo esqueleto. A parte de busca e pontuação de MMHC é uma busca gananciosa padrão, a qual, partindo de um grafo vazio vai adicionando, apagando ou revertendo arestas (que estão no esqueleto obtido por MMPC) com o objetivo de obter o DAG que 
maximiza a função de escore.

Em um esquema similar a MMPC e SC, Wang et al. (2007) propuseram um método híbrido de duas fases. A primeira fase é o algoritmo Heuristic PC (Secção 3.1) concebido pelos mesmos autores, o qual gera um grafo esqueleto que serve como espaço de busca da seguinte fase. A segunda fase utiliza a metodologia aproximada de ponderação de modelos (model averaging) MCMC (do ingles Markov Chain Monte Carlo) que produz um serie de DAGs (cadeia de Markov) mediante modificações locais randômicas partindo de um DAG semente. O método devolve um DAG médio com suas arestas etiquetadas com o nível de confiança das mesmas (o número de vezes que aparece na cadeia), assim o usuário pode decidir um limiar para determinar quais arestas são confiáveis e quais não o são.

No contexto de aprendizagem ótimo de RBs, também foram propostos métodos híbridos. Os exemplos mais notáveis são de Perrier et al. (2008) e Kojima et al. (2010) que formalizaram o conceito de superestrutura, a qual é calculada com métodos de testes de independências e serve como restrição estrutural na busca da estrutura ótima.

Métodos híbridos também têm sido propostos envolvendo heurísticas evolutivas, como será descrito na subseção seguinte.

\subsection{Métodos evolutivos}

Na última década a literatura de RBs tem mostrado um marcado interesse por métodos de computação evolutiva como heurísticas de busca e pontuação no problema da aprendizagem estrutural (Daly et al., 2011). Provavelmente, esse elevado interesse seja devido ao sucesso que computação evolutiva tem mostrado em vários outros problemas, tanto na ciência como na indústria (Dasgupta e Michalewicz, 1997). Nesta seção são revisadas as principais contribuições na aprendizagem estrutural de RBs envolvendo heurísticas evolutivas. Para melhor compreensão de tais contribuições, a seção é dividida em sete partes, que correspondem aos principais aspectos da heurística evolutiva no contexto de aprendizagem estrutural.

\subsubsection{Paradigma Evolutivo}

Os algoritmos genéticos têm sido o paradigma evolutivo com maior predominância na literatura de aprendizagem estrutural de RBs. Os primeiros trabalhos nesse campo vieram de 
Larranaga et al. (1996b,a). Em (Larranaga et al., 1996b) foi descrita a aplicação de um algoritmo genético canônico para evoluir DAGs, aplicando operadores de reparação quando são produzidas estruturas inválidas. Em (Larranaga et al., 1996a) é descrito um outro algoritmo genético que evolui ordens ancestrais, o $\mathrm{GAK} 2^{3}$, no qual são propostos vários operadores de recombinação e mutação adaptados de problemas de otimização combinatórias. O procedimento K2 é usado em GAK2 como função de escore, o qual avalia cada ordem mediante a busca (greedy search) do melhor DAG coerente com a ordem. A vantagem deste método é que os operadores sempre produzem estruturas válidas, sendo desnecessários operadores de reparação. Seguindo estes trabalhos seminais, vários outros algoritmos genéticos foram propostos subsequentemente, tais como Campos e Huete (2000a); Hsu et al. (2002); Cotta e Muruzabal (2002); Harwood e Scheines (2002); van Dijk et al. (2003); van Dijk e Thierens (2004); Wong e Leung (2004); Kim et al. (2005); Faulkner (2007); Delaplace et al. (2007); Tian et al. (2007); Jia et al. (2008); dos Santos et al. (2010a); Carvalho (2011); Park e Cho (2012). As diferenças principais nesses métodos estão no espaço de busca (DAGs, ordens ancestrais, classes de equivalência), nos operadores genéticos e na forma de representar as soluções, como se verá mais adiante nesta seção.

Um segundo paradigma com significativa presença na literatura envolve os chamados métodos de programação evolutiva. A diferença principal deste paradigma em relação aos algoritmos genéticos é que programação evolutiva não usa operadores de recombinação, sendo os operadores de mutação e seleção os responsáveis da evolução. Um dos primeiros trabalhos nesta linha veio de Wong et al. (1999) com o algoritmo MDLEP (do inglês Minimum Description Length Evolutionary Programming) onde se propõe um operador de mutação que escolhe o ponto de mutação baseado no aumento em escore que tal mutação causaria. Os trabalhos de Muruzabal e Cotta (2004) e Muruzabal e Cotta (2007) também são exemplos relevantes na linha de programação evolutiva, onde se propõe e analisa vários operadores de mutação tanto no espaço de DAGs quanto no espaço de CPDAGs. Outros trabalhos de programação evolutiva na aprendizagem estrutural de RBs têm sido descritos recentemente em (Stefano et al., 2010) e (dos Santos et al., 2010b).

Recentemente, Khanteymoori et al. (2011) introduziram um terceiro paradigma baseado em otimização por reprodução assexuada - ARO (do inglês asexual reproduction optimiza-

\footnotetext{
${ }^{3}$ Apesar de que na publicação não é dada nenhuma denominação especial a esse algoritmo, nesta tese ele é chamado de GAK2, já que combina um algoritmo genético (GA) com o procedimento K2. Esse nome também é dado para evitar confusão com um outro método referenciado aqui, chamado de K2GA (Faulkner, 2007). GAK2 participa em vários experimentos da presente tese e portanto a sua necessidade de ser nomeado.
} 
tion). Essa abordagem simula computacionalmente o mecanismo de brotamento que ocorre em alguns organismos pluricelulares como esponjas e hidras, onde os indivíduos produzem seus filhos como brotos neles, sem precisar de parceiros. Similarmente, na aprendizagem com ARO um individuo (DAG) produz seu filho (chamado de gema) como uma copia similar a ele, mas com uma pequena parte alterada. O filho então substitui a seu pai se consegue superar ele em escore, senão uma nova gema é tentada e o ciclo se repete.

\subsubsection{Espaço de busca}

Três tipos de espaço de busca têm sido reportados na literatura: o espaço de DAGs, o espaço de ordens ancestrais e o espaço de classes de equivalências ou CPDAGs. O espaço de DAGs é o mais simples e natural já que os estados nele codificam diretamente possíveis soluções, sem requerer de rotinas de codificação/decodificação. No entanto, a maioria de operadores de busca são não fechados nesse espaço (podem produzir soluções com ciclos e portanto estão fora desse espaço), sendo necessária a utilização de operadores de reparação para remover os ciclos das soluções ilegais e assim torná-las válidas (ou alternativamente, descartar elas) implicando numa perda de desempenho computacional. Entre os trabalhos mais relevantes que buscam diretamente no espaço de DAGs estão: Larranaga et al. (1996b); Cotta e Muruzabal (2002); Harwood e Scheines (2002); van Dijk et al. (2003); van Dijk e Thierens (2004); Wong e Leung (2004); Kim et al. (2005); Faulkner (2007); Delaplace et al. (2007); Tian et al. (2007); Khanteymoori et al. (2011).

O espaço de ordens ancestrais tem sido também o alvo de vários algoritmos de aprendizagem estrutural. Um estado (ordem ancestral) nesse espaço não representa uma única solução DAG senão todo um subespaço de DAGs que são consistentes com a ordem ancestral. Por esse motivo é que heurísticas de busca local (como K2) são normalmente usadas para encontrar o melhor DAG do subespaço expandido pela ordem. A vantagem do espaço de ordens é a não necessidade de operadores de reparação. A desvantagem é um aumento na demanda computacional para avaliar os estados desse espaço e também uma perda de eficiência, desde que um único DAG pode estar representado por múltiplos estados no espaço de ordens. Entre os trabalhos mais relevantes que buscam no espaço de ordens ancestrais estão: Larranaga et al. (1996a); Campos e Huete (2000a); Hsu et al. (2002); Stefano et al. (2010); dos Santos et al. $(2010 a, b))$.

A busca no espaço de classes de equivalência ou CPDAGs tem sido motivada principal- 
mente por uma esperada redução do espaço de busca, desde que, diferentemente dos espaços de DAGs e ordens ancestrais, cada estado no espaço de CPDAGs representa uma solução diferente (codifica um conjunto de independências condicionais diferente). Os trabalhos mais relevantes nesta linha foram de Muruzabal e Cotta (2004), van Dijk e Thierens (2004) e Jia et al. (2008). No entanto, os resultados experimentais mostraram que o ganho que se tem buscando no espaço de CPDAGs é marginal e as vezes negativo, devido principalmente a um dramático aumento da complexidade dos operadores de busca nesse espaço (van Dijk e Thierens, 2004).

\subsubsection{Codificação das soluções}

A forma como as soluções são codificadas depende do espaço de busca. No espaço de DAGs, tradicionalmente tem sido usada a matriz de adjacência, a qual é uma forma bastante simples e direta de codificação. A desvantagem é que essa codificação torna-se muito ineficiente para ao representar DAGs de baixa conectividade, já que as matrizes são muito esparsas (maiormente zeros). Os principais métodos que usam esta forma de codificação são: (Larranaga et al., 1996b; Wong e Leung, 2004; Delaplace et al., 2007; Jia et al., 2008; Khanteymoori et al., 2011).

$\mathrm{Na}$ literatura existem representações mais compactas para DAGs do que a matriz de adjacência. Por exemplo, Tian et al. (2007) usou uma codificação que associa a cada nó do DAG o conjunto de nós que pertencem à família do nó. Os trabalhos de (Cotta e Muruzabal, 2002; Harwood e Scheines, 2002; van Dijk et al., 2003; van Dijk e Thierens, 2004) codificam o DAG como uma lista de pares ordenados que representam as arestas.

Os estados no espaço de ordens ancestrais são codificados diretamente com as mesmas ordens (também chamadas de permutações) (Larranaga et al., 1996a; Campos e Huete, 2000a; Hsu et al., 2002; dos Santos et al., 2010a,b). Representações mistas têm sido descritas recentemente, nos quais um DAG é codificado mediante uma matriz ou lista de conectividade que define o esqueleto da rede e uma ordem ancestral que dá a direcionalidade à mesma (Kim et al., 2005; Faulkner, 2007; Stefano et al., 2010; Carvalho, 2011). Nessas representações mistas são normalmente definidos operadores de busca para cada parte da representação (se busca simultaneamente na conectividade e na direcionalidade da rede), aumentando assim as capacidades explorativas dos métodos. Outra vantagem das representações mistas é que devido à ordem ancestral é intrinsecamente evitada a codificação de estruturas ilegais. 


\subsubsection{Operadores de busca}

Os operadores de busca são os mecanismos em que o espaço de busca é explorado. $\mathrm{Na}$ abordagem de aprendizagem estrutural evolutiva, esses mecanismos assumem a forma de operadores de recombinação, mutação, seleção e reparação. Uma grande quantidade de propostas foram realizadas para tal finalidade nos diversos espaços de busca, paradigmas evolutivos e formas de codificar as soluções.

Os operadores tradicionais de recombinação de um-ponto e multi-ponto foram aplicados para recombinar DAGs em (Larranaga et al., 1996b; Delaplace et al., 2007; Tian et al., 2007) e matrizes de conexão em (Kim et al., 2005; Jia et al., 2008; Carvalho, 2011). Operadores de recombinação mais especializados foram propostos em (Cotta e Muruzabal, 2002; van Dijk et al., 2003; Wong e Leung, 2004; Faulkner, 2007), em que a recombinação é feita a nível de famílias e considerando o escore local das famílias (razão pela qual são chamados de operadores fenotípicos). De especial interesse é o operador de recombinação Merge de Wong e Leung (2004), o qual produz uma estrutura filha juntando as melhores famílias dos pais e ao mesmo tempo garantido a aciclicidade da estrutura resultante. Adicionalmente Merge consegue determinar o escore do filho a partir dos escores locais dos pais, evitando assim chamar à normalmente dispendiosa função de escore.

Em relação aos operadores de mutação no espaço de DAGs, podem ser encontrados operados simples de adição, eliminação, e inversão de arestas (Larranaga et al., 1996b; Wong et al., 1999; Wong e Leung, 2004; Kim et al., 2005; Tian et al., 2007; Carvalho, 2011). Também são encontrados operadores que escolhem os pontos de mutação guiados por alguma função que indica a chance de sucesso da operação (Wong e Leung, 2004; Delaplace et al., 2007; Faulkner, 2007).

Em relação aos operadores de reparação, eles são necessários na maioria de métodos que usam operadores de recombinação e mutação no espaço de DAGs, já que normalmente se produzem estruturas ilegais. Esses operadores detectam os ciclos nas estruturas inválidas e tendem a fazer a mínima quantidade de modificações na estrutura para tornar ela válida. Exemplos desses operadores foram descritos por van Dijk et al. (2003) e Delaplace et al. (2007).

No espaço de ordens ancestrais, Larranaga et al. (1996a) descreveram e analisaram vários operadores de recombinação (PMX, CX, OX1, OX2, POS, VR, AP) e mutação (DM, EM,ISM, SIM, IVM, SM) que foram adaptações de operadores propostos para o problema do caixeiro 
viajante (Larranaga et al., 1999). Esses operadores foram também usados em subsequentes métodos evolutivos de aprendizagem estrutural, tais como Campos e Huete (2000a), Hsu et al. (2002) e Kim et al. (2005). Recentemente, dos Santos et al. (2010a,b) propuseram os operadores de mutação RMX e o DMO, que segundo os autores produzem estruturas de melhor qualidade. A desvantagem dos operadores de mutação anteriores aparece quando se necessita reaproveitar computações locais para melhorar a eficiência computacional. Isto porque eles acabam frequentemente afetando várias famílias da estrutura de entrada, requerendo-se da reavaliação do escore de todas as famílias afetadas. Em vista disso, Teyssier e Koller (2005) propôs um operador de mutação estritamente local, o operador swap, no qual somente posições consecutivas da ordem ancestral podem ser trocadas de posição, afetando assim ao máximo duas famílias por operação.

No espaço de CPDAGs, a literatura mostra poucos operadores de busca, sendo os mais relevantes os trabalhos de Muruzabal e Cotta (2007) e Jia et al. (2007), que adotam os operadores locais desenvolvidos por Chickering (2002).

\subsubsection{Redução do espaço de busca}

Dada a vastidão do espaço de busca, especialmente em altas dimensões, vários sistemas evolutivos de aprendizagem estrutural incorporam mecanismos para reduzir ou restringir o espaço de busca a regiões promissoras. No espaço de ordens ancestrais, por exemplo, a forma mais simples de fazer essa redução é impondo um número máximo de pais por nó (também chamado de máximo indegree). A justificativa dessa ideia é baseada na suposição que as estruturas a aprender são vagamente conexas. Exemplos dessa restrição podem ser encontrados em (Larranaga et al., 1996a) e (Faulkner, 2007).

Um esquema mais elaborado para reduzir o espaço de busca veio de Campos e Huete (2000a) que propuseram o uso de testes de independência (de ordem 0 e 1) para estimar um grafo esqueleto. Um algoritmo genético é então executado buscando a melhor ordem ancestral para dirigir as arestas desse esqueleto e assim obter o DAG. O uso de grafos esqueletos como espaços de busca tem sido também relatado em (van Dijk et al., 2003; van Dijk e Thierens, 2004; Jia et al., 2008).

Em uma linha relacionada, Wong e Leung (2004) descreveram um sistema evolutivo, chamado de HEA (do inglês hybrid evolutionary algorithm), que ao invés de pré-aprender um grafo esqueleto para depois fazer uma busca nele, somente são armazenados os maiores p-valores en- 
contrados entre pares de variáveis. Já no processo evolutivo, esses p-valores são contrastados contra um parâmetro $\alpha$ (nível de significância) para decidir a existência das arestas. O interessante nesse esquema é que o valor $\alpha$ é colocado a evoluir junto com os DAGs. Dessa maneira, não somente os DAGs são evoluidos dentro do espaço restringido, senão que os espaços mesmos são objeto de evolução. Uma proposta similar foi descrita por Stefano et al. (2010), mas o uso de p-valores foi substituído por uma medida de informação mútua entre pares de variáveis.

\subsubsection{Eficiência Computacional}

Dada a dificuldade do problema de aprendizagem estrutural, vários métodos evolutivos implementam algumas estratégias para melhorar a sua eficiência computacional no processo de busca. Uma dessas estratégias tradicionalmente usada é o reuso das computações locais da função de escore. Isso se torna relevante quando se precisa calcular o escore de um DAG que é resultado de operadores que afetam algumas poucas famílias (operadores locais), já que os escores dessas famílias são os únicos cálculos necessários para obter o escore global do DAG. Como exemplos relevantes de métodos evolutivos que reusam escores locais tem-se o HEA de Wong e Leung (2004) e o K2GA de Faulkner (2007). No HEA, todos os seus operadores de busca foram projetados para reusar computações locais. No K2GA, o reuso é implementado mediante uma lista cache, que mantém as computações locais mais frequentemente usadas.

Delaplace et al. (2007) descreveram uma outra forma de ganhar eficiência exploratória mediante a identificação e controle do retrocesso no processo evolutivo. Nessa proposta, uma lista tabu é usada para armazenar as últimas estruturas convergidas (estruturas que o algoritmo evolutivo não consegue melhorar em um quantidade determinada de gerações). Assim, toda nova estrutura criada é inserida na população com uma penalização em escore se ela é encontrada na lista tabu. Dessa maneira a exploração de novas regiões é promovida.

\subsubsection{Ajuste de Parametros}

A configuração de parâmetros é uma questão importante em todo sistema evolutivo já que o desempenho dele é afetado por seus parâmetros. Alguns métodos evolutivos de aprendizagem estrutural de RBs tem considerado este tema de forma cuidadosa. Wong e Leung (2004), por exemplo, propuseram um esquema semi-adaptativo para balançar dinamicamente a quantidade total de recombinação e mutação ao longo do processo evolutivo, mas com cada operador de 
mutação tendo uma probabilidade fixa de ser executado. Delaplace et al. (2007) propuseram um esquema de autorregulação para a taxa de mutação, a qual é aumentada para indivíduos menos aptos e reduzida para indivíduos mais aptos. A ideia disso é colocar um maior esforço exploratório em indivíduos que ainda não estão bem adaptados. Recentemente, Khanteymoori et al. (2011) descreveram um esquema determinístico para ajustar dinamicamente a quantidade de exploração e aproveitamento no algoritmo evolutivo. 


\section{Capítulo 4}

\section{Sistema Evolutivo Eficiente para Aprendizagem de Estruturas de Redes Bayesianas - EES-BN}

Neste capítulo é descrito o sistema proposto para aprender estruturas de redes Bayesianas, chamado de Sistema Evolutivo Eficiente para Aprendizagem de Estruturas de Redes Bayesianas ou de forma abreviada como EES-BN (do ingles Efficient Evolutionary System for Bayesian Network Structure Learning). Na Seção 4.1 é apresentada a arquitetura geral de EES-BN. Na Seção 4.2 são descritos os algoritmos desenvolvidos para redução do espaço de busca para EES-BN. Na Seção 4.3 é apresentado o esquema de codificação de soluções usado. A Seção 4.4 descreve o operador de recombinação desenvolvido para EES-BN. A Seção 4.5 descreve os operadores de mutação e substituição empregados. A Seção 4.6 apresenta um mecanismo desenvolvido para evitar convergência prematura. Finalmente, a Seção 3.7 descreve o esquema de autoajuste de parâmetros implementado em EES-BN.

\subsection{Arquitetura do sistema}

A figura 4.1 mostra a arquitetura geral de EES-BN. O paradigma evolutivo selecionado é uma variante de algoritmo genético que, em adição aos operadores de recombinação, mutação e substituição normalmente presentes em algoritmos genéticos, inclui também um bloco de controle e injeção de diversidade, desenvolvido para evitar convergência prematura, como será 
descrito linhas abaixo.

O alvo geral no desenvolvimento de EES-BN foi maximizar a eficiência do aprendizado (maximizar a precisão na recuperação das estruturas de modelo e minimizar o custo computacional do aprendizado). Para tal fim, métodos eficazes foram desenvolvidos para serem inseridos nos diversos blocos do sistema, tais como redução do espaço de busca, codificação de soluções, recombinação, injeção de diversidade, e ajuste de parâmetros, como será descrito nas seções seguintes. Embora a literatura de aprendizagem evolutiva de RBs mostra diversos paradigmas evolutivos, EES-BN adota o paradigma de algoritmos genéticos dado seu notável potencial no problema de aprendizagem estrutural. Trabalhos como os de Wong e Leung (2004) e de dos Santos et al. (2010a)) mostraram que mediante um projeto cuidadoso de operadores genéticos é possível aumentar a qualidade das redes recuperadas. Também, resultados recentes na área de algoritmos genéticos, tal como o de Chang et al. (2010) que introduzem métodos de controle de diversidade, podem ser aproveitados na construção de um sistema de aprendizagem mais eficiente. EES-BN, constitui assim um esforço de integrar eficientemente as melhores peças da literatura recente e também de propor novos componentes para obter um sistema que ofereça uma saliente precisão de aprendizagem e ao mesmo tempo tempos computacionais competitivos.

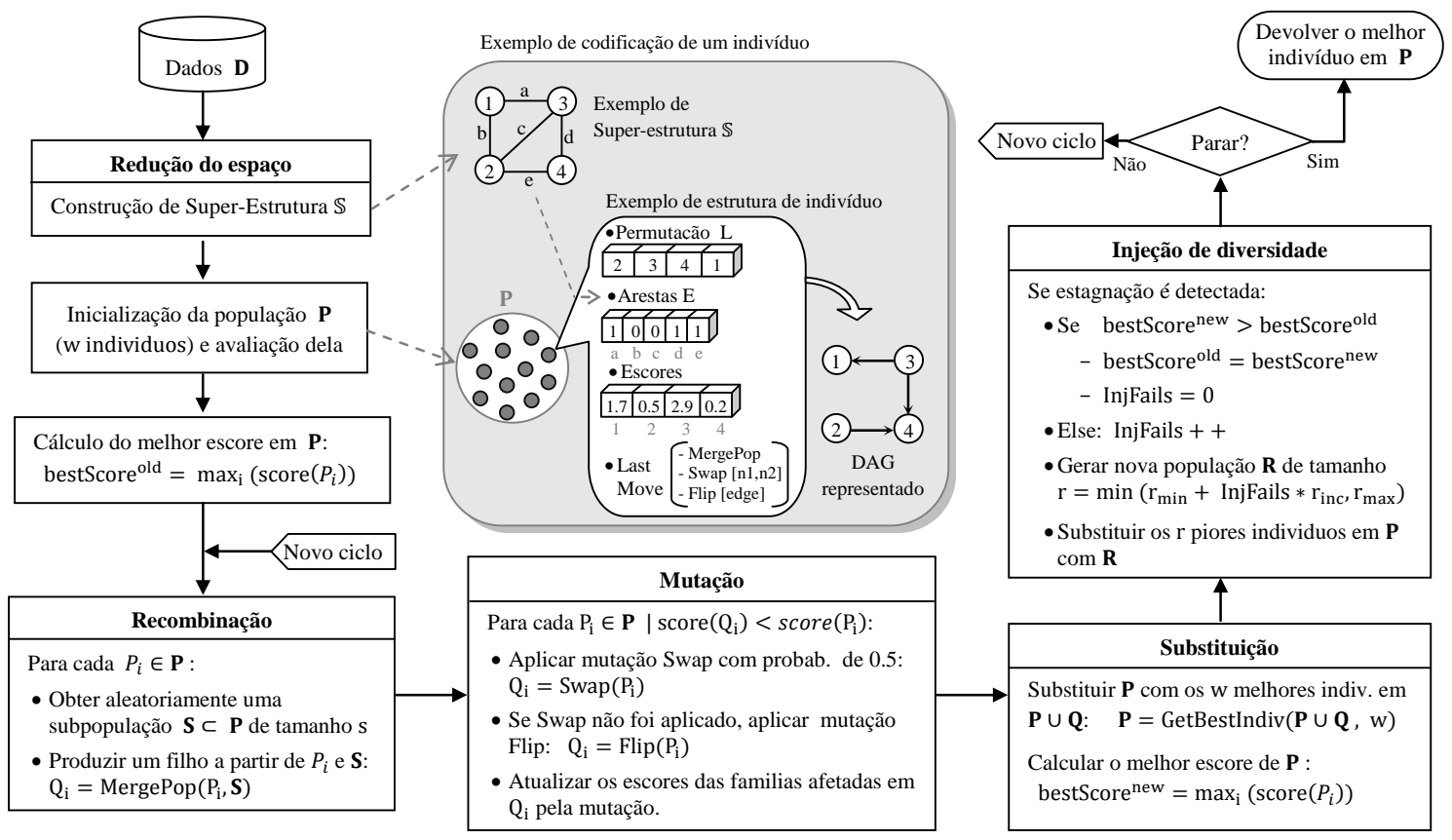

Figura 4.1: Arquitetura de EES-BN. 
Brevemente, EES-BN começa reduzindo o espaço de busca, estimando para isso uma superestrutura (dois métodos alternativos baseados em testes de independência condicional são propostos para essa tarefa, Seção 4.2). Uma população de indivíduos (soluções candidatas) é então inicializada usando a superestrutura estimada como molde para codificá-los. Uma vez avaliada a população, segue um ciclo evolutivo em que podem ser executados até quatro operações, dependendo do estado da evolução: recombinação (sempre executado), mutação (executado se recombinação falha), substituição (sempre executado) e injeção de diversidades (executado quando é detectada estagnação na população). O processo é repetido até que um critério de parada seja satisfeito, em cujo caso o sistema devolve a melhor solução encontrada.

\subsection{Redução do espaço de busca}

Como foi observado na Seção 3.3, tanto os métodos de aprendizagem estrutural de redes Bayesianas baseados unicamente em testes de independência como os baseados em busca e pontuação possuem desvantagens que limitam a sua aplicação em problemas de alta dimensão e poucas amostras. Nessa necessidade, métodos híbridos foram surgindo na última década tentando aproveitar os pontos fortes de cada abordagem. A ideia subjacente na maioria desses métodos é usar testes de independência condicional para descartar arestas improváveis e assim focalizar a busca (baseada em escore) nas arestas que ofereçam chances mínimas de ser verdadeiras. Essa ideia foi formalizada recentemente no contexto de aprendizagem estrutural exata com os trabalhos de Perrier et al. (2008) e Kojima et al. (2010), nos quais é definido o conceito de superestrutura completa (grafo não dirigido que contêm o esqueleto da RB verdadeira, Capítulo 2). Nesses trabalhos é concluído que a aprendizagem de uma estrutura de RB pode ser grandemente facilitada se for fornecida uma superestrutura completa esparsa. Isso motivou a adoção em EES-BN de um esquema híbrido baseado em superestrutura como o componente redutor do espaço de busca.

No entanto, em aplicações práticas, o aprendizado de superestruturas completas nem sempre é possível. Primeiro porque muitas vezes não há forma de verificar a completude das superestruturas (não é conhecida a estrutura verdadeira), e segundo porque na presença de poucas amostras, ruído de amostragem e pouca confiabilidade dos testes estatísticos é possível que algumas arestas verdadeiras sejam perdidas no processo de aprendizagem e algumas outras arestas não reais sejam incluídas na estrutura resultante. Nesse cenário realista em que não é possível garantir o aprendizado de uma superestrutura completa, Perrier et al. (2008) e Kojima 
et al. (2010) enfatizaram a importância de aprender superestruturas dando maior ênfase na inserção de arestas verdadeiras do que na eliminação de arestas não verdadeiras. Isto porque as arestas verdadeiras ausentes na superestrutura não podem ser recuperadas na fase de busca e pontuação, enquanto que as arestas "extras"são sujeitas a revisão nessa fase.

A maioria dos métodos existentes que podem ser usados para estimar superestruturas não foram em realidade projetados sob os requerimentos acima mencionados. Alguns métodos como o PC (Spirtes et al., 2000), o TPDA (Cheng et al., 2002) e o Heuristic PC (Wang et al., 2007) são encontrados como sub-rotinas de métodos de aprendizagem estrutural, responsáveis da recuperação do grafo esqueleto da estrutura sendo aprendida, a qual é posteriormente dirigida. Outros métodos, como os de Tsamardinos et al. (2006a), Pena et al. (2007) e De Morais e Aussem (2010) (chamados de métodos "locais"), foram projetados para recuperar a adjacência em torno de uma variável alvo de interesse (como por exemplo a variável classe em aplicações de classificação e seleção de atributos). Apesar de que todos esses métodos possuem provas de exatidão assintótica (conseguem inferir o esqueleto verdadeiro, ou parte dele nos métodos locais, sob condições de amostra infinita, fidelidade e testes de independência confiáveis), em situações reais a maioria desses métodos não controlam de forma ativa a taxa de erros falsopositivos (arestas extra) e falso-negativos (arestas verdadeiras ausentes). No entanto, como sugerido por Perrier et al. (2008) e Kojima et al. (2010), na abordagem híbrida é muito importante aprender superestruturas colocando um especial esforço em manter a taxa de erros falso-negativos tão baixa quanto possível, pois ela não poderá ser melhorada na fase de busca.

Reconhecendo a falta de métodos eficientes na literatura com as características acima mencionadas, neste trabalho foram desenvolvidos dois métodos para tal finalidade, os quais podem ser facilmente utilizáveis por EES-BN para reduzir o espaço de busca. Esses métodos são descritos a seguir.

\subsubsection{Método de estimação de superestruturas: Opt01SS}

Nesta subseção é apresentado o primeiro método desenvolvido para estimação de superestruturas, chamado de Opt01SS (do inglês Optimized Zero-First-Order Super-Structure) (Villanueva e Maciel, 2012b). O nome é derivado de uma de suas características mais destacáveis, a qual é a utilização de testes de independência condicional de ordem 0 e 1 estruturados em uma forma otimizada para aprender superestruturas em situações de pouca amostra. Dois problemas importantes tornam a tarefa de aprendizagem especialmente desafiadora quando se dispõe de 
poucas amostras: i) presença de relações ADRs nos dados (van Dijk et al., 2003; De Morais e Aussem, 2010), e ii) inconsistência dos testes de independência condicional (Steck e Tresp, 1999). Lembrando a Seção 3.1, uma relação ADR é uma relação forte entre duas variáveis em que somente uma pequena fração de amostras nos dados disponíveis não apresenta uma relação ou dependência determinística entre essas variáveis (van Dijk et al., 2003). A presença de ADRs nos dados pode levar a cometer erros no processo de aprendizagem. A razão disso é que os testes de independência condicional podem perder confiabilidade quando um ADR é envolvido no teste. Para exemplificar, considere a estrutura verdadeira da Figura 4.2, na qual as variáveis $Z$ e $X$ possuem uma relação ADR e as variáveis $X$ e $Y$ têm uma relação com um fraco suporte nos dados. Se no processo de inferência estrutural o teste de independência condicional entre $X$ e $Y$ dado $Z$ é realizado, é provável que o resultando seja independência $Y \perp X \mid Z$, já que os valores de $Z$ exercem tal influência em $X$ devido ao ADR que terminam ofuscando a dependência entre $Y$ e $X$ (já que tem um débil apoio nos dados), e portanto a aresta verdadeira $Y \rightarrow X$ termina sendo eliminada na estrutura sendo aprendida (estrutura direita da Figura 4.2).

\section{Estrutura verdadeira}

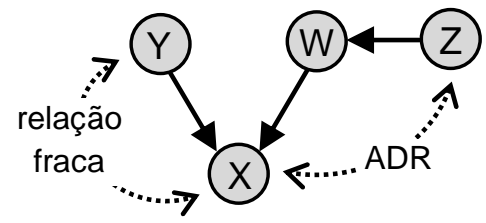

Provável estrutura a aprender devido ao ADR

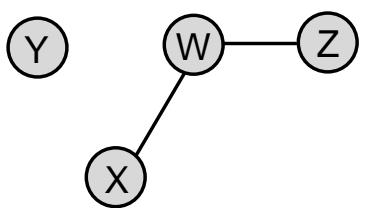

Figura 4.2: Exemplo para ilustrar como um ADR (entre $X$ e $Z$ ) pode frustrar a detecção de uma aresta verdadeira $(Y-X)$ que tem um fraco suporte nos dados. A aresta é perdida quando se testa $Y \perp X \mid Z$ e o resultado é independência (devido à forte influência que $Z$ exerce em $X$ ocultando a tênue dependência entre $X$ e $Y$ ).

O segundo problema está relacionado com as incertezas introduzidas pela insuficiência de amostras e também pelo ruído de amostragem (que se torna relevante em cenários de pouca amostra). Tais incertezas são refletidas como inconsistências no conjunto de independências e dependências detectadas no processo de aprendizado (tal conjunto é comumente referido como CIDS, do inglês conditional independence and dependence statements) (Steck e Tresp, 1999). Conjuntos inconsistentes de CIDS não podem ser simultaneamente representadas em um único DAG. A Figura 4.3 mostra um exemplo ilustrando a detecção de um conjunto inconsistente de CIDS e como tal conjunto acaba sendo representado por métodos tracionais de aprendizagem de esqueletos e pelo método proposto Opt01SS. As inconsistências nesse exemplo estão nas 
independências $X \perp Z \mid Y$ e $Y \perp Z \mid X$, que não podem ser representadas simultaneamente em um DAG. Métodos tradicionais de aprendizagem de esqueletos como (Spirtes et al., 2000; Cheng et al., 2002; Wang et al., 2007; Kalisch e Bühlmann, 2007) usam a estratégia comum de eliminar uma aresta assim que um separador é encontrado para a mesma, e tal eliminação nunca mais é revista. Nessa estratégia, o esqueleto aprendido do exemplo só terá a aresta $X-Y$ (Figura 4.3C), e portanto não será possível alcançar a estrutura verdadeira na fase de busca e pontuação se tal esqueleto for usado como superestrutura. No mesmo exemplo, Opt01SS consegue colocar as duas arestas duvidosas no mesmo esqueleto (Figura 4.3C), como será descrito linhas abaixo, dando a oportunidade à etapa de busca e pontuação de alcançar as duas estruturas em duvida implicadas da inconsistência (Figura 4.3E) e assim resolver mediante escore a situação conflitante.
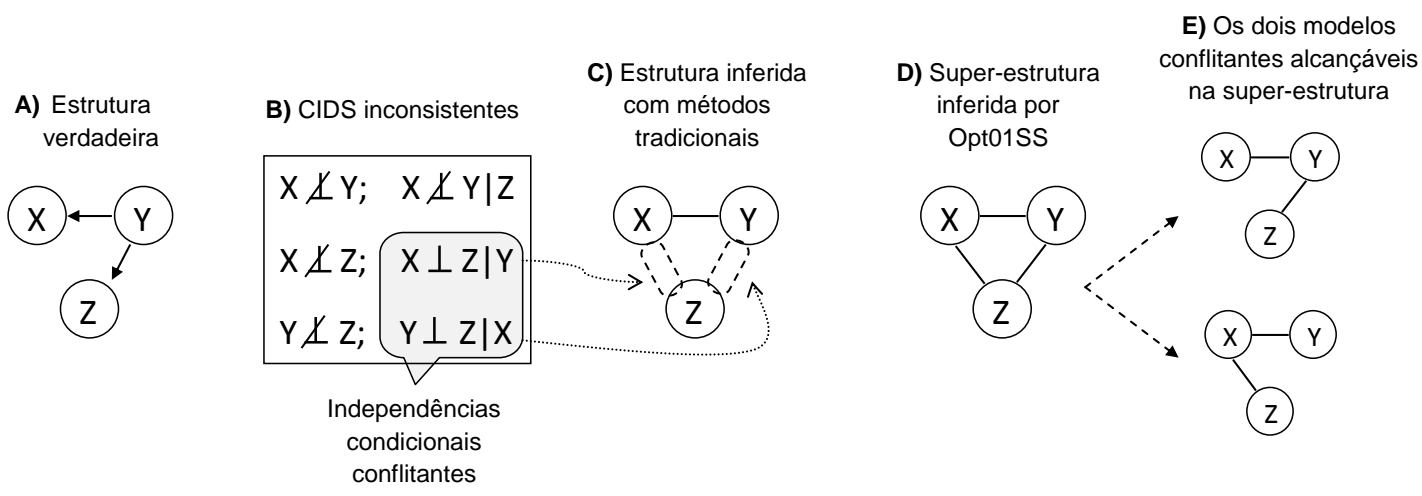

Figura 4.3: Exemplo ilustrando a detecção de um conjunto inconsistente de CIDS (conditional independence and dependence statements) e como eles são representados por métodos tradicionais de aprendizagem de esqueletos e por Opt01SS. A) mostra o DAG verdadeiro. B) mostra o conjunto de CIDS inconsistente, em que a inconsistência está nas independências $X \perp Z \mid Y$ e $Y \perp Z \mid X$. C) mostra a estrutura normalmente inferida por métodos tradicionais. D) mostra a estrutura inferida por Opt01SS. E) Os dois modelos conflitantes que podem ser alcançados na etapa de busca e pontuação.

Opt01SS (pseudocódigo em Algoritmo 1) implementa três fases a fim de minimizar os problemas acima mencionados. A primeira fase (linhas 1-5) começa a partir de um grafo completamente conectado $\mathbb{S}$ e executa testes de independência de ordem 0 (independência marginal) entre todos os pares de variáveis, eliminando as arestas de $\mathbb{S}$ cujos nós sejam identificados como marginalmente independentes (a validade teórica desta etapa é dada pelo Teorema 4). Esta fase é similar às encontradas em métodos tradicionais baseados em testes de independência, como PC, TPDA e Heuristic PC. Todo teste de independência em Opt01SS (marginal ou condicional) é realizado através da função $D e p$ (Tabela 4.1), a qual calcula a partir do conjunto de dados 
disponíveis $D$ o grau de dependência $\operatorname{dep}_{X, Y \mid \mathbf{Z}}$ entre duas variáveis $X, Y$ condicionado num conjunto de variáveis $\mathbf{Z}$ (que é vazio no caso de teste de independência marginal), sendo o valor $d e p_{X, Y \mid \mathbf{Z}}=0$ para o caso de independência. Para calcular o grau de dependência, a função Dep obtém primeiro o valor da estatística $G^{2}$ (Neapolitan, 2003) e com isso seu respectivo p-valor (embora qualquer outra estatística de independência condicional possa ser usada). $\mathrm{O}$ p-valor é então verificado contra um nível de significância predefinido $\alpha$. Se o p-valor é maior que $\alpha$ então a hipótese nula (independência condicional) não pode ser rejeitada e o valor devolvido por $D e p$ é zero (indicando $X \perp Y \mid \mathbf{Z}$ ). Se por outro lado, o p-valor é menor que $\alpha$ então o valor de dependência devolvido é $\operatorname{dep}_{X, Y \mid \mathbf{Z}}=1-p_{-}$valor $/ \alpha$, garantindo com isso um valor de dependência normalizado no intervalo $[0,1]$.

Para ganhar eficiência, a função $D e p$ trabalha com uma estrutura global de dados $\mathcal{C}$, chamada de cache de valores de dependência (ou simplesmente cache de dependências), a qual é usada para armazenar todo cálculo realizado $d e p_{X, Y \mid Z}$, em que o condicionante $\mathbf{Z}$ é de ordem zero ou um $(|\mathbf{Z}|<2)$. O cache de dependências serve também em Dep para consultar se o cálculo solicitado já foi previamente realizado (em cujo casso Dep recupera e devolve tal valor). Para cada par de variáveis $X, Y$ existe uma entrada em $\mathcal{C}$, denotada como ${ }^{1} \mathcal{C}_{\langle X, Y\rangle}$, que armazena os valores de dependência de ordem 0 e 1 calculados entre $X$ e $Y$. Essa entrada é implementada como um estrutura de dicionário chave-valor. Assim, o valor $d e p_{X, Y \mid \mathbf{Z}} \mathrm{e}$ armazenado no dicionário $\mathcal{C}_{\langle X, Y\rangle}$ na chave $\mathbf{Z}$.

Uma vez finalizada a primeira fase de testes de independência marginal, Opt01SS executa uma segunda fase de eliminação de arestas mediante a busca de separadores de ordem 1 nas arestas que sobraram. Essa segunda fase é implementada como um ciclo que itera entre duas etapas: i) busca de separadores nas arestas marcadas para revisão, Edges2Check (linhas 8-18), e ii) verificação da robustez dos separadores encontrados (linhas 19-23). O conjunto Edges2Check entra nesse ciclo, inicializado com as arestas restantes da primeira fase. A etapa de busca de separadores consiste em procurar para cada aresta $X-Y \in E d g e s 2 C h e c k$ uma variável $Z$ em que o teste de independência resulte em $X \perp Y \mid Z$. Tal separador $Z$ é sequencialmente buscado na adjacência atual de $X$ e $Y$ (obtida com a função $A d j$, Tabela 4.1), apoiado no resultado do Corolário 1 (Capitulo 2) que estabelece que se duas variáveis $X, Y$ estão d-separadas então o conjunto separador é formado pelos pais de $X$ ou pelos pais de $Y$. Quando um separador $Z$ é encontrado para a aresta $X-Y$, esta é temporalmente eliminada de

\footnotetext{
${ }^{1} \mathrm{O}$ simbolo \langle\rangle significa par não ordenado.
} 


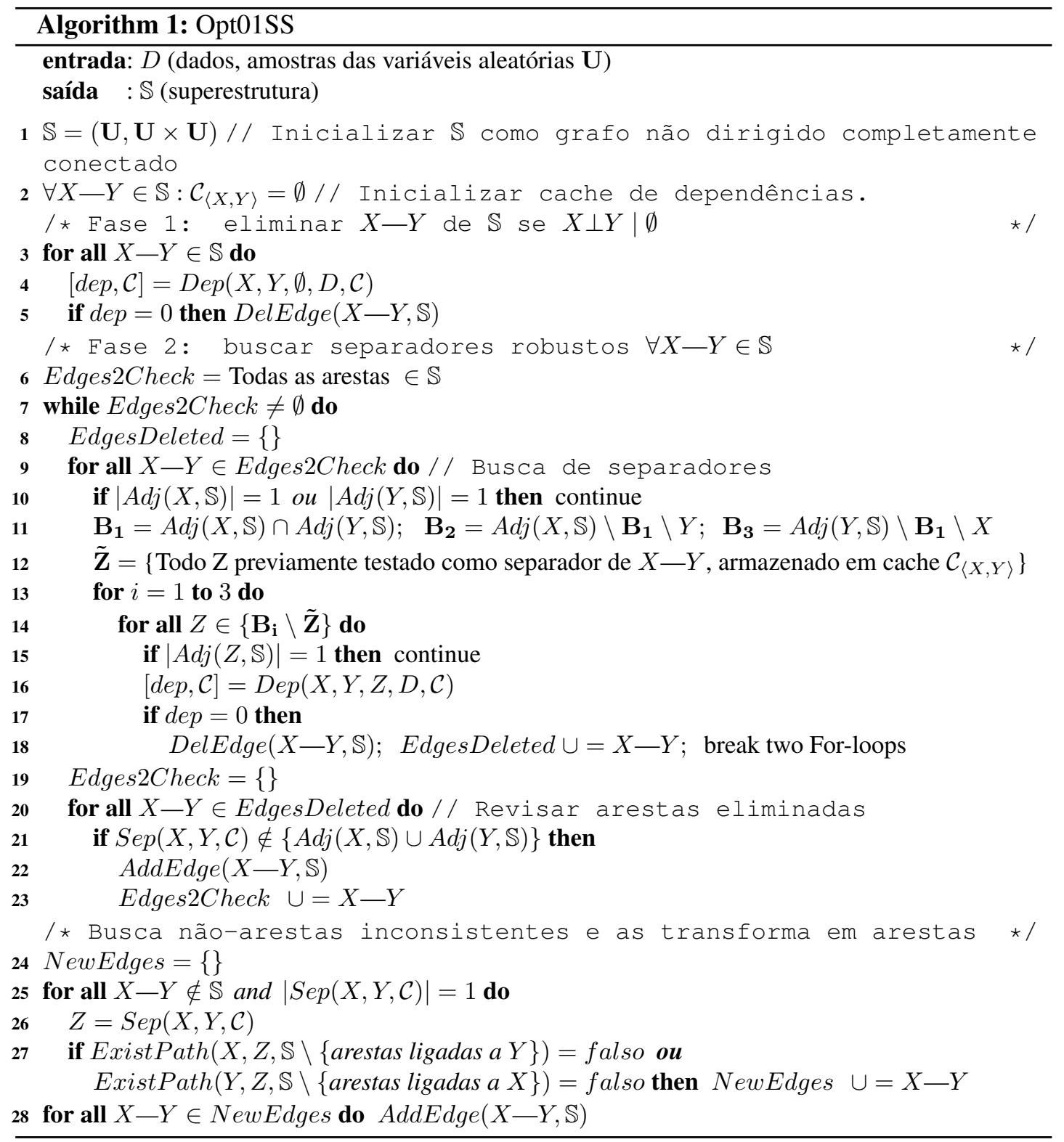

$\mathbb{S}$ e colocada no conjunto de arestas eliminadas do ciclo atual (EdgesDeleted) para posterior verificação; também a busca de separador para $X-Y$ é finalizada. A adjacência de $X$ e $Y$ é dividida em três subconjuntos disjuntos com a finalidade de ganhar eficiência computacional: os nós adjacentes a $X$ e $Y\left(\mathbf{B}_{1}\right)$, os nós adjacentes a $X$ mas não a $Y\left(\mathbf{B}_{2}\right)$, e os nós adjacentes a $Y$ mas não a $X\left(\mathbf{B}_{3}\right)$, como mostrado na Figura 4.4. O primeiro desses subconjuntos a ser revisado é $\mathbf{B}_{1}$. Isto porque na pratica foi notado que os separadores são encontrados com maior frequência nesse subconjunto de adjacência comum, com o qual o processo de descoberta do separador (se existir) é acelerado. Outras otimizações implementadas para aumentar eficiência nessa etapa de busca de separadores são: i) evitar a busca de separadores em arestas onde um dos nós é um nó folha (nó que só tem ao outro nó da aresta como única adjacência, por exemplo 
o nó $Z_{l}$ na Figura 4.4), já que tais arestas não podem ser separadas porque não há nenhum outro caminho a bloquear diferente da aresta (implementado na linha 10); e ii) evitar testar como separadores os nós folhas, já que graficamente esses nós não podem bloquear nenhum caminho (implementado na linha 15).

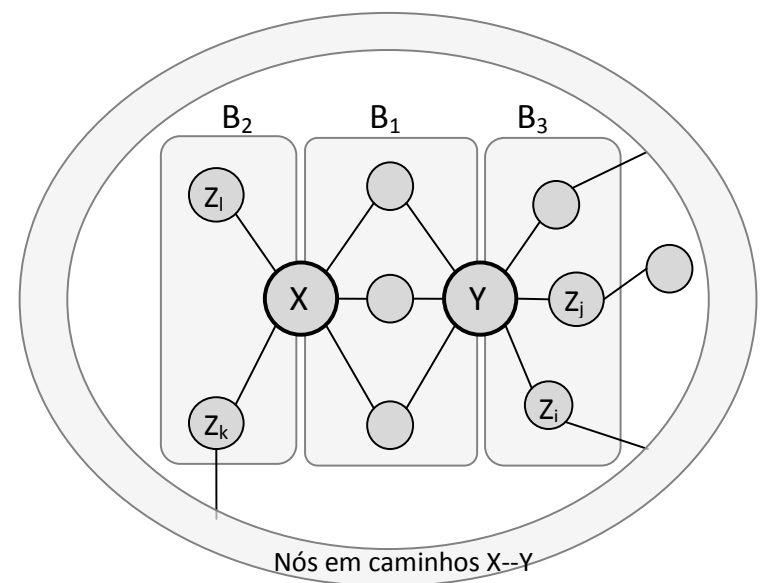

Figura 4.4: Exemplo de partição da adjacência em Opt01SS para buscar um separador entre as variáveis $X, Y$. $\boldsymbol{B}_{1}$ contém os nós adjacentes tanto a $X$ como a $Y . \boldsymbol{B}_{2}$ contém os nós adjacentes a $X$ mas não a $Y$. $\boldsymbol{B}_{3}$ contém os nós adjacentes a $Y$ mas não a $X$. O anel representa a sub-rede formada por nós que participam em caminhos conectando $X \operatorname{com} Y$.

Após todas as arestas em Edges2Check serem verificadas no ciclo atual, as arestas que foram eliminadas (armazenadas em EdgesDeleted) são sujeitas a revisão na segunda etapa do ciclo. Essa revisão consiste em comprovar para cada aresta $X-Y \in E d g e s D e l e t e d$ se seu separador encontrado $Z$ está ainda na adjacência de $X$ e $Y$. Se esse não for o caso, então é provável que $Z$ tenha sido induzido pela presença de algum ADR e portanto é chamado de separador não robusto. Nesse caso, a aresta $X-Y$ é colocada de volta a $\mathbb{S}$ e também adicionada no conjunto Edges2Check (que é inicializado em vazio ao começar a segunda etapa) para buscar um novo separador na seguinte iteração da fase 2. Toda variável $Z$ encontrada como "separador não robusto"de uma aresta $X-Y$ sai de consideração como candidato a separador da mesma em futuras buscas de separadores (de fato, para evitar repetições nos testes, todas as variáveis testadas como separadoras de uma aresta entram no cache de dependências e portanto elas não são mais testadas como separadoras dessa aresta devido a que elas são excluídas antes de começar a busca de separadores, linhas 12,14). O ciclo de busca e revisão de separadores é executado até que o conjunto Edges2Check não tem mais arestas para processar.

A revisão das arestas eliminadas na fase 2 ajuda a minimizar a possibilidade de ofuscação de arestas com tênue dependência na presença de ADRs. Para ilustrar isso, consideremos o 
Tabela 4.1: Funções auxiliares usadas em Opt01SS e OptHPC.

\begin{tabular}{|c|c|}
\hline Função & Descrição \\
\hline $\mathbf{A d j}_{X} \leftarrow \operatorname{Adj}(X, \mathbb{G})$ & Devolve a adjacência do nó $X$ no grafo $\mathbb{G}$. \\
\hline $\mathbf{S p s}_{X}^{\mathbf{J}} \leftarrow \operatorname{Sps}(X, \mathbf{J}, \mathbb{G})$ & $\begin{array}{l}\text { Devolve o conjunto de esposos do nó } X \text { com filhos co- } \\
\text { muns } \mathbf{J} \text { no grafo } \mathbb{G} \text {. Se } \mathbf{J}=\emptyset \text { então todos os esposos } \\
\text { do nó } X \text { são devolvidos. }\end{array}$ \\
\hline $\operatorname{DelEdge}(E d g e, \mathbb{G})$ & Elimina a aresta $E d g e$ do grafo $\mathbb{G}$ \\
\hline $\operatorname{AddEdge}(E d g e, \mathbb{G})$ & Adiciona a aresta $E d g e$ ao grafo $\mathbb{G}$. \\
\hline flag $\leftarrow \operatorname{ExistPath}(X, Y, \mathbb{G})$ & $\begin{array}{l}\text { Verifica se existe um caminho entre os nós } X \text { e } Y \text { no } \\
\text { grafo } \mathbb{G} \text {. } \mathrm{O} \text { valor devolvido em flag toma o valor } \\
\text { verdadeiro se é encontrado o caminho, caso contrário, } \\
\text { devolve falso. }\end{array}$ \\
\hline \multirow[t]{2}{*}[\operatorname{dep}_{X,Y|\mathbf{Z}},\mathcal{C}]{$\leftarrow D e p(X, Y, \mathbf{Z}, D, \mathcal{C})$} & $\begin{array}{l}\text { Devolve o grau de dependência } \operatorname{dep}_{X, Y \mid \mathbf{Z}} \text { entre as va- } \\
\text { riáveis aleatórias } X \text { e } Y \text { condicionado no conjunto } \mathbf{Z} \text {. } \\
\text { Se }|\mathbf{Z}|<2 \text { então } \operatorname{dep}_{X, Y \mid \mathbf{Z}} \text { é procurado primeiro no ca- } \\
\text { che de dependências } \mathcal{C} \text {, de não ser encontrado ali então } \\
\operatorname{dep}_{X, Y \mid \mathbf{Z}} \text { é calculado com os dados fornecidos } D \text { e logo } \\
\text { armazenado na entrada } \mathcal{C}\langle X, Y\rangle \text { do cache. }\end{array}$ \\
\hline & $\begin{array}{l}\text { Procura um valor } \operatorname{dep}_{X, Y \mid Z}=0 \text { na entrada do cache } \\
\mathcal{C}_{\langle X, Y\rangle} \text { e devolve } Z \text { (a chave do dicionário) que arma- } \\
\text { zena tal valor. }\end{array}$ \\
\hline$\left[\right.$ flag $\left., \mathbf{Z}_{\text {sep }}, \mathcal{C}\right] \leftarrow$ Find $S e p(X, Y, \mathbf{Z}, D, \mathcal{C})$ & $\begin{array}{l}\text { Procura um subconjunto } \mathbf{Z}_{\text {sep }} \subseteq \mathbf{Z} \text { de forma exaustiva } \\
\text { que satisfaça } \operatorname{dep}_{X, Y \mid \mathbf{Z}_{\text {sep }}=0 \text { (o cache de dependên- }}=0 \text { ara consultar/armazenar va- } \\
\text { cias } \mathcal{C} \text { é usado nessa busca para } \\
\text { lores de dependência de ordem } 0 \text { e } 1 \text { ). Se tal subcon- } \\
\text { junto é encontrado então flag é devolvido com valor } \\
\text { verdadeiro junto com o subconjunto encontrado } \mathbf{Z}_{\text {sep }} \text {, } \\
\text { caso contrário, flag é devolvido com valor falso. }\end{array}$ \\
\hline
\end{tabular}

exemplo da Figura 4.2. Devido ao ADR entre $X$ e $Z$ e à fraca relação entre $Y$ e $Z$ é provável que após finalizar a etapa de busca de separadores da primeira iteração da fase 2 a estrutura aprendida seja $\mathbb{S}=\left\{\begin{array}{ll}Y & X-W-Z\end{array}\right\}$ com separadores $\operatorname{Sep}(Y-W)=\emptyset, \operatorname{Sep}(Y-Z)=\emptyset$, $\operatorname{Sep}(X-Y)=Z, \operatorname{Sep}(X-Z)=W$. Na segunda etapa, ao momento de revisar a aresta eliminada $X-Y$ o algoritmo descobre que o separador da mesma $(Z)$ não está na adjacência de $X$ ou de $Y$ e portanto recoloca tal aresta em $\mathbb{S}$ e no conjunto Edges $2 C h e c k$. Na segunda iteração, estando $X-Y$ no conjunto de arestas por revisar $E d g e s 2 C h e c k$, a variável $Z$ não é considerada como separador candidato para tal aresta (já que $Z$ está no cache de dependências indicando que ela já foi testada) e a única variável que resta por testar como separador é $W$, a qual falha como separador, deixando assim a aresta $X-Y$ na estrutura $\mathbb{S}$.

A terceira fase de Opt01SS lida com a presença de CIDS inconsistentes. Para isso é usado o resultado teórico de Steck e Tresp (1999) chamado de condição de caminho necessário ou NPC (do inglês Necessary Path condition), o qual é colocado a seguir para maior clareza: 
(Steck e Tresp, 1999). Dado um conjunto de variáveis aleatórias $\mathbf{U}$ com distribuição conjunta $P$, representado por uma mapa perfeito $\mathbb{G}$ : se duas variáveis $X, Y \in \mathbf{U}$ são condicionalmente independentes em $P$ dado um subconjunto de variáveis $\mathbf{Z} \subseteq\{\mathbf{U} \backslash\{X, Y\}\}$ e por sua vez $X$ e $Y$ são condicionalmente dependentes dado qualquer subconjunto próprio $\mathbf{Z}^{\prime} \subset \mathbf{Z}$, então $X$ e $Y$ não são adjacentes em $\mathbb{G}$ e existem caminhos não envolvendo $Y$ entre $X$ e cada $Z \in \mathbf{Z}$, assim como caminhos não envolvendo $X$ entre $Y$ e cada $Z \in \mathbf{Z}$.

A condição NPC permite verificar a consistência de arestas ausentes (chamadas de nãoarestas) na estrutura $\mathbb{S}$ resultante das duas primeiras fases de Opt01SS. Para isso é assumido que todas as não-arestas determinadas na primeira fase (com testes de independência marginal) são consistentes. Dessa maneira, somente as não-arestas produzidas com testes de independência condicional de ordem 1 (na segunda fase) são verificadas por consistência. Por construção do algoritmo, estas últimas não-arestas são marginalmente dependentes (senão não seriam revisadas na segunda fase) e portanto a condição NPC é aplicável. A verificação de consistência implicada da condição NPC consiste em observar para cada não-aresta $\langle X, Y\rangle$ da fase 2 com separador $Z$ a existência de dois caminhos:

1. um caminho entre $X$ e $Z$ no grafo resultante de remover todas as arestas em $\mathbb{S}$ ligando $Y$; e

2. um caminho entre $Y$ e $Z$ no grafo resultante de remover todas as arestas em $\mathbb{S}$ ligando $X$.

A função ExistPath (Table 4.1) é usada para realizar a verificação da existência desses caminhos, a qual antes de fazer qualquer verificação calcula a matriz $\mathrm{PNM}^{2}$ da estrutura fornecida (usando para isso o procedimento descrito por Wong e Leung (2004)) e então determina a existência do caminho lendo dessa matriz as entradas dos nós consultados. Se um dos caminhos acima mencionados é encontrado inexistente então a não-aresta sendo verificada é inconsistente com a condição NPC. Nesse caso, a não-aresta é transformada em aresta em $\mathbb{S}$, o que implica que toda independência condicional encontrada inconsistente sob o critério NPC não é mapeada na superestrutura sendo aprendida. Isso dá a possibilidade de que toda aresta duvidosa seja revisada e resolvida na etapa de busca e pontuação. No exemplo da Figura 4.3 é ilustrada essa situação, em que as duas não-arestas $\langle X, Z\rangle$ e $\langle Y, Z\rangle$ resultantes dos testes de indepen-

\footnotetext{
${ }^{2}$ A matriz PNM (do inglês Path Number Matrix) contém em cada entrada $(i, j)$ o número de caminhos que ligam o nó $i$ com o nó $j$,
} 
dência $X \perp Z \mid Y$ e $Y \perp Z \mid X$ da segunda fase são transformadas como arestas na superestrutura na terceira fase, já que tais não-arestas não são consistentes com NPC.

\subsubsection{Método de estimação de superestruturas: OptHPC}

Recentemente, De Morais e Aussem (2010) descreveram um método local, chamado de HPC (do inglês Hybrid Parents and Children), que como seu nome sugere, objetiva a identificação do conjunto de pais e filhos de uma variável alvo fornecida. O interessante em HPC, que o torna diferente da maioria de métodos propostos para essa mesma tarefa, é que ele implementa mecanismos para controlar ativamente a taxa de erros falso-negativos em situações de pouca amostra, alta conectividade e presença de ADRs, enquanto que oferece também exatidão assintótica nas condições ideais de amostra infinita e testes de independência infalíveis.

Tais características são compatíveis com as requeridas para a etapa de redução do espaço de busca em EES-BN, razão pela qual HPC tornou-se de interesse da presente pesquisa. No entanto, dada a natureza local de HPC, foi notado que uma aplicação direta deste método na recuperação da estrutura global da rede (mediante a execução de HPC sobre cada variável da rede) para ser usada como superestrutura pode implicar em uma severa degradação de eficiência computacional. Por exemplo, ao executar HPC numa variável alvo $T$ que pertence a um domínio de variáveis $\mathbf{U}$, vários testes de independência condicional são realizados na forma $T \perp X \mid \mathbf{Z}(X \in \mathbf{U}, \mathbf{Z} \subset \mathbf{U})$. Posteriormente, ao executar HPC sobre $X$, alguns testes envolvendo $T$ são executados novamente (aqueles da forma $X \perp T \mid \mathbf{Z}$ ). Essas repetições de testes de independência são propagadas ao longo da rede e podem acabar afetando severamente o desempenho do método, principalmente em problemas de alta dimensão, já que os testes de independência são operações computacionalmente custosas.

Nesta seção é apresentado o método OptHPC (do inglês Optimized Hybrid Parents and Children) (Villanueva e Maciel, 2012c), o qual foi desenvolvido com o objetivo de aproveitar as vantagens de HPC quanto ao controle de erros falso-negativos e também de melhorar a eficiência computacional dele para ser utilizável por EES-BN como estimador de superestruturas na redução do espaço de busca. Dado que OptHPC está fortemente ligado a HPC, será primeiro descrito o método HPC por razões de legibilidade.

\section{Hybrid Parents and Children - HPC}

HPC (pseudocódigo principal no Algoritmo 2) pode ser considerado como um método 
ensemble, já que combina vários métodos estimadores de pais e filhos (também chamados de estimadores PC, do inglês parents and children). HPC recebe como entrada uma variável alvo $T$, o conjunto de dados $D$ e o domínio de variáveis $\mathbf{U}$ e devolve uma estimativa do conjunto de pais e filhos de $T, \mathbf{P C}_{T}$. HPC começa extraindo um superconjunto de pais e filhos de $T$, $\mathbf{P C S}_{T}$ e um superconjunto de esposos de $T, \mathbf{S P}_{T}$, invocando para isso às rotinas DE-PCS (do inglês Data-Efficient Parents and Children Superset) e DE-SPS (do inglês Data-efficient Spouses Superset) respectivamente, linhas 1-2.
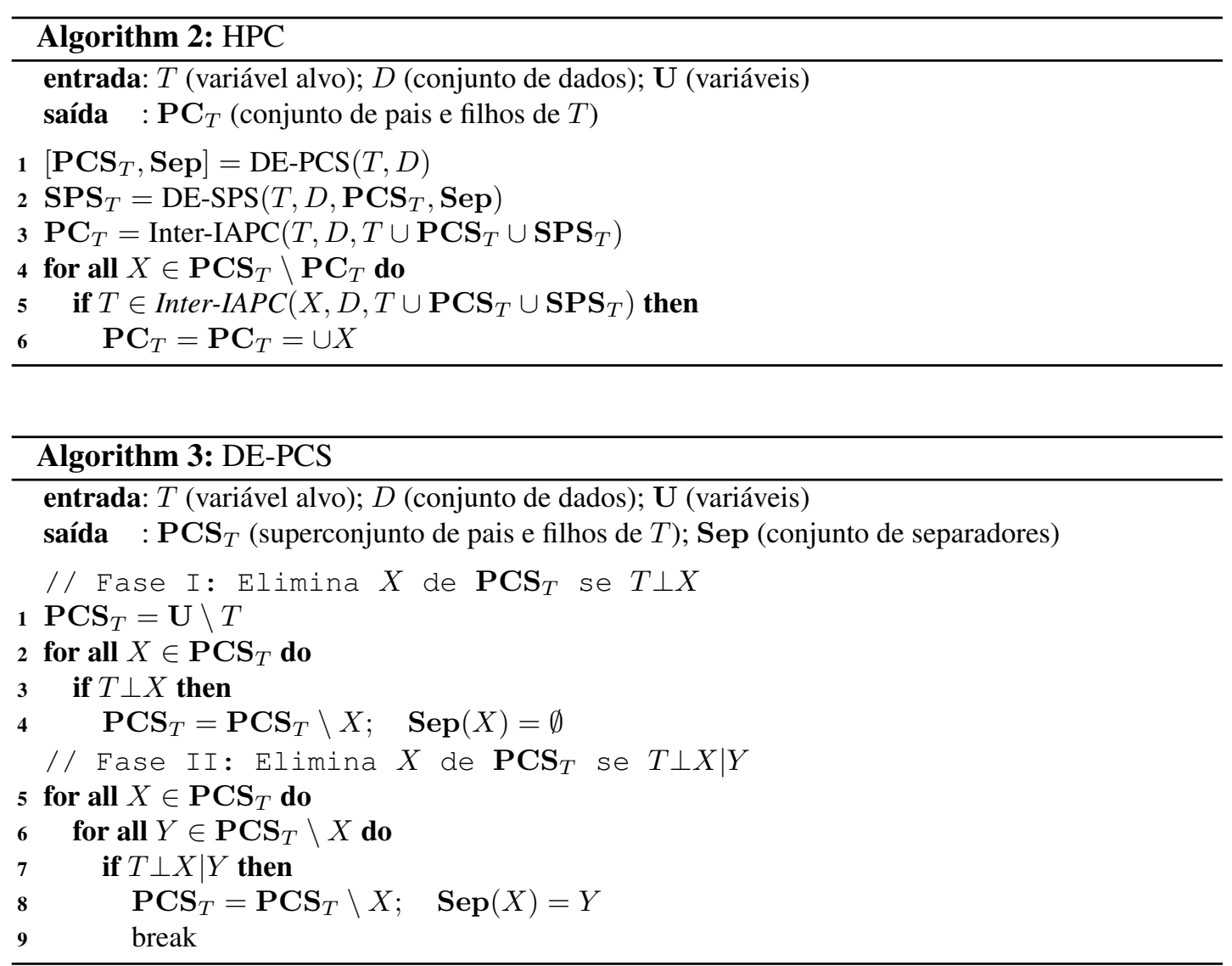

A rotina DE-PCS (pseudocódigo no Algoritmo 3) coloca em $\mathbf{P C S}$ todas as variáveis de U que permanecem associadas com $T$ após de realizar testes de independência marginal (linhas 2-4) e testes de independência condicional de ordem 1 (linhas 5-9).

A rotina DE-SPS (pseudocódigo no Algoritmo 4) obtém o superconjunto de esposos $\mathbf{S P S}_{T}$ colocando nele toda variável $Y \in \mathbf{U}$ que apesar de estar separada de $T$ por algum separador $Z_{Y, T}$ (e portanto $Y$ não pertence a $\mathbf{P C S}_{T}$ ) ela permanece associada com $T$ quando condicionado em $Z_{Y, T}$ e alguma outra variável no superconjunto $\mathbf{P C S}_{T}$ (linhas 3-5). Antes de retornar SPS $_{T}$, DE-SPS realiza um refinamento nele, identificando e retirando falsos esposos que são ancestres ou descendentes de verdadeiros esposos de $T$ (linhas 5-9). 

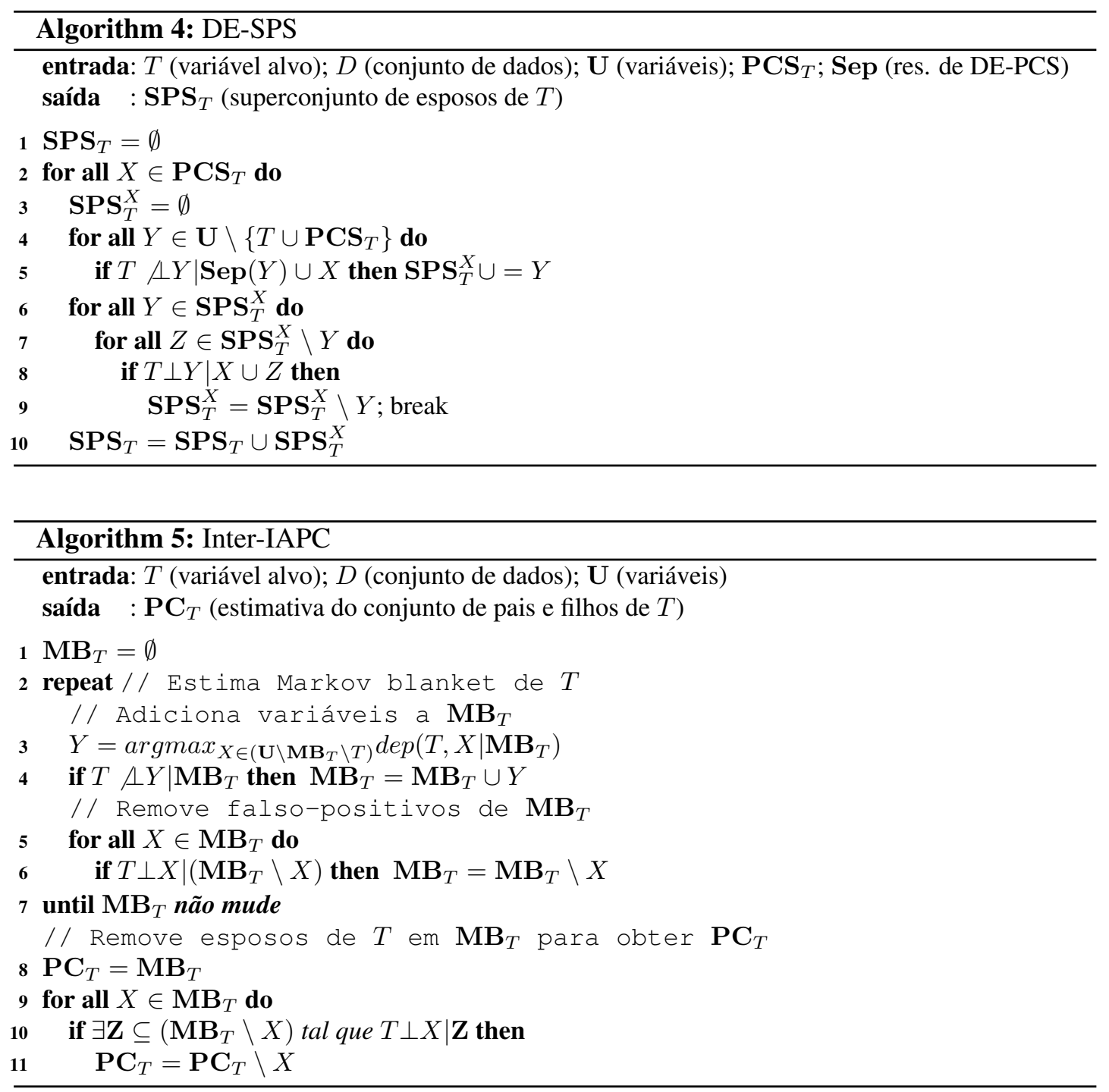

Com $\mathbf{P C S}_{T}$ e SPS ${ }_{T}$ determinados, HPC invoca à rotina Inter-IAPC (do inglês Interleaved Incremental Association Parents and Children) para encontrar um primeiro conjunto de pais e filhos candidato de $T$. Inter-IAPC (pseudocódigo no Algoritmo 5) realiza uma estimativa de $\mathbf{P C}_{T}$ sobre o universo de variáveis passado por HPC (que é o conjunto formado por $T$ e seus superconjuntos de pais, filhos e esposos, $\left\{T \cup \mathbf{P C S}_{T} \cup \mathbf{S P S} \mathbf{S}_{T}\right\}$ ), inferindo primeiro o Markov blanket de $T, \mathbf{M B}_{T}$. Essa inferência é realizada iterativamente adicionando a $\mathbf{M B}_{T}$ a variável $Y$ (fora do atual Markov blanquet) que exibe a maior dependência com $T$ condicionado no atual Markov blanquet $\mathbf{M B}_{T}$ (linhas 3-4). Uma verificação e eliminação de falso-positivos em $\mathbf{M B}_{T}$ é realizada após cada inserção de variável nele (linhas 5-6). Uma vez que não existe mais variáveis a inserir a $\mathbf{M B}_{T}$ segue uma fase de identificação e remoção de esposos nesse conjunto, devolvendo ao final a estimativa de pais e filhos de $T, \mathbf{P C}_{T}$. HPC usa então essa estimativa como base, ao qual serão inseridos mais pais e filhos (que serão buscados no 
conjunto $\mathbf{P C S}_{T} \backslash \mathbf{P C}_{T}$, linhas 4-6 de HPC). O ponto chave de HPC para controlar a taxa de erros falso-negativos reside justamente nessa busca de pais e filhos adicionais. Métodos locais tradicionais como IAMB (Tsamardinos et al., 2003), MMPC (Tsamardinos et al., 2006a) e GetPC (Pena et al., 2007) determinam que uma variável $Y$ forma parte do conjunto de pais e filhos da variável $T$ se é verificado que $T$ é parte do conjunto de pais e filhos de $Y$ (critério chamado de correção de simetria). No método HPC, essa verificação é relaxada, sendo que e as variáveis $X$ adicionais a ser inseridas no atual $\mathbf{P} \mathbf{C}_{T}$ têm que satisfazer a condição menos rigoroso da linha 5 de HPC, a qual estabelece que se $X \in\left\{\mathbf{P C S}_{T} \backslash \mathbf{P C}_{T}\right\}$ então $X$ é realmente um pai ou filho de $T$ se $T$ pertence ao resultado de $\operatorname{Inter-IAPC}\left(X, D, T \cup \mathbf{P C S}_{T} \cup \mathbf{S P S}_{T}\right)$ (condição chamada de busca descentralizada).

De Morais e Aussem (2010) mostraram empiricamente que HPC consegue aprender o conjunto de pais e filhos com menos erros falso-positivos do que vários algoritmos do estado da arte, tais como MMPC e GetPC. Os autores também mostraram teoricamente que HPC converge ao conjunto exato de pais e filhos na condição ideal de infinitos dados, fidelidade e infalibilidade dos testes de independência.

\section{Optimized Hybrid Parents and Children - OptHPC}

O método OptHPC aqui apresentado otimiza todas as rotinas integrantes de HPC para ser utilizadas eficientemente na recuperação da estrutura global (razão pela qual essas rotinas foram renomeadas anexando um "*"ao final dos seus nomes originais), além de introduzir uma rotina adicional, chamada de OptHPC (pseudocódigo no Algoritmo 6), para gerenciar tal aprendizado. Similarmente ao algoritmo Opt01SS, a rotina OptHPC recebe como entrada o conjunto de variáveis aleatórias do domínio $\mathbf{U}$ e um banco de dados $D$ contendo observações dessas variáveis e retorna como saída a superestrutura inferida $\mathbb{S}$. OptHPC constrói essa superestrutura chamando iterativamente à versão modificada de HPC (HPC*) sobre cada variável do domínio como variável alvo, a qual devolve a estimativa do conjunto de pais e filhos (que se reflete em $\mathbb{S}$ como arestas entre cada variável desse conjunto e a variável alvo).

OptHPC utiliza a mesma função Dep de Opt01SS (Tabela 4.1) para realizar os testes de independência. Duas estruturas globais são introduzidas em OptHPC para armazenar e compartilhar resultados de testes de independência obtidos em cada chamada a HPC*, e assim evitar repetições dos mesmos: i) um grafo $\dot{\mathbb{G}}$ que mapeia toda independência condicional de ordem 0 ou 1, assim como v-estruturas identificadas ao longo do processo ( $\dot{\mathbb{G}}$ é inicializado como grafo completamente conectado, ou seja, sem representar nenhuma independência); e ii) um cache 
de dependências $\mathcal{C}$ que armazena os graus de dependência $\operatorname{dep}_{X, Y \mid \mathbf{Z}}$ (para todo $|\mathbf{Z}|<2$ ) calculados por Dep, similar ao empregado em Opt01SS. Embora OptHPC não restrinja a ordem dos testes de independência, somente os resultados dos testes de ordem 0 e 1 são armazenados em $\dot{\mathbb{G}}$ e $\mathcal{C}$. Isto porque na maioria de aplicações tais testes representam a maior parte dos testes necessários para inferir a rede e também porque armazenar eles é relativamente simples nas estruturas $\dot{\mathbb{G}}$ e $\mathcal{C}$ (a complexidade do cache e a demora em buscar nele seria fortemente exacerbada se fossem armazenados testes de maior ordem).
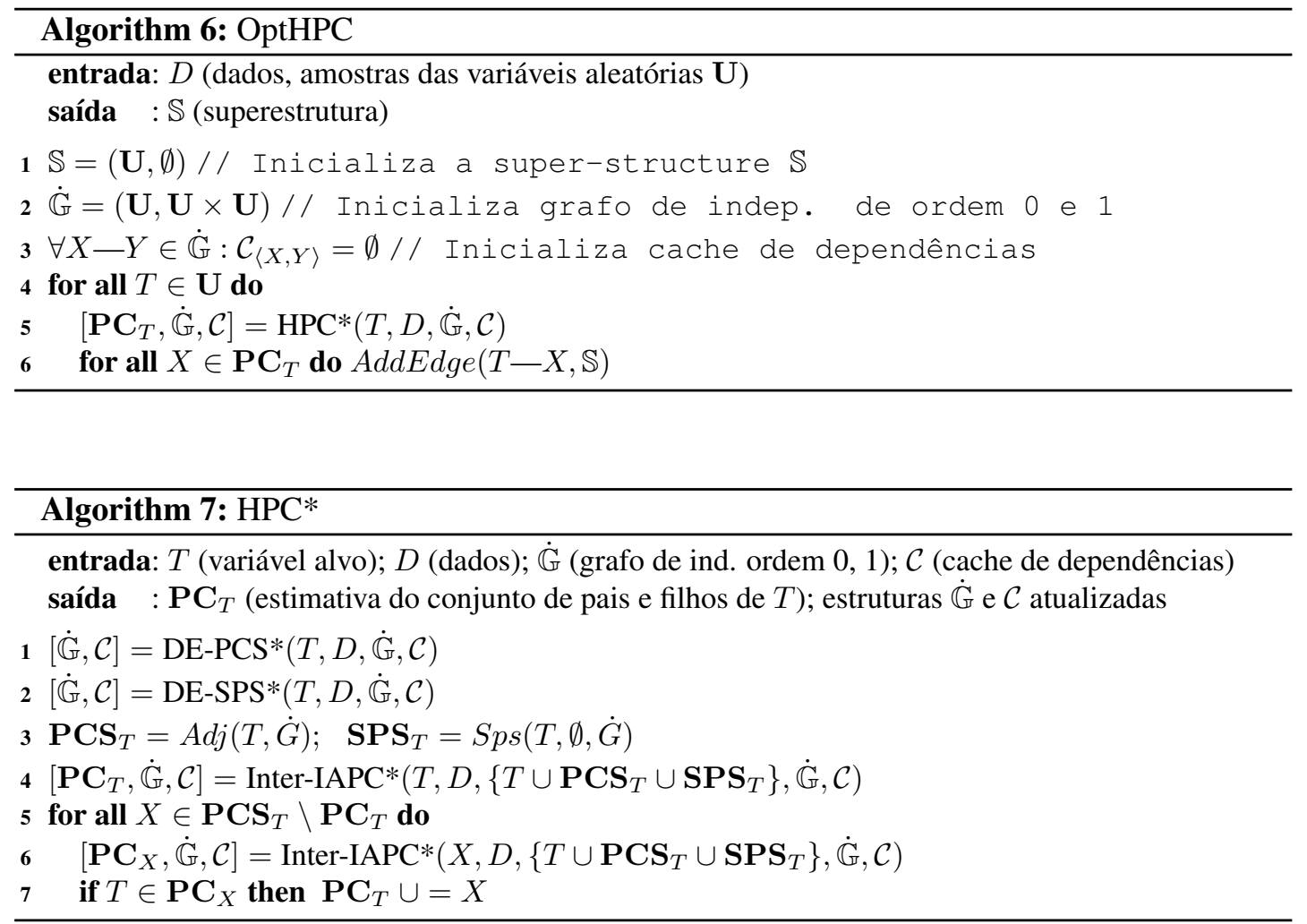

A rotina HPC* (pseudocódigo no Algoritmo 7) obtém a estimativa do conjunto de pais e filhos $\mathbf{P C}_{T}$ da variável alvo fornecida $T$ usando essencialmente os mesmos passos de HPC, isto é: i) obter superconjuntos de pais, filhos e esposos (linhas 1-3); ii) obter uma primeira estimativa do $\mathbf{P} \mathbf{C}_{T}$ a partir dos superconjuntos anteriores (linha 4); e iii) buscar mais variáveis que possam ser inseridas a $\mathbf{P} \mathbf{C}_{T}$ com a busca descentralizada (linhas 5-7). No entanto, HPC* difere de HPC na forma como são operados tais passos. HPC* junto com suas três subrotinas otimizadas (DE-PCS*, DE-SPS* e Inter-IAPC*) estão estruturados para trabalhar em um contexto global usando as estruturas $\dot{\mathbb{G}}$ e $\mathcal{C}$, como descrito a seguir.

A sub-rotina DE-PCS* (pseudocódigo no Algoritmo 8), responsável de determinar o superconjunto de pais e filhos da variável alvo $T$, trabalha diretamente sobre a estrutura $\dot{\mathbb{G}}$, colocando 

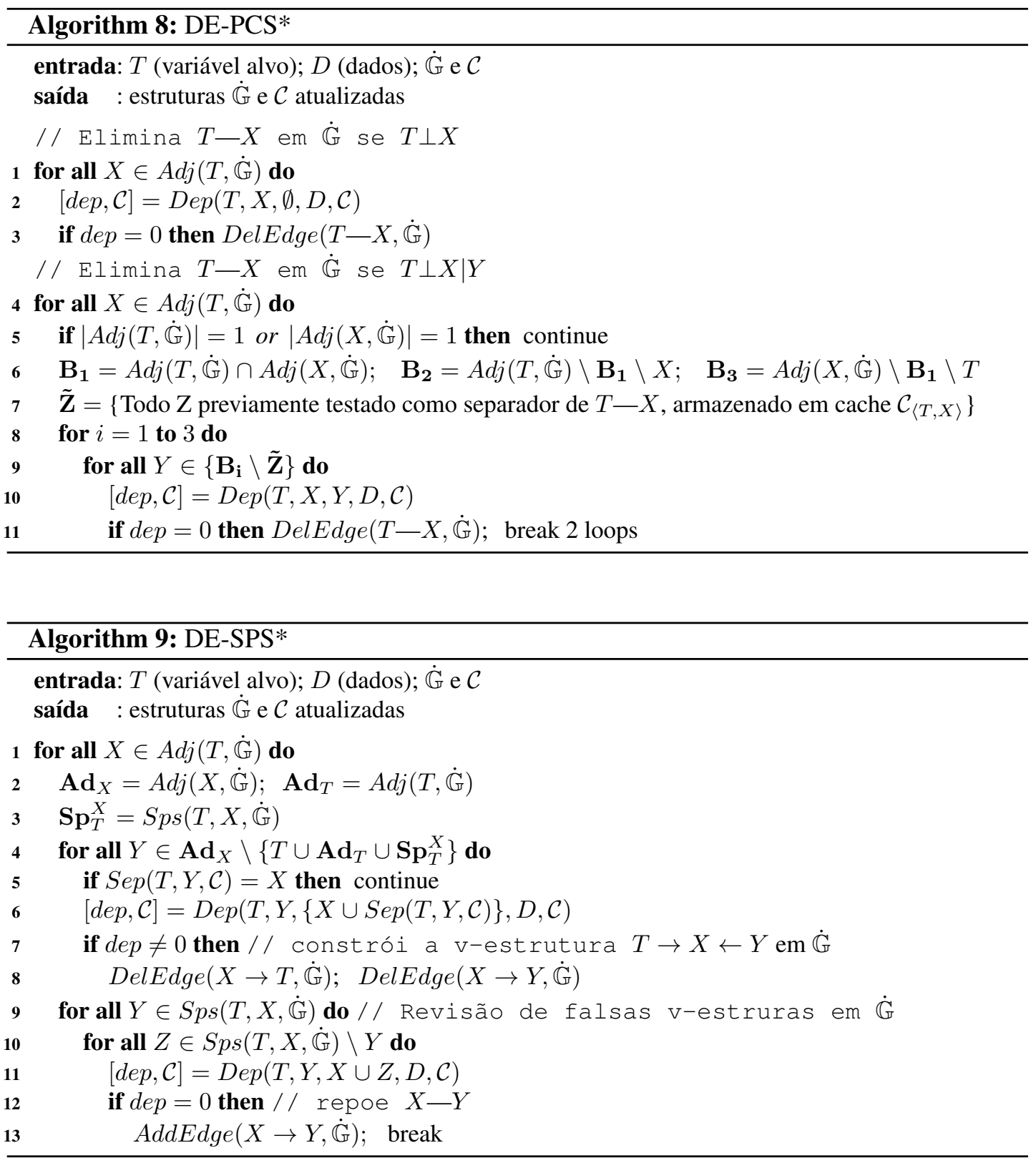

seus resultados nela. Primeiro são eliminados da adjacência de $T$ todos os nós com independência marginal com $T$ e logo todas os nós com independência condicional de ordem $1 \operatorname{com} T$. Ao trabalhar diretamente sobre a estrutura global $\dot{\mathbb{G}}$ (ao invés de usar subconjuntos internos, como DE-PCS) são reaproveitadas computações feitas anteriormente nela, evitando repetições nos testes. Por exemplo, se uma variável $Y$ é retirada da adjacência de $T$ porque foi encontrado um separador entre elas, numa futura chamada a DE-PCS* sobre $Y$ será encontrado que $T$ não é parte da adjacência de $Y$ e, portanto não será feito nenhum teste envolvendo ele. DE-PCS* incorpora também outras otimizações trazidas de Opt01SS, tais como: i) prevenir a busca de separadores em arestas em que um dos nós é um nó folha (linha 5); ii) buscar os separadores 
das arestas começando pela adjacência comum dos nós da aresta (linhas 6-8); e iii) evitar testes de independência com separadores já testados e que estão armazenados no cache de dependências $\mathcal{C}$, linha 7 (por exemplo, em alguma previa chamada a DE-PCS*). DE-PCS* finaliza retornando a estrutura $\dot{\mathbb{G}}$ com a adjacência de $T$ atualizada, junto com o cache de dependências contendo os novos cálculos de dependência realizados. Após finalizar a sub-rotina DE-PCS* sobre a variável alvo $T$, qualquer outra sub-rotina pode recuperar o superconjunto $\mathbf{S P C}_{T}$ obtendo simplesmente a adjacência de $T$ em $\dot{\mathbb{G}}$ (mediante a função $A d j$, Tabela 4.1), tal como é realizado na linha 3 de HPC**

De maneira similar a DE-PCS*, a sub-rotina DE-SPS* (pseudocódigo no Algoritmo 9), responsável de identificar o conjunto de esposos da variável alvo $T$, recebe como entrada a estrutura $\dot{\mathbb{G}}$ e o cache de dependências $\mathcal{C}$ e devolve atualizações dessas estruturas na parte que envolve v-estruturas associadas a $T$ (e que servem para identificar graficamente os esposos de $T$ ). DE-SPS* executa testes de independência até de segundo ordem, mas estes últimos não são salvos em $\mathcal{C}$. DE-SPS* tenta localizar rapidamente esposos $Y$ de $T$ procurando eles na adjacência (não adjacente a $T$ ) de cada nó $X$ adjacente a $T$, desconsiderando os esposos previamente encontrados (linhas 4-8). Uma v-estrutura $T \rightarrow X \leftarrow Y$ é identificada nos dados se $Y$ está separado de $T$ por algum separador $Z$ mas é dependente de $T$ quando condicionado no conjunto $\{X, Z\}$. Toda v-estrutura identificada em DE-SPS* é refletida em $\dot{\mathbb{G}}$ dirigindo as arestas respectivas (linha 8). Uma fase de revisão de v-estruras é também implementado em DE-SPS* (linhas 9-13), onde para toda v-estrutura identificada $T \rightarrow X \leftarrow Y$ é verificado que $Y$ não seja ancestre ou descendente de algum outro esposo de $T$, caso contrario $Y$ é desconsiderado como esposo de $T$ e a bidirecionalidade da aresta $Y \rightarrow X$ é devolvida (linha 13). Após finalizar a execução da sub-rotina DE-SPS* sobre a variável alvo $T$, qualquer outra sub-rotina pode recuperar o superconjunto de esposos de $T, \mathbf{S P S}_{T}$, obtendo simplesmente todos os nós no extremo oposto de v-estruturas com $T$ em $\dot{\mathbb{G}}$ (função implementada em Sps, Tabela 4.1), tal como é feito na linha 3 de HPC*. A função Sps aceita também um segundo argumento J, o qual, se não é vazio, instrui a $S p s$ a recuperar somente os esposos de $T$ cujos filhos estejam em $\mathbf{J}$ (funcionalidade usada nas linhas 3, 9 and 10 de DE-SPS*).

A sub-rotina Inter-IAPC* (pseudocódigo no Algoritmo 10) usa também as estruturas $\dot{\mathbb{G}}$ e $\mathcal{C}$ quando um teste de independência de ordem 0 ou 1 é requerido. No entanto, dado que a rotina Inter-IAPC* utiliza testes de independência de ordem superior o resultado final dela é trabalhado num conjunto interno $\left(\mathbf{P C}_{T}\right)$. Similar a Inter-IAPC, a sub-rotina Inter-IAPC* começa 


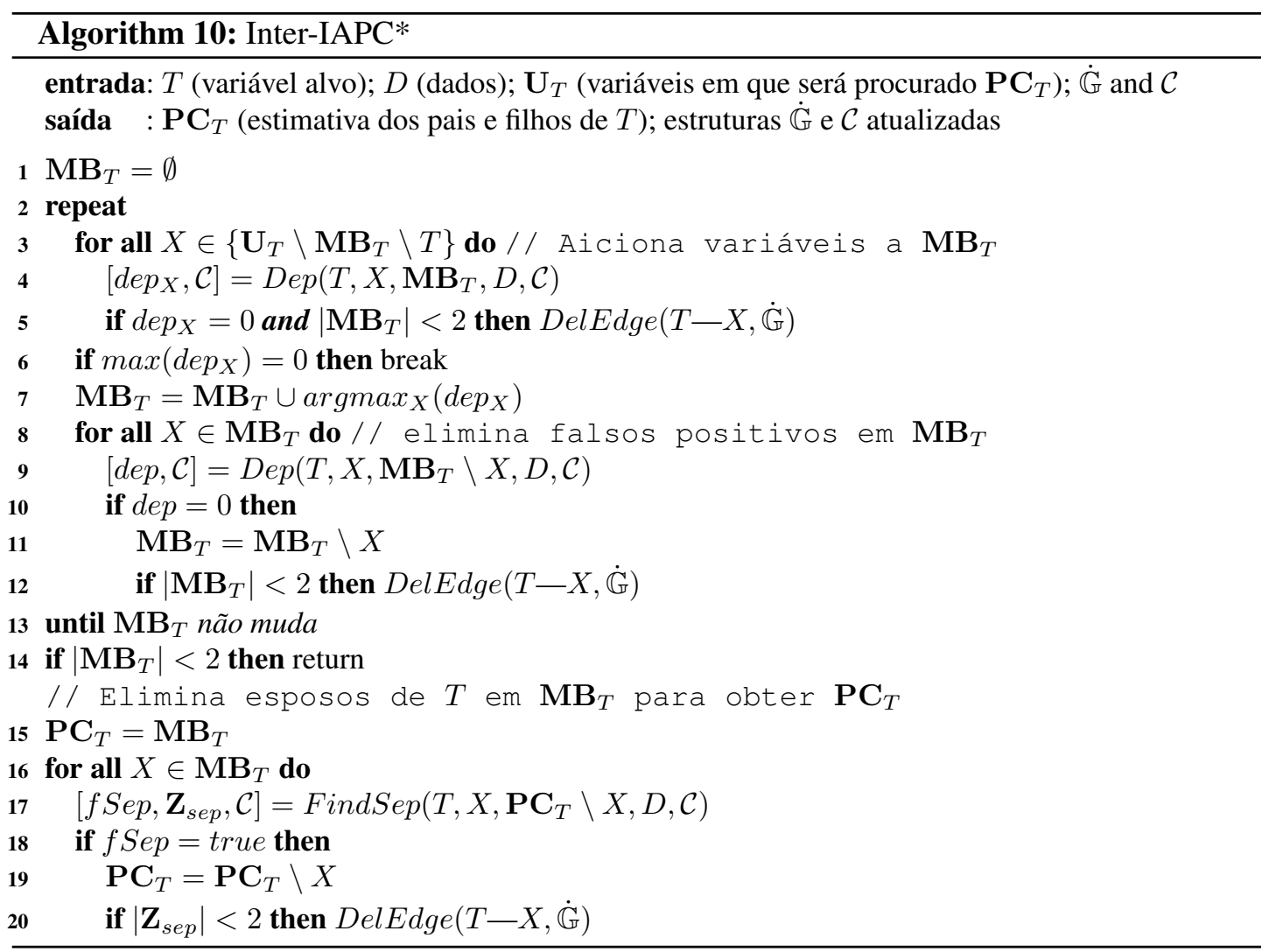

inferindo o Markov blanket da variável $T$ alvo, $\mathbf{M B}_{T}$ (ciclo 1-13) para logo identificar o conjunto de pais e filhos $\mathbf{P} \mathbf{C}_{T}$ mediante a eliminação de esposos de $T$ presentes em $\mathbf{M B}$ (linhas 15-20). Para identificar esses esposos é usada a função FindSep (Tabela 4.1), a qual busca para cada $X \in \mathbf{M B}_{T}$ um subconjunto $\mathbf{Z}_{\text {sep }}$ que torne $T$ e $X$ condicionalmente independentes dado $\mathbf{Z}_{\text {sep }}$. Diferentemente de Inter-IAPC, que busca $\mathbf{Z}_{\text {sep }}$ em todo o Markov blanket $\mathbf{M} \mathbf{B}_{T}$, InterIAPC* busca $\mathbf{Z}_{\text {sep }}$ no conjunto de pais e filhos identificados até o momento atual $\left(\mathbf{P C}_{T} \backslash X\right)$ o qual começa como $\mathbf{M B}_{T}$ e vai diminuindo em tamanho a medida que são identificados mais esposos. Essa otimização não altera teoricamente o resultado, mas na prática tem uma consequência importante na diminuição do número de testes de independência: dado que $\mathbf{Z}_{\text {sep }}$ é buscado exaustivamente, o fato de diminuir em uma unidade o tamanho do conjunto donde ele é buscado implica uma redução exponencial no número de subconjuntos a seres testados. Outra otimização implementada em Inter-IAPC* é encontrada na linha 6, onde a construção do Markov blanket $\mathbf{M B}_{T}$ é terminada tão logo é observado que não existem mais variáveis candidatas para entrar nele, evitando nesse caso a desnecessária verificação de falso-positivos em $\mathbf{M B}_{T}$. 


\subsection{Representação de soluções em EES-BN}

Várias formas de representar soluções têm sido descritas na literatura para os diferentes tipos de espaço de busca, como foi apresentado na Seção 3. Entre todas essas propostas de representação, é possível observar nos resultados da literatura que os métodos de aprendizagem evolutiva que usam representações fechadas (que evitam de forma intrínseca a codificação de estruturas ilegais) tendem a apresentar desempenhos computacionais mais elevados. Essa observação é entendível, desde que tais representações dispensam das operações de reparação de soluções que são normalmente computacionalmente custosas (Kim et al., 2005; Carvalho, 2011). Adicionalmente, o número de estruturas ilegais tende a dominar o espaço de busca com representações não fechadas, inclusive em redes de baixa dimensão (Jia et al., 2008). Por exemplo, para uma representação com matriz de adjacência e uma rede de 10 nós o número de estruturas ilegais é aproximadamente $99.8 \%$ do total de estruturas possíveis que essa representação permite (Jia et al., 2008).

Existem dois tipos de representações fechadas na literatura (Seção 3.4.3): a que usa unicamente ordens ancestrais (Larranaga et al., 1996a; Campos e Huete, 2000a; Hsu et al., 2002; dos Santos et al., 2010a,b) e a que combina ordens ancestrais com estruturas esqueletos (Kim et al., 2005; Faulkner, 2007; Stefano et al., 2010; Carvalho, 2011). No entanto, a primeira representação requer rotinas de busca local (tal como a heurística K2 deCooper e Herskovits (1992) ) para mapear entre ordens ancestrais e DAGs e assim poder avaliar as soluções, o que envolve certo custo computacional que pode ser elevado em redes de alta dimensão. Adicionalmente, os operadores de busca nessa representação conduzem frequentemente a grandes e imprevisíveis saltos no espaço de busca que podem fazer perder regiões promissórias.

Com base nas observações acima, foi desenvolvida uma representação fechada para EESBN que adota a ideia de hibridização entre ordens ancestrais e estruturas esqueletos. A novidade desta representação em relação às existentes da literatura é que ela incorpora implicitamente as restrições estruturais da superestrutura estimada previamente $\mathbb{S}$ (com qualquer um dos dois métodos descritos na seção anterior), fazendo com que toda solução representável por ela esteja em conformidade com $\mathbb{S}$. Dois componentes fundamentais definem tal representação: i) uma vetor $L$ de variáveis permutadas (ordem ancestral), e ii) um vetor binário $E$ de tamanho igual ao numero de arestas em $\mathbb{S}$, em que cada elemento $E[i]$ indica se a $i$-ésima aresta de $\mathbb{S}$ está presente (valor 1) ou não (valor 0) na estrutura codificada. Com essa representação é possível codificar todo DAG (e somente DAGs) com grafo esqueleto contido em $\mathbb{S}$. A aciclicidade da 
representação é garantida pela ordem ancestral $L$. Um exemplo ilustrativo da representação proposta é mostrada na Figura 4.1 para um problema de 4 variáveis onde a superestrutura estimada $\mathbb{S}$ contém 5 arestas. É importante notar também que cada solução em EES-BN (também chamada de indivíduo) armazena um vetor LocalScores que contém os escores das famílias de cada nó, o quais são usados nos operadores de busca. Também os indivíduos matem uma variável LastMove, que indica a última operação realizada no indivíduo, a qual pode ser (seções seguintes): 'MergePop' (operação de recombinação), 'Swap [n1,n2]' (operação de mutação Swap entre nós $n 1$ e $n 2$ ) e 'Flip [edge]' (operação de mutação Flip na aresta edge). Essa variável é usada para o controle de retrogressão, como será descrito na Seção 4.5.

\subsection{Recombinação em EES-BN: operador MergePop}

A escolha do operador de recombinação é um passo chave em todo projeto de algoritmo genético, dado que ele é o principal mecanismo de intercambio de informação útil entre indivíduos para localizar rapidamente soluções melhores (Srinivas e Patnaik, 1994). Entre a diversidade de operadores de recombinação propostos para aprendizagem estrutural de RBs (Seção 3.4.4), destaca-se o operador Merge de Wong e Leung (2004). Tal operador possui algumas características atrativas que o diferenciam dos demais operadores, entre elas tem-se: i) garantir a produção de indivíduos filhos válidos (DAGs); ii) construir o indivíduo filho herdando as melhores famílias dos indivíduos pais; iii) produzir indivíduos filhos avaliados, ou seja, não é necessário chamar à função de escore já que os filhos herdam os escores das famílias dos pais; e iv) produzir os filhos numa classe de equivalência diferente à classe de equivalência dos pais.

Apesar das características atrativas de Merge, é notório que a produção de bons indivíduos filhos é dependente da qualidade das famílias dos pais geradores, mas como eles são apenas dois em número, as opções para escolher as famílias é limitada. Na tentativa de melhorar o pool de famílias a escolher na construção dos filhos e assim aumentar a possibilidade de localizar rapidamente melhores soluções foi desenvolvido o operador MergePop (Villanueva e Maciel, 2012a). Este operador estende Merge no sentido de poder trabalhar com um número arbitrário de indivíduos pais.

A Figura 4.5 mostra o pseudocódigo do operador MergePop, o qual receve como entradas um indivíduo IndA (chamado de indivíduo base) e uma subpopulação de indivíduos $\mathbf{S}$ (chamados de indivíduos doadores) e fornece como saída um indivíduo filho IndO, o qual é resultante 


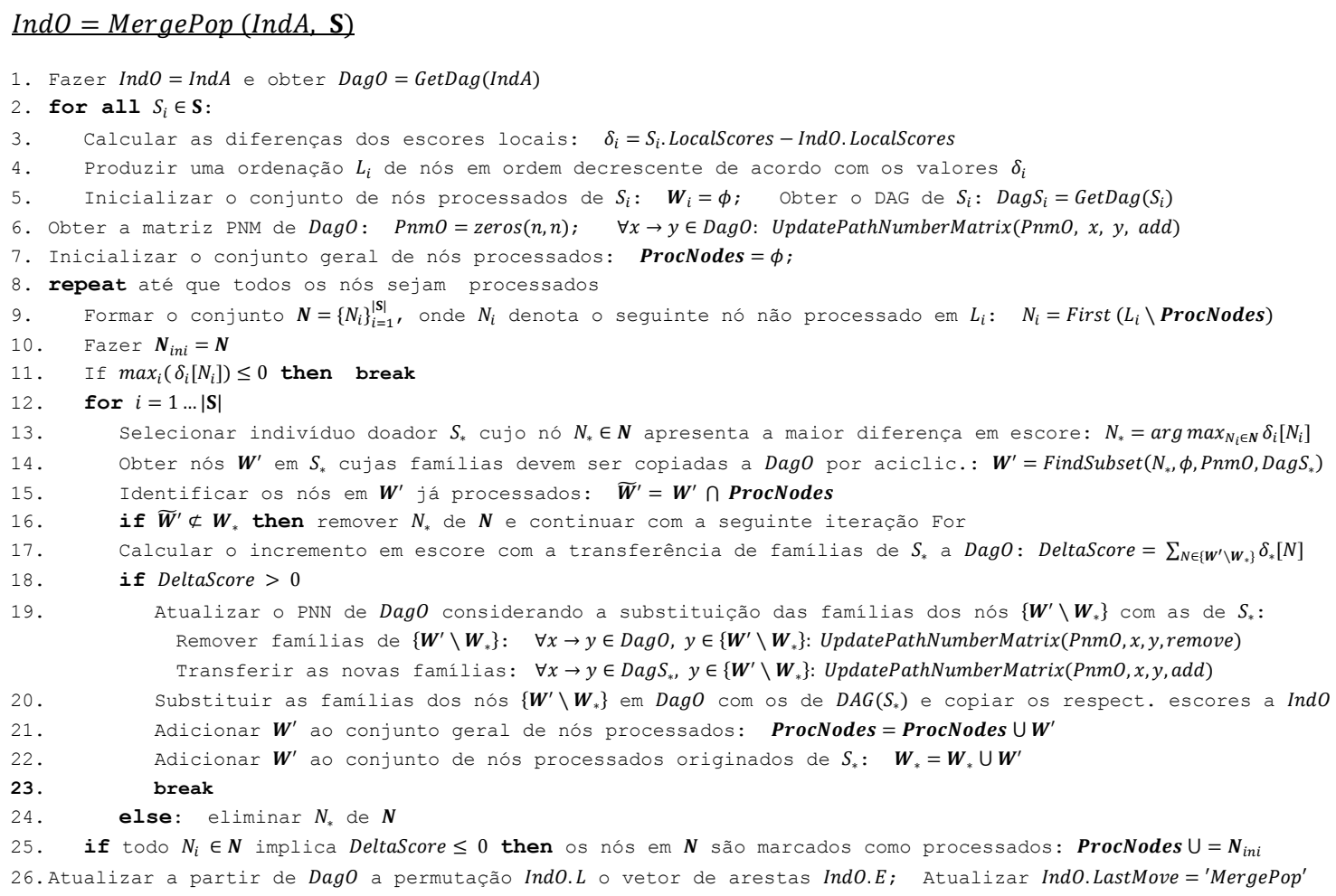

Figura 4.5: Pseudocódigo do operador de recombinação MergePop.

da modificação do indivíduo base IndA mediante a transferência de algumas "boas"famílias dos indivíduos doadores S. MergePop trabalha diretamente com o DAG de IndO, DagO, que é inicializado com o DAG do indivíduo IndA e vai sendo modificado ao longo do processo (a função GetDag é usada em EES-BN para obter o DAG de un indivíduo, a qual simplesmente orienta suas arestas $E$ conforme sua ordem ancestral $L$ ). MergePop inicia calculando para cada indivíduo $S_{i} \in \mathbf{S}$ a difença do seu vetor de escores locais em relação ao vetor de escores locais de IndA (diferença armazenada no vetor $\boldsymbol{\delta}_{i}$, linha 3). Logo é produzida uma ordenação $\boldsymbol{L}_{i}$ dos nós segundo os valores de $\boldsymbol{\delta}_{i}$ em ordem decrescente (linha 4).

O trabalho principal de MergePop consiste em obter iterativamente (linhas 8-26) famílias para $\operatorname{Dag} O$ buscando elas conforme às ordenações obtidas em $\boldsymbol{L}_{i}$ (começando com os primeiros nós que oferecem as melhores diferenças em escore). Em cada iteração, todos os indivíduos em $\mathbf{S}$ competem para doar uma família (e todas as associadas a ela que evitam a formação de ciclos) a $\operatorname{Dag} O$. Para isso, no inicio da iteração é formado o conjunto $\boldsymbol{N}$ com os seguintes nós ainda não processados de cada ordenação $\boldsymbol{L}_{i}$, linha 9 (os nós processados são os nós cujas famílias já foram estabelecidas para $\operatorname{Dag} O$ e são colocados no conjunto geral ProcNodes; também o conjunto $\boldsymbol{W}_{i}$ mantém nós processados, mas somente aqueles origi- 
nados do indivíduo $S_{i}$ ). O indivíduo escolhido como potencial doador de família na iteração atual é aquele indivíduo $S_{*}$ cujo nó $N_{*} \in \boldsymbol{N}$ apresenta a maior diferença em escore local entre todos os nós no conjunto atual $N$. Uma vez identificado tal indivíduo $S_{*}$ é executado o procedimento recursivo FindSubset ${ }^{3}$ para encontrar todos os nós $\boldsymbol{W}^{\prime}$ no indivíduo $S_{*}$ cujas famílias precisam também ser transferidas para $D a g O$ e assim garantir a aciclicidade dele (a simples transferência da família de $N_{*}$ ao $D a g O$ pode introduzir ciclos nele).

Uma vez determinado o conjunto de nós $\boldsymbol{W}^{\prime}$ em $S_{*}$ é verificado se existem nós nesse conjunto que já foram processados previamente (estão no conjunto ProcNodes, linha 15). Se é encontrado que nenhum nó em $\boldsymbol{W}^{\prime}$ foi processado anteriormente, ou que os que foram processados foram originados do mesmo indivíduo $S_{*}$ (estão no conjunto $\boldsymbol{W}_{*}$ ), então o processo de doação de famílias é continuado, caso contrário, o nó $N_{*}$ é removido de $N$ e se prossegue com a seguinte iteração para buscar um outro indivíduo doador, já que a doação atual não pode ser realizada porque poderia resultar em um DAG inválido. Quando a doação continua, MergePop calcula o aumento em escore, DeltaScore, que seria obtido de ser efetivada a doação atual (o qual é obtido somando as diferenças dos escores locais dos nós cujas famílias seriam efetivamente doadas a $\operatorname{Dag} O$, ou seja, $\boldsymbol{W}^{\prime} \backslash \boldsymbol{W}_{*}$ ). Se o valor de DeltaScore é positivo então a doação é materializada (linhas 19-22), atualizando nesse processo a matriz PNM do $D a g O$ com as novas famílias (o qual é realizado removendo primeiro as arestas das famílias atuais e logo colocando as arestas das novas famílias, para isso é usada a função UpdatePathNumber Matrix (Wong e Leung, 2004) em cada remoção/adição de aresta). Também são copiados os escores locais das famílias atualizadas a $I n d O$ e os nós de $\boldsymbol{W}^{\prime}$ são colocados nos conjuntos ProcNodes e $\boldsymbol{W}_{*}$ para indicar que já foram processados. Após a doação, uma nova competição é realizada com os seguintes nós não processados em cada ordenação $\boldsymbol{L}_{i}$. Se o valor de DeltaScore não é positivo então a doação com o atual nó $N_{*}$ é rejeitada (removendo $N_{*}$ de $\boldsymbol{N}$, linha 24) e um novo nó é procurado. Se todos os nós $N_{i} \in \boldsymbol{N}$ falham em incrementar o escore então tais nós são colocados no conjunto de nós processados (linha 25) para evitar reprocessamento.

O ciclo principal de MergePop finaliza quando não há mais nós a serem processados ou quando a melhor diferença em escore da atual competição não é positiva, o qual é um indicativo de que não existe mais famílias em $\mathbf{S}$ que possam ser copiadas a $D a g O$ para aumentar

\footnotetext{
${ }^{3}$ Tal procedimento é similar ao descrito por Wong e Leung (2004). A única diferença é que na implementação de MergePop a matriz PNM (path number matrix) do DAG sendo trabalhado DagO é inicializada e atualizada fora de FindSubset e é fornecida a ela como argumento. FindSubset usa tal matriz PNM para determinar eficientemente a presença de caminhos cíclicos.
} 
seu escore. Uma vez finalizado o ciclo de doações, MergePop atualiza o vetor de arestas $E$ e a ordem ancestral $L$ do indivíduo sendo gerado IndO conforme o DAG obtido em DagO. Também é atualizada a variável LastMove desse indivíduo com o valor "MergePop"para indicar seu origem. O vetor LocalScores não é necessário ser atualizado ao finalizar, já que ele é atualizado com cada transferência de famílias no ciclo de doações.

EES-BN aplica MergePop a cada indivíduo $P_{i}$ (como individuo base) da população atual $\mathbf{P}$ para produzir um indivíduo $Q_{i}$ da população filha $\mathbf{Q}$ (bloco recombinação na Figure 4.1). Em cada aplicação de MergePop a subpopulação de doadores $\mathbf{S}$ é obtida aleatoriamente de $\mathbf{P}$ (excluindo o indivíduo $P_{i}$ no qual MergePop é aplicado, já que ele é o indivíduo base). Como será mostrado no seguinte capítulo, MergePop possui uma grande habilidade de reconstituir rapidamente boas famílias espalhadas na população para produzir melhores soluções, razão pela qual é colocada a primeira prioridade em EES-BN dentro de todos seus operadores de busca.

\subsection{Mutação e Substituição em EES-BN}

Todo indivíduo criado por recombinação que não consegue melhorar o escore do indivíduo base gerador é sujeito a uma fase de mutação. Tal situação acontece com maior frequência quando a população sendo evoluída $\mathbf{P}$ se aproxima à convergência, onde se torna mais difícil encontrar novas "boas"famílias para reconstituir e que resultem em indivíduos melhores. Nesse sentido, a fase de mutação implementada em EES-BN foi concebida para realizar pequenas alterações em indivíduos já otimizados, com o propósito de produzir eventualmente melhores famílias que aumentem o escore de tais indivíduos. As mutações são realizadas de forma local (afetam somente uma aresta) com base na consideração de que é mais provável produzir uma solução melhor fazendo pequenas alterações a uma solução boa do que fazendo grandes alterações nela. Assim, a fase de mutação pode ser vista como uma fase de ajuste fino que segue à fase de aproximação dada pela recombinação.

Dois operadores de mutação são implementados na fase de mutação: o operador Flip e o operador Swap. O operador Flip atua sobre o vetor de arestas $E$ do indivíduo de entrada invertendo o valor de algum elemento escolhido aleatoriamente por ele. A consequência dessa operação é a adição ou eliminação de alguma aresta (da superestrutura $\mathbb{S}$ ) no indivíduo sendo mutado. A ideia de Flip foi usada também nos trabalhos de Kim et al. (2005) e Carvalho 
(2011), porém em uma representação sem restrição do espaço de busca. A vantagem de Flip é que para calcular o escore do indivíduo mutado só é necessário calcular o escore local do nó cuja família é alterada, o qual é computacionalmente mais simples do que calcular o escore da rede inteira.

O operador Swap toma a ideia de Teyssier e Koller (2005), agindo de forma local sobre a ordem ancestral $L$ do indivíduo de entrada. Especificamente, uma posição dentre $L$ é escolhida aleatoriamente (com exceção da última posição) e seu valor intercambiado com o valor da posição seguinte. O resultado dessa operação é a mudança de direção da aresta que coneta os nós dessas posições (se existir tal aresta em $E$ ). A vantagem desse operador, ao igual que Flip, é a sua natureza local, requerendo somente o recálculo dos escores das famílias dos dois nós envolvidos na operação para obter o escore total da estrutura.

Os dois operadores de mutação são aplicados de forma mutuamente exclusiva em EESBN, tendo cada um uma chance de 50\% de ser escolhido. Para evitar regressar a soluções já exploradas (retrogressão), ambos os operadores usam também a informação armazenada na variável LastMove dos indivíduos. Especificamente, se o operador Swap é escolhido e o valor em LastMove indica que o indivíduo de entrada foi resultado de uma operação Swap entre os nós $n 1$ e $n 2$ então tais nós são proibidos de participar na atual operação Swap (senão resultaria na estrutura previa à última mutação desse indivíduo). Da mesma forma, se o operador Flip é selecionado e o indivíduo de entrada $P_{i}$ indica na sua variável LastMove que ele foi produto de uma mutação Flip na aresta $e$, então tal aresta é excluída de participar na operação Flip atual.

Ao concluir a operação de mutação (qualquer dos dois operadores) é armazenada na variável LastMove a string da operação que foi realizada concatenada com os argumentos usados (os valores de $n 1$ e $n 2$ em Swap, ou o valor $e$ em Flip). A mutação é feita em EES-BN sobre o indivíduo $P_{i}$ em que MergePop falhou, e não sobre o indivíduo filho $Q_{i}$ por ele produzido (pois ele é de menor qualidade que $P_{i}$ ), o qual é substituído pelo indivíduo que resulta da mutação.

Uma vez concluídas as fases de recombinação e mutação na geração atual, são encontradas duas populações: a população atual $\mathbf{P}$ e uma nova população $\mathbf{Q}$ (do mesmo tamanho $w$ que P) que contém os resultados de recombinações e em alguns casos de mutações. Essas duas populações são então submetidas a um processo de substituição no qual é gerada uma nova população que substitui a $\mathbf{P}$ e que é obtida escolhendo os melhores $w$ indivíduos em escore da 
população conjunta $\mathbf{P} \cup \mathbf{Q}$ (função GetBestIndiv na Figura 4.1). A nova população é então usada na seguinte fase de EES-BN que é descrita a seguir.

\subsection{Injeção de Diversidade em EES-BN}

Uma das principais dificuldades encontradas nos algoritmos genéticos tradicionais quando aplicados em problemas com numerosos ótimos locais é a convergência prematura do processo evolutivo a soluções sub-ótimas, que frequentemente não são satisfatórias (Chang et al., 2010). Isso acontece devido à declinação da diversidade da população a medida que o processo evolutivo avança a um ótimo local. Ao perder diversidade, o operador de recombinação perde efetividade em localizar soluções melhores dado que os genes dos indivíduos se tornam similares, deixando a evolução em mãos da mutação. O problema é que muitas vezes é necessário uma mutação grande para retirar a população do ótimo local atual. No entanto, mutações grandes evitam o reuso de computações locais e dificultam o processo de convergência ao introduzir elevados níveis de ruído. Este problema tem sido abordado em vários trabalhos na literatura de algoritmos genéticos, tais como Shimodaira (1996, 2001); Chang et al. (2010).

Dentre dessa literatura, encontra-se o trabalho recente de Chang et al. (2010) que propõe um esquema dinâmico e simples para diminuir a possibilidade de convergência prematura. Esse esquema consiste em um bloco de controle de diversidade que é acoplado no ciclo evolutivo e que mede continuamente a diversidade da população, colocando novos indivíduos na população se tal diversidade cai abaixo de um determinado limiar.

Dada a efetividade, simplicidade, e autorregulação do esquema de Chang et al., ele foi tomado como base para implementar o bloco de injeção de diversidade em EES-BN (Figura 4.1). No entanto, diferentemente do esquema de Chang et al. em que são usadas métricas $a d-h o c$ para medir a diversidade da população, o esquema proposto para EES-BN usa uma simples medida de estagnação da população para decidir a injeção de indivíduos. Tal medida é definida pela diferença em escores médios das populações ao inicio do ciclo evolutivo e após executar as fases de recombinação, mutação e substituição. Embora essa medida não estima diretamente a diversidade da população, ela é efetiva em detectar estagnação da população em quanto escore (o que ao final é o que se pretende otimizar), além de ter um custo computacional muito reduzido em seu cálculo quando comparado com as métricas de diversidade de Chang et al. (2010). 
O bloco de injeção de diversidade em EES-BN é somente ativado quando a medida de estagnação for menor a um limiar predefinido $\Delta$ (dada como uma fração do escore médio inicial), em cujo caso é assumido que uma estagnação da população tem acontecido. Nesse caso, um conjunto de $r$ novos indivíduos é criada e introduzida na população $\mathbf{P}$ substituindo os $r$ piores indivíduos dela. $\mathrm{O}$ valor $r$ é ajustado proporcionalmente com o número de vezes que o bloco de injeção de diversidade falha em retirar à população do estado de estagnação (contador InjFails; este contador é zerado cada vez que a população entra em uma nova estagnação, verificado quando o melhor escore da população atual bestScore ${ }^{\text {new }}$ supera ao melhor escore da ultima população em estagnação bestScore ${ }^{\text {old }}$, Figura 4.1). A função usada para esse ajuste é dada por:

$$
r=\min \left(r_{\min }+r_{i n c} * I n j F a i l s, r_{\max }\right)
$$

onde $r_{\min }$ denota o número mínimo de indivíduos a injetar, $r_{\max }$ denota o número máximo de indivíduos a injetar, e $r_{i n c}$ indica o número de indivíduos a incrementar após uma injeção sem sucesso. Quando uma nova estagnação da população é detectada o número de indivíduos a injetar é colocado em $r_{\text {min }}$. Se após tal injeção a população volta a convergir ao mesmo estado de estagnação anterior (bestScore $e^{\text {new }}$ é igual a bestScore $e^{o l d}$ ) então o número de indivíduos a injetar é aumentado em $r_{i n c}$ em relação ao último número $r$ de indivíduos injetados. Tal processo continua até atingir um máximo de $r_{\max }$ indivíduos injetados, mantendo esse valor constante se a estagnação continuar (até atingir o critério de parada ou sair de estagnação).

A estratégia de aumentar gradualmente a intensidade da injeção obedece aos requerimentos de eficiência computacional de EES-BN, já que tal estratégia permite balançar a quantidade de diversidade injetada e o custo computacional dessa operação. Tal custo é dominado pelo cálculo dos escores dos indivíduos injetados, já que como eles são completamente novos, é necessário calcular os escores de todas as suas famílias, operação que é computacionalmente demandante. A ideia é que se o esforço atual de injeção de diversidade não é suficiente para tirar à população do estado de estagnação atual então um novo esforço será realizado com uma intensidade maior na seguinte iteração. Dessa forma, as chances da população estagnada sair dessa situação são incrementadas com o tempo (se esse estado for um ótimo local), característica desejada em toda heurística de otimização. O desempenho de EES-BN foi encontrado sendo moderadamente robusto às variações dos valores dos parâmetros do bloco de injeção. Em todos os experimentos executados no presente trabalho tais parâmetros foram colocados como $r_{\min }=0.1 w, r_{\max }=0.5 w, r_{i n c}=0.1 w$ e $\Delta=0$ ( $w$ é o tamanho da população), 
valores que deram resultados aceitáveis.

\subsection{Autorregulação em EES-BN}

A estrutura de EES-BN foi projetada para que a atividade dos seus principais componentes seja autorregulada no decorrer do processo evolutivo. Assim, nos estágios iniciais da evolução quando o processo dista da convergência, o operador de recombinação MergePop é praticamente o único operador utilizado, já que nessa etapa é frequente observar que os indivíduos filhos $\mathbf{Q}$ superam sem dificuldade a seus pais $\mathbf{P}$ dada a facilidade para encontrar novas configurações das famílias existentes na população que resultam em indivíduos de melhor escore. A mutação é raramente usada nessa etapa inicial, e quando acontece é para ajudar a melhorar algum indivíduo $P_{i}$ em que o MergePop não teve sucesso, devido a que, ou tal indivíduo já era bastante ótimo ou porque a subpopulação de doadores escolhida não tinha famílias de boa qualidade (fato que pode ser minimizado ao aumentar o tamanho de tal subpopulação). Uma consequência benéfica de que MergePop seja o operador dominante na etapa inicial é a baixa invocação à função de escore, a qual é uma operação computacionalmente demandante por ter que percorrer os dados de treinamento. Dessa maneira, EES-BN tenta primeiro tirar proveito das qualidades da população atual antes de introduzir novos genes (famílias) nela.

A medida que o processo evolutivo se aproxima a convergência, o operador MergePop tende a ter maiores dificuldades em produzir melhores filhos. Nesse cenário, os operadores de mutação são usados com maior frequência em EES-BN, aumentando a possibilidade de produzir famílias mais ajustadas. Eventualmente, todos os indivíduos da população poderiam ser submetidos a mutação no caso em que MergePop falhe em produzir melhores filhos nessa população. Ainda assim, a fase de recombinação é necessária, já que se uma mutação altera uma família de algum indivíduo conferindo-lhe um escore melhor então o operador de recombinação será responsável de assimilar tal família em todos os indivíduos da população nos seguintes ciclos evolutivos. Diferentemente da recombinação, os operadores de mutação precisam chamar à função de escore para recalcular os escores locais modificados, custo computacional que é relativamente baixo já que envolve no máximo duas famílias (no caso do operador Swap). Dessa maneira, as operações de recombinação e mutação são complementares e sua atividade é automaticamente regulada conforme sejam necessitadas no processo evolutivo. Esse esquema contrasta com os típicos algoritmos genéticos em que a quantidade de recombinação e mutação é predefinida antes da evolução e mantida constante no processo evolutivo. 
A atividade do bloco de injeção de diversidade é também autorregulada pelo processo evolutivo em EES-BN, já que ele é somente ativado quando as fases de recombinação e mutação não conseguem aumentar mais o escore da população. Nesse cenário, chamado de estagnação, o bloco de injeção de diversidade age gradativamente até conseguir tirar à população do estado de estagnação. A injeção de diversidade é intermitente, já que uma vez injetados novos indivíduos na população as fases de recombinação e mutação podem levar vários ciclos evolutivos até assimilar e refinar as boas famílias que possam ter sido introduzidas na última injeção. A moderação no uso do bloco de injeção de diversidade é devida a que tal bloco representa a operação com maior custo computacional em EES-BN e portanto seu esquema de regulação foi projetado para ele ser usado no momento e quantidade estritamente necessária. 


\title{
Capítulo 5
}

\section{Avaliação Experimental}

Neste capítulo é apresentada uma avaliação experimental do desempenho do sistema EESBN proposto. Na Seção 5.1 são descritos os dados usados ao longo dos experimentos. Na Seção 5.2 são avaliados os métodos propostos de estimação de superestruturas para EES-BN. A Seção 5.3 apresenta resultados da avaliação do desempenho do operador de recombinação MergePop. A Seção 5.4 apresenta um análise experimental da contribuição dos blocos de recombinação, mutação e injeção de diversidade no desempenho de EES-BN. A Seção 5.5 avalia métodos de inicialização para EES-BN. Finalmente, a Seção 5.6 apresenta uma comparação empírica do desempenho de EES-BN com vários métodos representativos para aprendizagem estrutural de redes Bayesianas.

\subsection{Dados}

Os bancos de dados usados nos diferentes experimentos apresentados neste capítulo correspondem a quatro redes Bayesianas comumente usadas como referências na literatura de RBs:

\begin{abstract}
Alarm (Beinlich et al., 1989), rede que foi construída para modelar problemas potenciais de anestesia que poderiam surgir na sala de operações. Consiste de 37 variáveis discretas e 46 arestas, representando 8 problemas de diagnóstico, 16 sintomas e 13 variáveis intermédias que relacionam problemas de diagnóstico aos sintomas;

- Child (Cowell et al., 1999), sistema para diagnosticar recém nascidos com possíveis doenças congênitas do coração. Consiste de 20 variáveis discretas que incluem sintomas, resultados de laboratório e estado clínico do bebê.
\end{abstract}


- Insurance (Binder et al., 1997), rede para avaliar riscos de seguros de automóveis. Consiste de 27 variáveis discretas e 52 arestas relacionando atributos do veículo, variáveis socioeconômicas do proprietário e habilidades e histórico de condução do mesmo.

- Hailfinder (Abramson et al., 1996), sistema para predizer alterações graves no clima. Consiste de 56 variáveis discretas e 66 arestas. Esta rede é caracterizada por sua complexidade, já que apresenta famílias de elevado tamanho (até 17 variáveis) e algumas variáveis com ampla gama de valores possíveis (até 11 valores).

A Tabela 5.1 mostra as principais características das RBs acima mencionadas. A seleção dessas redes foi motivada por representarem sistemas de tomada de decisões reais e cenários de variada complexidade, sendo Child e Alarm as mais simples e Insurance e Hailfinder as mais complexas dado seu tamanho de domínio e densidade de conexões.

Além das RBs descritas acima, versões estendidas das mesmas são incluídas em alguns experimentos deste estudo. O procedimento para realizar tal extensão é o método conhecido como tiling (descrito em (Tsamardinos et al., 2006b)), o qual constrói redes de alta dimensionalidade mediante a junção de várias copias de uma RB básica (chamada de tile) de um modo que as propriedades estruturais e probabilísticas da rede básica sejam conservadas na rede estendida. No presente estudo, as extensões usadas correspondem a 3, 5 e 10 tiles das redes originas descritas acima. As propriedades dessas redes estendidas são também mostradas na Tabela 5.1, tendo como nomes a concatenação do nome da rede básica e o número de tiles da extensão. A introdução de versões estendidas de RBs foi feita a fim de avaliar o comportamento dos métodos com o aumento da dimensionalidade das redes.

O site \{www.dsl-lab.org/supplements/mmhc_paper/mmhc_index.html\}, mantido pelos autores do método MMHC (Tsamardinos et al., 2006a), contém bancos de dados amostrados de todas as RBs incluídas neste estudo, tanto das redes básicas como as estendidas. Nesse repositório existem 30 bancos de dados por RB (10 bancos de 500 amostras, 10 bancos de 1000 amostras e 10 bancos de 5000 amostras) dos quais foram escolhidos os 5 primeiros bancos de cada tamanho amostral para a presente avaliação. Adicionalmente, foram gerados 5 bancos de dados de 250 amostras fazendo sub-amostragem dos bancos de 500 amostras (escolhendo de forma intercalada as amostras). Assim, para cada RB são usados para os experimentos 20 bancos de dados com tamanhos de 250, 500, 1000 e 5000 amostras. O uso de bancos de dados de variado tamanho amostral foi realizado a fim de avaliar o efeito do tamanho amostral no desempenho dos métodos. 
Tabela 5.1: Redes Bayesianas usadas na avaliação experimental. Domínio é o número de valores que assumem as variáveis da RB. Máximo $|\mathbf{P C}|$ indica o tamanho do maior conjunto de pais e filhos na RB.

\begin{tabular}{lrrcc}
\hline Rede & No. Variáveis & No. Arestas & Domínio & Máximo $|\mathbf{P C}|$ \\
\hline Alarm & 37 & 46 & $2-4$ & 6 \\
Alarm3 & 111 & 149 & $2-4$ & 6 \\
Alarm5 & 185 & 265 & $2-4$ & 8 \\
Alarm10 & 370 & 570 & $2-4$ & 9 \\
\hline Child & 20 & 25 & $2-6$ & 8 \\
Child3 & 60 & 79 & $2-6$ & 8 \\
Child5 & 100 & 126 & $2-6$ & 8 \\
Child10 & 200 & 257 & $2-6$ & 8 \\
\hline Insurance & 27 & 52 & $2-5$ & 9 \\
Insurance3 & 81 & 163 & $2-5$ & 9 \\
Insurance5 & 135 & 281 & $2-5$ & 10 \\
Insurance10 & 270 & 556 & $2-5$ & 11 \\
\hline Hailfinder & 56 & 66 & $2-11$ & 17 \\
Hailfinder3 & 168 & 283 & $2-11$ & 19 \\
Hailfinder5 & 280 & 458 & $2-11$ & 19 \\
Hailfinder10 & 560 & 1017 & $2-11$ & 21 \\
\hline
\end{tabular}

\subsection{Avaliação de Opt01SS e OptHPC}

Nesta seção é apresentado um estudo comparativo dos métodos propostos para recuperação de superestruturas Opt01SS e OptHPC contra cinco outros métodos do estado-da-arte. A comparação é focalizada em dois fatores: i) precisão na recuperação da superestrutura, e ii) custo computacional dos algoritmos. Para esta avaliação são usados os conjuntos de dados descritos na seção anterior, onde a estrutura verdadeira é conhecida. A precisão é avaliada através dos conhecidos índices sensibilidade (Sn) e especificidade (Sp) (Tamada et al., 2011a), os quais são definidos a seguir:

$$
\begin{gathered}
S n=T P /(T P+F N) \\
S p=T P /(T P+F P)
\end{gathered}
$$

onde $T P$ denota o número de arestas estimado pelo método e que pertencem ao esqueleto da $\mathrm{RB}$ verdadeira (arestas verdadeiras positivas), $F N$ indica o número de arestas que não foram estimadas pelo método mas que pertencem ao esqueleto da RB verdadeira (arestas falsonegativas), FP denota o número de arestas estimadas pelo método mas que não estão no 
esqueleto verdadeiro (arestas falso-positivas). Os índices $S n$ e $S p$ assumem valores normalizados no intervalo $[0,1]$, tomando o valor 1 no caso ideal em que todas e somente arestas verdadeiras positivas são aprendidas.

O custo computacional é estimado através do número total de testes estatísticos usados pelo método para aprender a superestrutura. Este índice, chamado abreviadamente de NSC (do inglês number of statistical calls), é usado frequentemente para comparar a eficiência computacional de métodos de aprendizagem estrutural de RBs baseados em testes de independência (Tsamardinos et al., 2006a; Yehezkel e Lerner, 2009; De Morais e Aussem, 2010). A racionalidade no uso da métrica NSC vem do fato que os testes de independência são operações computacionalmente custosas e os métodos baseados neles gastam a maior parte do tempo executando tais testes. Uma outra vantagem do índice NSC é que ele não depende da plataforma de computação usada (hardware, sistema operacional), medindo assim somente a eficiência computacional inerente dos métodos.

Em adição aos métodos Opt01SS e OptHPC, os seguintes métodos foram também incluídos na presente avaliação experimental:

HPC (De Morais e Aussem, 2010), algoritmo local (em que OptHPC esta baseado) para estimar o conjunto de pais e filhos de uma variável dada.

- Max-Min Parents and Children - MMPC (Tsamardinos et al., 2006a), algoritmo local para estimar o conjunto de pais e filhos de uma variável. Forma parte do método híbrido MMHC (do inglês Max-Min Hill Climbing) de aprendizagem de estruturas de RBs.

- GetPC (Pena et al., 2007), algoritmo local para estimar os pais e filhos de uma variável dada. Forma parte de um sistema de identificação de Markov blankets chamado de PCMB (do inglês Parents and Children based Markov Boundary algorithm).

- Heuristics PC algorithm - HeuPC (Wang et al., 2007), algoritmo global para recuperar o esqueleto de uma RB. Forma parte do sistema de aprendizagem hibrido BN-MCMC proposto pelos mesmos autores.

- 01SS, método global tradicional para aproximar o esqueleto de uma RB. Este método foi proposto informalmente várias vezes na literatura (exemplos, van Dijk et al. (2003); Wong e Leung (2004)) para reduzir o espaço de busca. Consiste simplesmente de remover de um grafo não dirigido completamente conectado todas as arestas cujos nós têm 
independência condicional de ordem 0 ou 1, daí o nome colocado neste trabalho para identificar ele. 01SS também pode ser visto como uma instância de Opt01SS em que só é executada a primeira fase e uma iteração da segunda fase sem nenhuma otimização.

A escolha dos métodos acima indicados foi realizada com base a seu caráter recente e representatividade na literatura. Os métodos locais HPC e GetPC são avaliados no presente estudo como estimadores de superestrutura mediante a aplicação direta deles sobre cada variável da rede e então conectando tais variáveis com seus respectivos pais e filhos estimados. No caso do método MMPC, foram implementadas as otimizações sugeridas pelos autores para a estimação da estrutura global (uso de cache e compartilhamento de cálculos).

Todos os métodos avaliados neste estudo foram codificados na mesma linguagem de programação (Matlab ${ }^{\circledR}$ versão 7.6) com a finalidade de ter uma mesma plataforma de comparação. A função Dep (Tabela 4.1) é usada por todos os métodos para assistir nos testes de independência e cálculos de graus de dependência. Com isso, a seleção da estatística de teste e o cálculo da métrica NSC é padronizada para todos os métodos e centralizada nessa função. Como descrito na Seção 4.2, a função $D e p$ implementa a estatística $G^{2}$ para calcular o grau de dependência e, consequentemente, determinar a existência de independência. A estatística somente é calculada se existir ao menos 5 amostras em média por célula (instanciação específica das variáveis testadas e variáveis condicionantes), caso contrário é assumida independência (prática sugerida por Tsamardinos et al. (2006a)). Os graus de liberdade da estatística $G^{2}$ são calculados segundo o método de Steck e Jaakkola (2002), o qual foi encontrado sendo mais apropriado para tamanhos de amostras reduzidos (Wang et al., 2007). O nível de significância $\alpha$ é mantido em 0.05 em todos os experimentos.

\subsubsection{Resultados de sensibilidade e especificidade}

Nas Figuras 5.1a-5.1h são apresentados os resultados obtidos para os índices de sensibilidade e especificidade nas quatro redes básicas. Cada curva corresponde a um método diferente e cada ponto nelas corresponde à média do índice nos 5 bancos de dados do mesmo tamanho amostral. Em todas as redes e métodos é possível observar um aumento da sensibilidade com o aumento do tamanho amostral, tendência que era esperada desde que um maior número de amostras ajuda a remover as incertezas dos testes estatísticos, especialmente em arestas verdadeiras com dependências fracas que ficam perdidas dentro do ruído amostral quando se tem dados limitados. Apesar da tendência comum da sensibilidade e considerando que todos os 
métodos usam o mesmo teste estatístico de independência, é interessante observar diferenças notórias da sensibilidade entre vários métodos ao longo dos tamanhos amostrais testados. Nos bancos de dados pequenos (250 e 500 amostras) existe uma clara tendência do método Opt01SS a oferecer uma sensibilidade superior aos outros métodos em todas as redes avaliadas. Essa vantagem é especialmente notória na rede Hailfinder (a rede de maior complexidade), onde Opt01SS apresenta valores de sensibilidade consideravelmente maiores do que os outros métodos, inclusive nos bancos de dados de alto número de amostras (1000 e 5000). Nessa mesma rede, o método clássico 01SS (igual ao Opt01SS, limita os testes de independência a ordem 0 e 1) apresenta valores de sensibilidade muito inferiores aos apresentados por Opt01SS. Esse resultado coloca em evidencia que as otimizações implementadas em Opt01SS são realmente efetivas em diminuir a taxa de erros falso-negativos (e portanto aumentar a sensibilidade) em cenários de pouca amostra.

Os valores de sensibilidade dos métodos OptHPC e HPC são encontrados muito próximos entre si em todos os casos e tendendo a igualar aos valores de Opt01SS nos bancos de dados de alto número de amostras (exceto na rede Hailfinder, onde Opt01SS é superior). Esse resultado indica que as otimizações computacionais implementadas em OptHPC não alteram a sensibilidade de HPC, a qual é claramente superior aos métodos MMPC e GetPC e HeuPC, corroborando assim os resultados de De Morais e Aussem (2010). O método clássico 01SS apresenta também valores próximos aos de Opt01SS em altos números de amostras, embora nos bancos pequenos ele tende a ser menos sensível que OptHPC e HPC. Os demais métodos (HeuPC, MMPC e GetPC) apresentam valores de sensibilidade que são em geral significativamente menores do que os anteriores. 


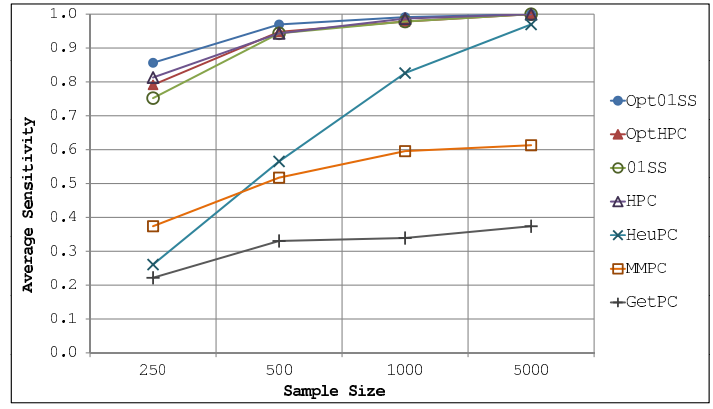

(a) Alarm (sensibilidade)

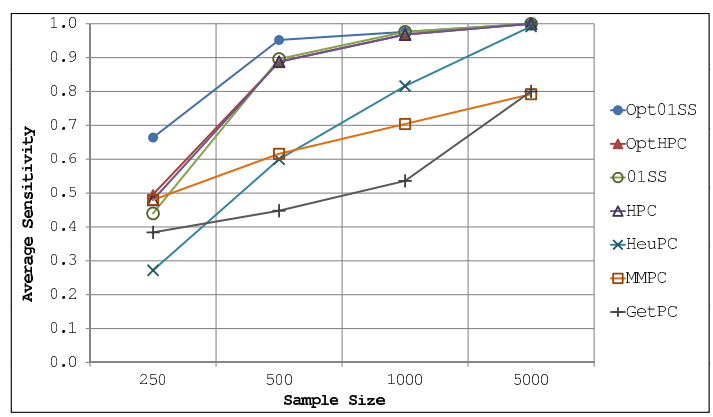

(c) Child (sensibilidade)

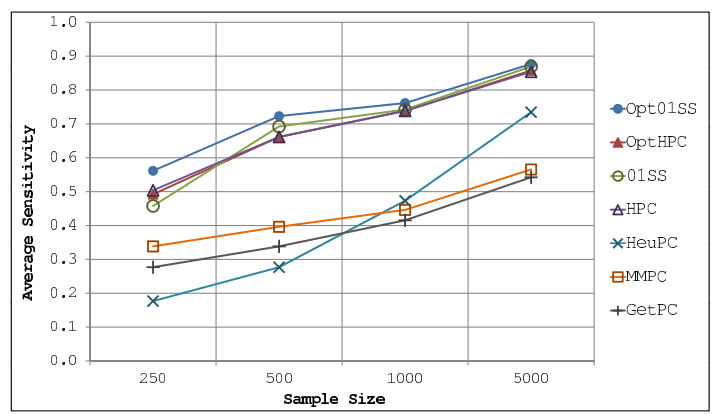

(e) Insurance (sensibilidade)

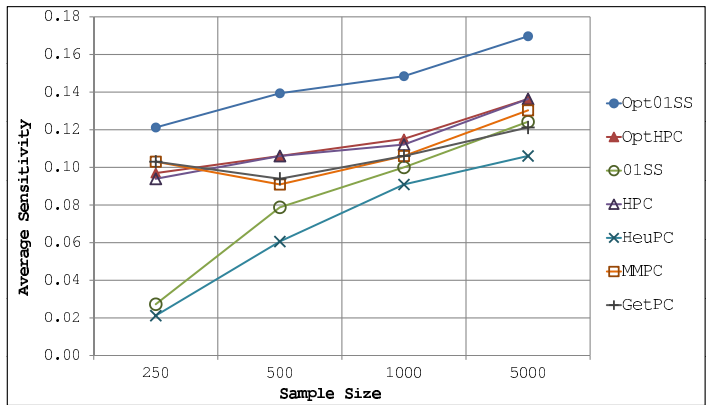

(g) Hailfinder (sensibilidade)

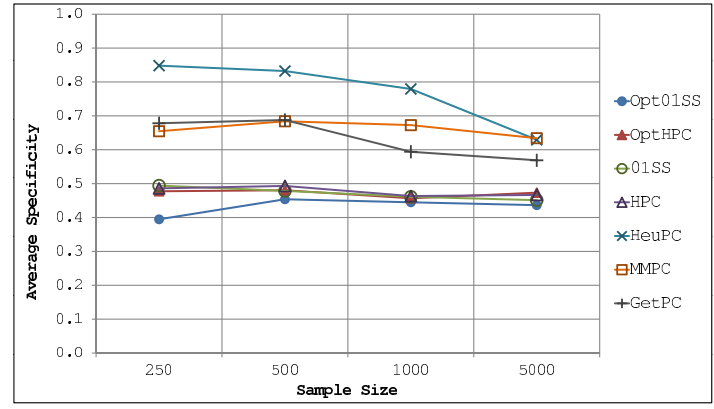

(b) Alarm (especificidade)

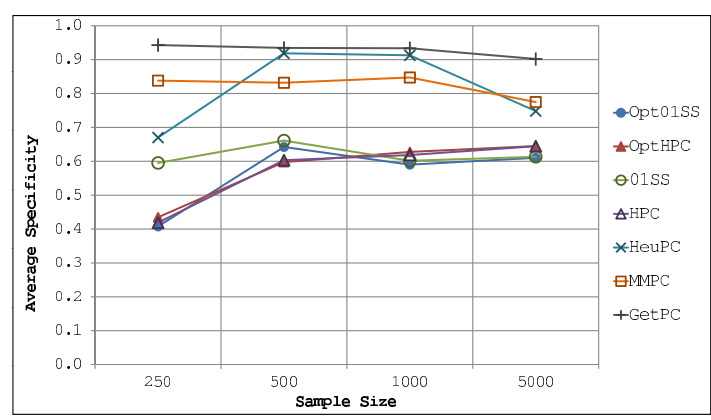

(d) Child (especificidade)

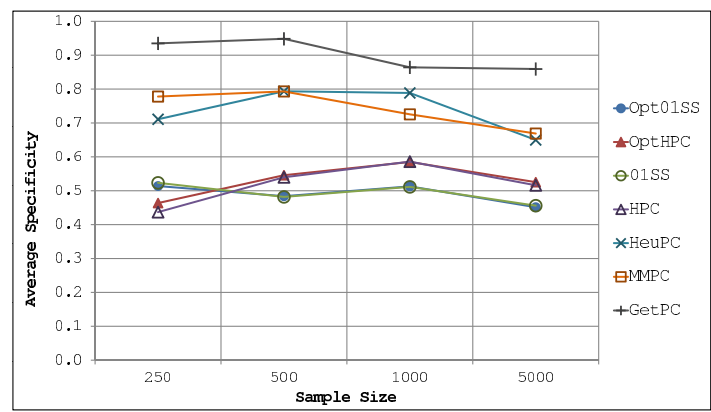

(f) Insurance (especificidade)

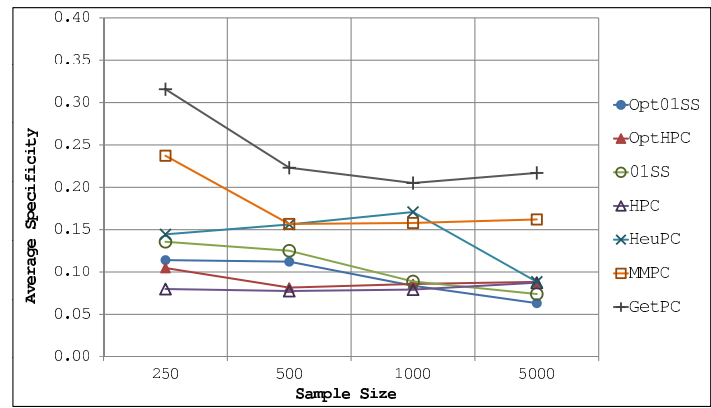

(h) Hailfinder (especificidade)

Figura 5.1: Resultados de sensibilidade (subfiguras da esquerda) e especificidade (subfiguras da direita) obtidos pelos diferentes métodos nas quatro redes Bayesianas básicas. Cada curva corresponde a um método diferente e cada ponto nelas corresponde à média do índice nos 5 bancos de dados do mesmo tamanho amostral. 
É de particular atenção o comportamento da sensibilidade oferecida pelo método HeuPC nas três primeiras redes. Tal método começa apresentando os mais baixos valores de sensibilidade nos bancos de 250 amostras, mas com o aumento do número de amostras a sensibilidade dele melhora a um ritmo maior do que os outros métodos (quase atingindo os níveis de Opt01SS nos bancos de 5000 amostras). Já na rede Hailfinder esse comportamento não é observado, provavelmente pela complexidade dessa rede, onde 5000 amostras parecem ser ainda poucos dados para evidenciar tal tendência. Uma explicação da relativamente pobre sensibilidade de HeuPC em bancos de poucas amostras pode ser encontrada na forte dependência desse método na condição de fidelidade monotônica (Cheng et al., 2002; Wang et al., 2007), uma condição mais rigorosa do que a condição de fidelidade usada pelos outros métodos e que é mais fácil de ser infringida em cenários de pouca amostra.

A relativamente baixa sensibilidade dos métodos MMPC e GetPC, inclusive em bancos de alta quantidade de amostras, pode ser entendida pelo fato que eles utilizam o critério de correção de simetria (Seção 4.2.2) para identificar falso-positivos nas adjacências dos nós, mas com o efeito colateral de tornar muito mais difícil a identificação de verdadeiro-positivos nas adjacências (De Morais e Aussem, 2010). O método HPC e o proposto aqui OptHPC usam o critério de busca descentralizada para decidir a inclusão de um nó na adjacência de outro nó, critério que é menos rigoroso do que a correção da simetria e que resulta efetivo em reduzir a taxa de erros falso-negativos em bancos de poucas amostras, como mostrado nos resultados da sensibilidade.

Em relação ao índice de especificidade, os resultados não mostram um comportamento definido da especificidade VS tamanho amostral ao longo dos métodos e redes estudadas. No entanto, é possível observar que os métodos que têm as maiores sensibilidades (Opt01SS, OptHPC, HPC e 01SS) oferecem os menores valores de especificidade (e vice-versa). Isso evidencia a disjuntiva sensibilidade-especificidade e a dificuldade em otimizar ambas as características simultaneamente. Os métodos OptHPC e HPC apresentam valores de especificidade muito próximos entre si em todos os casos (tal como o índice de sensibilidade), o que confirma que a precisão de HPC é mantida em OptHPC. A especificidade de Opt01SS é encontrada também próxima à especificidade dos métodos OptHPC e HPC, embora estes últimos tendem a apresentar valores relativamente maiores nos bancos com alto número de amostras. Isso pode ser explicado porque OptHPC e HPC não têm limitação na ordem dos testes de independência, fato que mostra seus efeitos quando se dispõe de alta quantidade de amostras (já que nesses 
casos os testes de independência de ordens superiores $(>2)$ deixam de ser impedidos de ser realizados, dado que a limitação imposta de 5 amostras por célula é superada).

Resumindo, os resultados das Figuras 5.1a-5.1h indicam que os métodos propostos Opt01SS e OptHPC oferecem um balanço sensibilidade-especificidade em favor da sensibilidade, enquanto que os métodos do estado-da arte HeuPC, MMPC e GetPC têm tal balanço em favor da especificidade. No entanto, como indicado por Perrier et al. (2008) e Kojima et al. (2010), para propósitos de aprendizagem híbrida de RBs é necessário colocar especial cuidado em minimizar a taxa de erros falso-negativos na estimação da superestrutura, desde que tal taxa será a taxa de erros falso-negativos de todo o sistema de aprendizagem (nenhum erro falso-negativo pode ser corrigido na fase de busca e pontuação). Claramente, Opt01SS e OptHPC estão em maior concordância com esse requerimento dada sua aumentada sensibilidade.

Para ter uma ideia da quantidade de espaço de busca que os diferentes métodos reduzem em relação a espaços irrestritos, é calculado a percentagem de não-arestas presentes na estrutura verdadeira que são colocadas como arestas na superestrutura estimada. A Tabela 5.2 mostra tais resultados, verificando-se que em média os métodos Opt01SS e OptHPC detectam respectivamente $10.1 \%$ e $8.2 \%$ de não-arestas como arestas, o que corresponde a uma redução de aproximadamente $90 \%$ do total de arestas do espaço irrestrito com Opt01SS, e quase $92 \%$ com OptHPC.

Tabela 5.2: Percentagem de não-arestas presentes na estrutura verdadeira que são detectadas como arestas na superestrutura estimada

\begin{tabular}{lcccccccc}
\hline \multirow{2}{*}{ Rede } & Tamanho & & \multicolumn{7}{c}{ Método } \\
\hline \multirow{2}{*}{ Alarm } & Amostral & Opt01SS & OptHPC & 01SS & HPC & HeuPC & MMPC & GetPC \\
& 250 & $9.8 \%$ & $6.5 \%$ & $5.7 \%$ & $6.4 \%$ & $0.4 \%$ & $1.5 \%$ & $0.8 \%$ \\
& 500 & $8.7 \%$ & $7.6 \%$ & $7.7 \%$ & $7.2 \%$ & $0.8 \%$ & $1.8 \%$ & $1.1 \%$ \\
& 1000 & $9.2 \%$ & $8.6 \%$ & $8.5 \%$ & $8.5 \%$ & $1.7 \%$ & $2.2 \%$ & $1.7 \%$ \\
\hline Child & 5000 & $9.6 \%$ & $8.3 \%$ & $9.0 \%$ & $8.5 \%$ & $4.3 \%$ & $2.6 \%$ & $2.1 \%$ \\
& 250 & $14.7 \%$ & $9.8 \%$ & $4.8 \%$ & $10.3 \%$ & $2.1 \%$ & $1.5 \%$ & $0.4 \%$ \\
& 500 & $8.2 \%$ & $9.2 \%$ & $7.2 \%$ & $9.0 \%$ & $0.8 \%$ & $1.9 \%$ & $0.5 \%$ \\
& 1000 & $10.4 \%$ & $8.7 \%$ & $9.9 \%$ & $9.2 \%$ & $1.2 \%$ & $1.9 \%$ & $0.6 \%$ \\
Insurance & 5000 & $9.7 \%$ & $8.4 \%$ & $9.6 \%$ & $8.4 \%$ & $5.1 \%$ & $3.5 \%$ & $1.3 \%$ \\
& 250 & $9.3 \%$ & $10.0 \%$ & $7.2 \%$ & $11.4 \%$ & $1.3 \%$ & $1.7 \%$ & $0.3 \%$ \\
& 500 & $13.5 \%$ & $9.8 \%$ & $13.0 \%$ & $10.0 \%$ & $1.3 \%$ & $1.8 \%$ & $0.3 \%$ \\
& 1000 & $12.8 \%$ & $9.2 \%$ & $12.5 \%$ & $9.1 \%$ & $2.2 \%$ & $2.9 \%$ & $1.1 \%$ \\
\hline Hailfinder & 5000 & $18.7 \%$ & $13.6 \%$ & $18.3 \%$ & $14.0 \%$ & $6.9 \%$ & $4.9 \%$ & $1.5 \%$ \\
\hline & 250 & $4.2 \%$ & $3.7 \%$ & $0.8 \%$ & $4.9 \%$ & $0.6 \%$ & $1.5 \%$ & $1.0 \%$ \\
& 500 & $4.9 \%$ & $5.2 \%$ & $2.5 \%$ & $5.7 \%$ & $1.5 \%$ & $2.2 \%$ & $1.5 \%$ \\
& 1000 & $7.3 \%$ & $5.5 \%$ & $4.6 \%$ & $6.0 \%$ & $2.0 \%$ & $2.5 \%$ & $1.8 \%$ \\
\hline Média & 5000 & $11.3 \%$ & $6.5 \%$ & $6.9 \%$ & $6.0 \%$ & $4.9 \%$ & $3.1 \%$ & $2.0 \%$ \\
\hline
\end{tabular}




\subsubsection{Resultados de custo computacional}

Na Figura 5.2 são apresentados os resultados para o índice NSC. Neste caso foram incluídos também os bancos de dados das redes estendidas a fim de avaliar a escalabilidade dos métodos. Cada subfigura mostra os resultados de uma determinada rede básica e as suas extensões. Cada curva mostra resultados de um determinado método, onde os pontos são plotados com o valor da abscissa sendo o número de variáveis da rede e o valor da ordenada sendo a média do índice NSC em todos os bancos de dados da mesma rede (média sobre os diferentes tamanhos amostrais). Tanto a abscissa como a ordenada são mostradas em escala logarítmica dado que existem diferenças em ordens de grandeza. Os resultados para HPC nas redes estendidas com tiling igual a 10 não são mostradas devido a que o método não conseguiu terminar seu processamento dentro de 30 horas (máximo tempo de processamento tolerado em todos os experimentos).

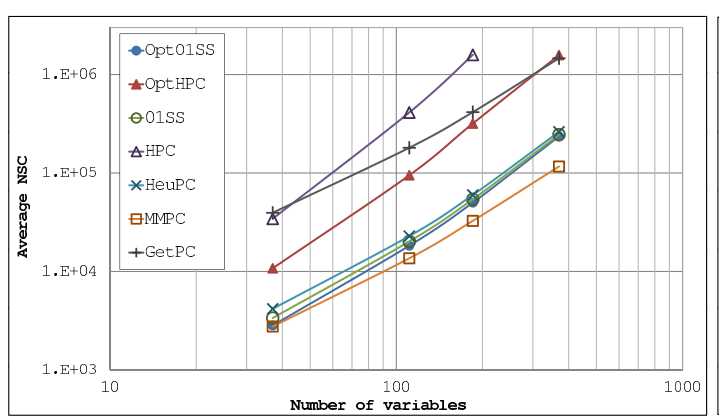

(a) Alarm

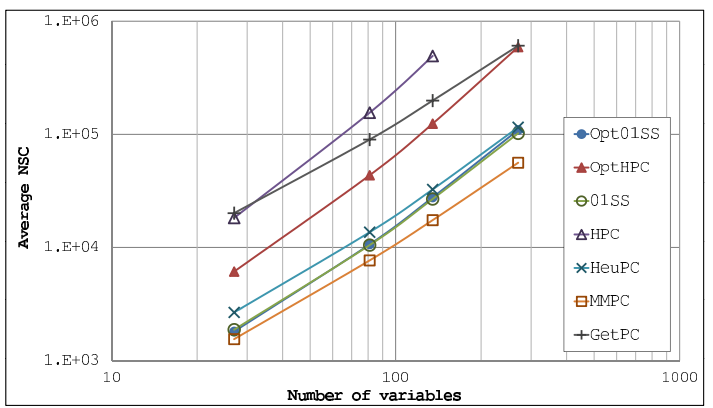

(c) Insurance

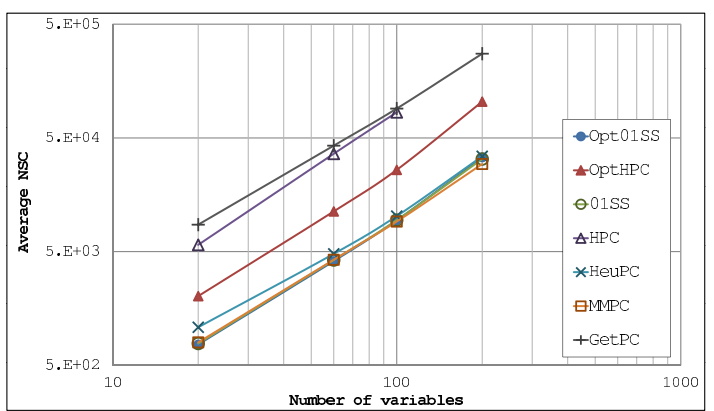

(b) Child

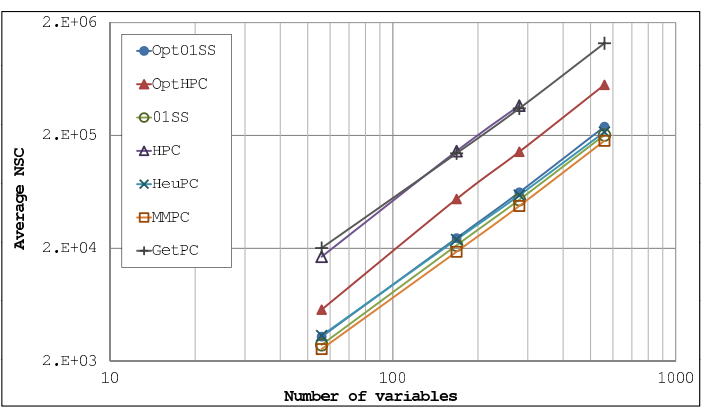

(d) Hailfinder

Figura 5.2: Resultados da métrica NSC (número de testes estatísticos). Cada subfigura apresenta resultados de uma rede básica e as suas extensões (Tabela 5.1). Cada curva mostra resultados de um determinado método, onde os pontos são plotados com valor de abscissa igual ao número de variáveis da rede e com valor de ordenada igual à média do índice NSC sobre todos os bancos de dados da mesma rede (média sobre os diferentes tamanhos amostrais). Os valores são mostrados em escala logarítmica em ambos os eixos dadas às grandes diferenças de grandeza dos resultados. 
Os resultados do índice NSC sugerem três grupos de métodos com comportamentos distintos: i) os métodos HPC e GetPC com valores de NSC significativamente maiores do que os outros métodos na maioria de redes avaliadas (embora GetPC apresenta uma escalabilidade melhor nas redes Alarm e Insurance); ii) o método OptHPC, com valores NSC intermediários e uma escalabilidade similar à de HPC; e iii) os métodos MMPC, Opt01SS, 01SS e HeuPC, os quais apresentam valores (e escalabilidades) similares do índice NSC, valores que são os mais baixos dentre de todos os métodos analisados (sendo MMPC o método que sobressai ligeiramente entre eles).

É interessante observar que o método proposto OptHPC usa em média somente $30 \%$ do número de chamadas estatísticas de HPC para obter praticamente a mesma resposta (como mostrado com os resultados de sensibilidade e especificidade), o qual destaca claramente a utilidade das otimizações computacionais implementadas em OptHPC para reduzir o número de testes estatísticos e aprender estruturas globais. O outro método proposto, Opt01SS, é encontrado apresentando valores NSC muito competitivos (os quais são em média os segundos melhores valores após MMPC). É interessante encontrar Opt01SS superando o índice NSC do método clássico 01SS na rede Alarm, já que Opt01SS pode ser visto como uma versão iterativa de 01SS e portanto era esperado maiores valores de NSC. Tal resultado pode ser entendido pela simplicidade da rede Alarm, a qual provavelmente apresenta um reduzido número de ADRs e portanto o número de iterações necessárias em Opt01SS para encontrar separadores robustos é também pequeno, que por sua vez permite que as otimizações computacionais implementadas em Opt01SS sejam evidenciadas (tais como o particionamento da adjacência das arestas, evitar condicionar em nós folhas e evitar revisar arestas com nós folhas).

Para ter uma ideia mais precisa da escalabilidade dos métodos testados, foi ajustada uma função exponencial $a n^{b}$ ( $n=$ número de variáveis; $a, b=$ constantes de ajuste) a cada curva da Figura 5.2. O método usado para realizar tais ajustes foi o método de mínimos quadrados. Os ajustes foram altamente representativos, tendo-se em média um coeficiente de aproximação $R^{2}$ de 0.997 e um desvio padrão de 0.002 . A Tabela 5.3 apresenta os expoentes $b$ das funções ajustadas, tendo-se valores próximos entre todos os métodos (variando entre 1.6 e 2 em média) com GetPC, MMPC e HeuPC apresentando os valores mais baixos, 01SS e Opt01SS apresentando valores intermédios e OptHPC e HPC apresentando os expoentes mais altos. A menor escalabilidade dos métodos propostos Opt01SS e OptHPC em relação aos métodos do estado-da-arte pode ser entendida pelo fato de que os métodos propostos realizam uma maior 
quantidade de testes estatísticos por variável para melhorar a taxa de erros falso-negativos, requerimento necessário para sistemas de aprendizagem híbridos como EES-BN.

Tabela 5.3: Expoentes (b) resultantes de ajustar a função $a n^{b}$ a cada curva da Figura 5.2 para estimar a escalabilidade dos métodos ( $n=$ numero de variáveis; $a, b=$ constantes de ajuste). O método usado para realizar tais ajustes foi o método de mínimos quadrados, obtendo-se em média um coeficiente de aproximação $R^{2}$ de 0.997 e um desvio padrão de 0.002 .

\begin{tabular}{lccccccc}
\hline Rede & \multicolumn{7}{c}{ Algoritmo } \\
& Opt01SS & OptHPC & 01 SS & HPC & HeuPC & MMPC & GetPC \\
\hline Alarm & 1.91 & 2.16 & 1.85 & 2.36 & 1.78 & 1.62 & 1.56 \\
Child & 1.64 & 1.70 & 1.61 & 1.67 & 1.49 & 1.56 & 1.50 \\
Insurance & 1.77 & 1.97 & 1.73 & 2.03 & 1.63 & 1.55 & 1.48 \\
Hailfinder & 1.86 & 1.99 & 1.85 & 1.92 & 1.80 & 1.84 & 1.81 \\
\hline Média & $\mathbf{1 . 7 9}$ & $\mathbf{1 . 9 6}$ & $\mathbf{1 . 7 6}$ & $\mathbf{2 . 0 0}$ & $\mathbf{1 . 6 8}$ & $\mathbf{1 . 6 4}$ & $\mathbf{1 . 5 9}$ \\
Desvio padrão & $\mathbf{0 . 1 0}$ & $\mathbf{0 . 1 7}$ & $\mathbf{0 . 1 0}$ & $\mathbf{0 . 2 5}$ & $\mathbf{0 . 1 3}$ & $\mathbf{0 . 1 2}$ & $\mathbf{0 . 1 3}$ \\
\hline
\end{tabular}

\subsection{Avaliação do operador de recombinação $M$ ergePop}

O desempenho do operador de recombinação MergePop é avaliado nesta seção contra o desempenho do operador original Merge em que ele esta baseado. Os bancos de dados empregados para esta avaliação são os bancos de 1000 amostras correspondentes às seguintes redes: Child, Child5, Insurance, Insurance5, Alarm e Alarm5 (Tabela 5.1). Em cada um desses bancos de dados é repetido por trinta vezes o seguinte experimento básico (também chamado de réplica) a fim de ter estatísticas suficientes de comparação:

1. gerar aleatoriamente uma população $\mathbf{P}$ de tamanho $w=50$ indivíduos (o número máximo de pais por nó é limitado a 6) e avaliar ela com a função de escore;

2. a cada indivíduo em $\mathbf{P}$ como indivíduo base aplicar os operadores Merge, MergePop (s=2), MergePop (s=3), MergePop (s=4), onde $s$ indica o tamanho da subpopulação de doadores (escolhidos também de $\mathbf{P}$ ). Os indivíduos filhos resultantes dessas operações são colocados então nas populações $\mathbf{Q}_{\mathbf{1}}, \mathbf{Q}_{\mathbf{2}}, \mathbf{Q}_{\mathbf{3}}, \mathbf{Q}_{4}$ respectivamente.

3. calcular a diferença de escores médios $\Delta_{i}$ de cada população filha $\mathbf{Q}_{\mathbf{i}}$ em relação à população pai $\mathbf{P}$, osu seja: $\Delta_{i}=\overline{s c o r e}\left(\mathbf{Q}_{\mathbf{i}}\right)-\overline{s c o r e}(\mathbf{P})$; armazenar também o tempo usado $t_{i}$ na geração de cada população $\mathbf{Q}_{\mathbf{i}}$; e

4. normalizar os valores $t_{i}$ e $\Delta_{i}$ dividindo eles pelos valores obtidos com o operador Merge $\left(t_{1}\right.$ e $\Delta_{1}$ respectivamente). 


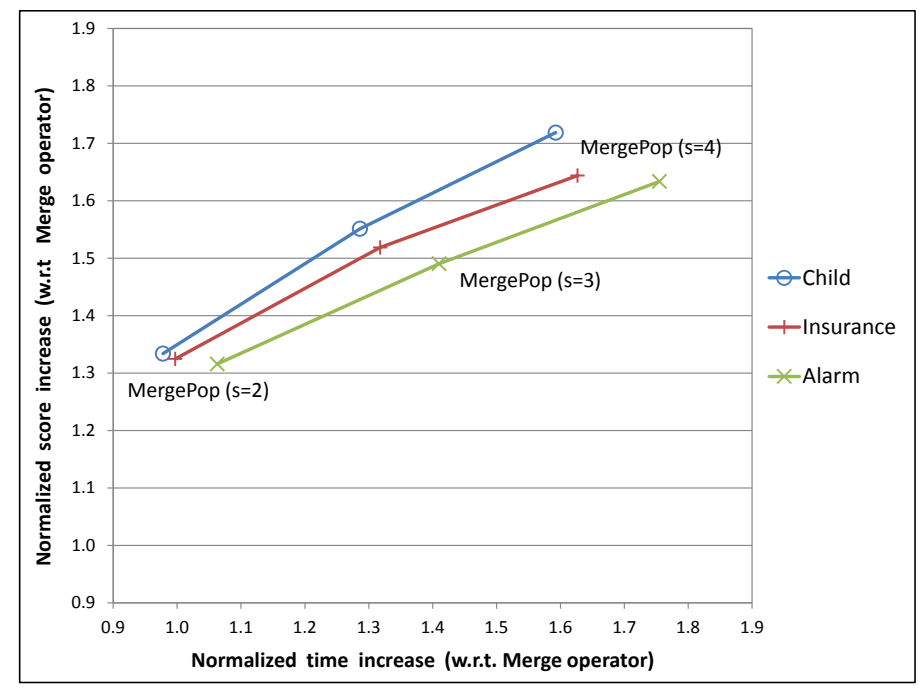

Figura 5.3: Resultados médios do aumento de escore normalizado como função do tempo computacional normalizado em 3 tamanhos de subpopulação de doadores de MergePop. Os resultados correspondem aos bancos de dados de 1000 amostras das redes básicas Child, Insurance e Alarm. O escore normalização é calculado como a razão dos aumentos de escore médios das populações filhas produzidas por MergePop e Merge em relação a suas populações pais. $\mathrm{O}$ tempo computacional normalizado é calculado como a razão dos tempos computacionais de MergePop e Merge em produzir a respectiva população filha.

A Figura 5.3 mostra para as 3 redes básicas testadas os resultados médios do aumento normalizado de escore $\Delta_{i}$ como função do tempo computacional normalizado em obter a população filha. É possível observar em todas as redes analisadas que o operador MergePop com somente dois indivíduos doadores $(s=2)$ consegue gerar uma população filha que melhora o escore da população pai em aproximadamente 1.3 vezes mais do que o operador Merge consegue melhorar, e o tempo de criação da população filha em MergePop com esse número de indivíduos doadores é aproximadamente igual ao tempo que Merge emprega para o mesmo propósito.

É observado também que ao aumentar o tamanho da subpopulação de doadores para 3 e 4 indivíduos aumenta também o ganho normalizado de escore na população filha e o tempo computacional para gerá-la. No entanto, o aumento do tempo computacional nesses casos tende a crescer a uma taxa um pouco maior do que o aumento normalizado do escore populacional. Essa tendência é ainda mais acentuada nas redes estendidas, tal como pode ser observado na Tabela 5.4. Por exemplo, na rede estendida Alarm 5 (a de maior dimensionalidade) com 2 indivíduos na população doadora tem-se um aumento normalizado do escore de 1.36 para um tempo normalizado de 1.34; já para 4 indivíduos na população doadora tem-se um aumento normalizado de escore de 1.72 com um tempo computacional normalizado de 2.24 . O aumento 
do custo computacional de MergePop ao aumentar o tamanho da subpopulação doadora é entendível pelo maior número de verificações e atualizações da matriz PNM que mantém a informação de conectividade da rede filha para decidir a incorporação de famílias nela. Contudo, os resultados sugerem que mantendo um número baixo do tamanho da subpopulação de doadores ( 2 ou 3 indivíduos) é possível ter um operador com um balanço positivo entre efetividade e custo na maioria dos casos. Para o restante dos experimentos apresentados neste capítulo será usado como operador de recombinação o operador MergePop com um tamanho da subpopulação de doadores $s=2$, a qual induz uma melhoria notável na qualidade dos filhos (em relação aos gerados pelo operador Merge) a um custo computacional marginal.

Tabela 5.4: Resultados médios do aumento normalizado de escore (ANE) e tempo computacional normalizado (TCN) no operador MergePop e três tamanhos da população de doadores (s). Os resultados correspondem aos bancos de dados de 1000 amostras das redes básicas e estendidas.

\begin{tabular}{|c|c|c|c|c|c|c|}
\hline \multirow[t]{2}{*}{ Rede } & \multicolumn{2}{|c|}{ MergePop (s=2) } & \multicolumn{2}{|c|}{ MergePop $(s=3)$} & \multicolumn{2}{|c|}{ MergePop $(s=4)$} \\
\hline & $\mathbf{T C N}$ & ANE & TCN & ANE & TCN & ANE \\
\hline Child & 0.98 & 1.33 & 1.29 & 1.55 & 1.59 & 1.72 \\
\hline Child5 & 1.11 & 1.33 & 1.48 & 1.52 & 1.84 & 1.64 \\
\hline Insurance & 1.01 & 1.32 & 1.32 & 1.52 & 1.63 & 1.64 \\
\hline Insurance 5 & 1.19 & 1.30 & 1.59 & 1.46 & 1.98 & 1.58 \\
\hline Alarm & 1.06 & 1.32 & 1.41 & 1.49 & 1.76 & 1.63 \\
\hline Alarm5 & 1.34 & 1.36 & 1.82 & 1.58 & 2.24 & 1.72 \\
\hline
\end{tabular}

\subsection{Avaliação dos blocos de recombinação, mutação e injeção de diversidade no desempenho de EES-BN}

Nesta seção é avaliada a contribuição relativa dos blocos de recombinação, mutação e injeção de diversidade no desempenho de EES-BN. Para tal fim são usados os mesmos bancos de dados da avaliação anterior e em cada um desses bancos s é realizado o seguinte experimento por trinta vezes a fim de ter resultados estatisticamente relevantes:

1. gerar de forma aleatória uma população $\mathbf{P}$ de tamanho $w=50$ indivíduos (o número máximo de pais por nó é limitado a 6) e avaliar ela com a função de escore;

2. executar EES-BN com $\mathbf{P}$ como população inicial e todos os seus blocos ativados. Finalizar a execução de EES-BN quando após nove injeções sucessivas de diversidade não se tem nenhum aumento no melhor escore da população ou quando são executadas 300 
gerações (o que ocorrer primeiro). Ao finalizar armazenar a melhor estrutura encontrada ( $\left.\operatorname{Dag}_{1}\right)$, o escore dela (score $\left.{ }_{1}\right)$, e o número de gerações realizados $\left(g_{1}\right)$;

3. executar EES-BN com $\mathbf{P}$ como população inicial e o bloco de injeção de diversidade desativado. Finalizar a execução de EES-BN após $g_{1}$ gerações, armazenado no final a melhor estrutura encontrada $\left(\operatorname{Dag}_{2}\right)$ e seu escore $\left(\right.$ score $\left._{2}\right)$;

4. executar EES-BN com $\mathbf{P}$ como população inicial e os blocos de injeção de diversidade e mutação desativados. Finalizar a execução de EES-BN após $g_{1}$ gerações, armazenado no final a melhor estrutura encontrada $\left(\operatorname{Dag}_{3}\right)$ e seu escore $\left(\right.$ score $\left._{3}\right)$;

5. calcular as diferenças em escore de cada estrutura obtida nos itens anteriores em relação ao escore médio da população inicial: $\Delta_{i}=\operatorname{score}_{i}-\overline{s c o r e}(P)$. Normalizar cada $\Delta_{i}$ dividindo eles pelo valor $\Delta_{1}$ (diferença em escore de EES-BN com todos seus blocos ativados);

6. para cada $D a g_{i}$ obter seu correspondente estrutura $P d a g_{i}$, que representa a classe de equivalência do $\operatorname{Dag}_{i}$. Para essa tarefa é usado o procedimento LABEL-EDGES de Chickering (2002));

7. calcular a distância estrutural SHD (do inglês Structural Hamming Distance) entre cada $\operatorname{Pdag}_{i}$ e o PDAG da estrutura verdadeira, tal como descrito por Tsamardinos et al. (2006a).

A distancia SHD é uma medida tradicional para inferir sobre a precisão de qualquer algoritmo de aprendizagem estrutural quando se conhece a estrutura a ser aprendida (Tsamardinos et al., 2006a; Yehezkel e Lerner, 2009), ela sumariza todos os erros estruturais cometidos pelos algoritmos de aprendizagem na recuperação da estrutura (ou seja, arestas ausentes, arestas extra, arestas dirigidas mal orientadas ou detectadas como não dirigidas).

A Figura 5.4 mostra um típico comportamento dos escores médios das populações evoluídas no experimento de acima num banco de dados da rede Alarm com tamanho amostral igual a 500. Pode ser observado que na etapa inicial da evolução (ao redor das primeiras dez gerações) as três configurações de EES-BN se comportam de maneira semelhante, partindo de um mesmo ponto (condição do experimento) e apresentando saltos grandes dos escores das populações, especialmente nas primeiras gerações. Isto confirma a habilidade do operador de recombinação MergePop em reconstituir rapidamente os blocos construtivos (famílias) espalhados na população inicial para produzir melhores indivíduos. 


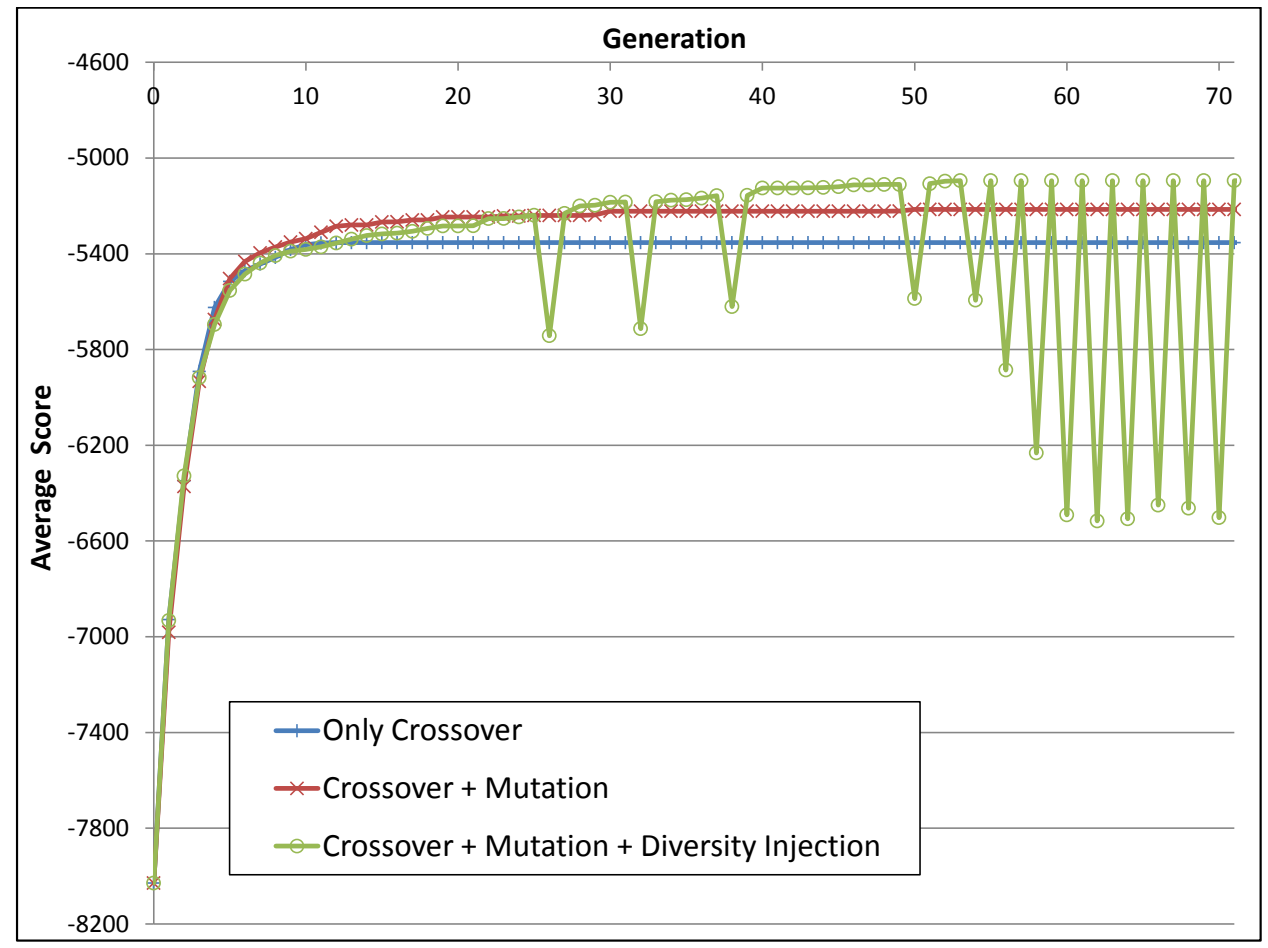

Figura 5.4: Evolução típica do escore médio da população em três configurações de EES-BN. Os resultados correspondem a um banco de dados de 500 amostras da rede Alarm. A população inicial foi a mesma para as três configurações

Após da etapa inicial de evolução, a configuração de EES-BN executando somente o bloco de recombinação mostra um escore populacional estável sem apresentar melhoras em gerações futuras. Resultado que era esperado desde que uma vez encontrada uma configuração ótima das famílias da população inicial não existe forma de melhorar ou introduzir novas famílias a serem assimiladas nessa configuração. Já nas outras configurações de EES-BN a situação é diferente. Na configuração com mutação é possível observar que depois da etapa inicial de evolução o escore médio da população continua a aumentar de uma forma vagarosa até aproximadamente 30 gerações em que o escore médio fica estável durante o resto da evolução. Isso evidencia que as mutações locais implementadas em EES-BN são efetivas em realizar ajustes finos nas famílias encontradas pela recombinação resultando eventualmente em melhores indivíduos. No entanto tal otimização baseada só em recombinação e mutação se torna cada vez menos efetiva a medida que o processo evolutivo avança.

Na configuração com os três blocos ativados em EES-BN é possível observar a importância que o bloco de injeção de diversidade desempenha em continuar melhorando a população uma vez que a evolução com os outros dois blocos chega a uma estagnação no escore populacional. Isso é observado nas 4 primeiras injeções de diversidade onde o escore médio cai fortemente 
Tabela 5.5: Resultados médios dos escores normalizados obtidos em EES-BN com os diferentes blocos ativados. A normalização é em relação ao aumento de escore médio que EES-BN consegue, com todos seus blocos ativados, desde a população inicial até a população final. Os números em parênteses indicam os correspondentes valores médios da distância estrutural SHD da rede aprendida em relação à classe de equivalência da rede verdadeira.

\begin{tabular}{lllll}
\hline Rede & Tamanho amostral & Recombinação & $\begin{array}{l}\text { Recombinação + } \\
\text { Mutação }\end{array}$ & $\begin{array}{l}\text { Recombinação + } \\
\text { Mutação + } \\
\text { Injeção de diversidade }\end{array}$ \\
\hline Child & 500 & $0.977(9.9)$ & $0.990(9.6)$ & $1.0(9.4)$ \\
Child & 1000 & $0.964(6.1)$ & $0.982(5.8)$ & $1.0(5.3)$ \\
\hline Child5 & 500 & $0.969(50.9)$ & $0.989(48.4)$ & $1.0(46.0)$ \\
Child5 & 1000 & $0.949(35.6)$ & $0.981(31.5)$ & $1.0(28.9)$ \\
\hline Insurance & 500 & $0.938(36.1)$ & $0.991(34.3)$ & $1.0(32.7)$ \\
Insurance & 1000 & $0.952(30.1)$ & $0.995(28.5)$ & $1.0(27.0)$ \\
\hline Insurance5 & 500 & $0.885(200.1)$ & $0.966(181.8)$ & $1.0(173.6)$ \\
Insurance5 & 1000 & $0.854(191.3)$ & $0.950(167.9)$ & $1.0(151.4)$ \\
\hline Alarm & 500 & $0.924(38.3)$ & $0.984(33.9)$ & $1.0(30.4)$ \\
Alarm & 1000 & $0.945(30.0)$ & $0.990(23.8)$ & $1.0(20.9)$ \\
\hline Alarm5 & 500 & $0.908(217.6)$ & $0.985(189.8)$ & $1.0(174.2)$ \\
Alarm5 & 1000 & $0.912(208.7)$ & $0.993(173.7)$ & $1.0(155.8)$ \\
\hline
\end{tabular}

devido a que os indivíduos injetados são geralmente menos adaptados do que os já evoluídos na população. No entanto, o escore da população é rapidamente recuperado e eventualmente superado nas poucas gerações seguintes pela ação dos operadores de recombinação e mutação. A melhoria do escore populacional é dada pelo fato de que os indivíduos injetados possuem famílias completamente novas, o qual aumenta a possibilidade de que alguma (ou várias) dessas famílias ao ser integradas em algum indivíduo da população (por recombinação) resulte em uma melhoria do seu escore. A acumulação das melhoras em escore populacional após cada injeção de diversidade bem sucedida resulta em indivíduos consideravelmente melhores do que os obtidos somente com recombinação e mutação na mesma quantidade de gerações.

A Tabela 5.5 apresenta os resultados médios dos escores normalizados das três configurações de EES-BN testadas. As médias foram calculadas sobre os resultados correspondentes a uma mesma rede e tamanho amostral (cinco bancos de dados e trinta experimentos em cada um deles). Estes resultados confirmam a tendência observada na Figura 5.4, sendo a configuração de EES-BN com só recombinação a que resulta no menor escore populacional em todos os casos. A segunda configuração (recombinação + mutação) apresenta valores normalizados de escore que estão próximos de 1 (valores da configuração de referência com os três blocos ativados). No entanto, a proximidade desses valores deve ser entendida de forma relativa, já que tais valores são normalizados em relação à faixa de variação do escore médio desde a população 
inicial até a otimizada com os três blocos de EES-BN agindo.

Complementado à informação de escore, a Tabela 5.5 mostra também os valores médios da distância estrutural SHD (em parênteses) das redes aprendidas em cada experimento em relação às classes de equivalência verdadeiras. É observado que pequenas diferenças de escores normalizados refletem diferenças significantes de precisão nas estruturas aprendidas. Um exemplo notório é dado nos experimentos da segunda configuração de EES-BN nos bancos de dados da rede Insurance5 com tamanho amostral 1000, onde tem-se um escore normalizado de 0.95 mas uma distância SHD que difere da distância SHD da terceira configuração em 17 erros estruturais.

\subsection{Avaliação da inicialização em EES-BN}

Os resultados prévios foram obtidos com a população inicial criada de forma aleatória. Nesta seção são apresentados resultados comparando essa inicialização com uma inicialização heurística baseada no método K2 (Cooper e Herskovits, 1992). Esta inicialização heurística consiste em gerar primeiro uma população de ordens ancestrais aleatórias das variáveis modeladas e logo cada uma dessas ordens é submetida ao método K2, o qual encontra (de forma greedy) a melhor estrutura consistente com a ordem. K2 foi implementado considerando somente as arestas da superestrutura na estrutura sendo aprendida. Ao igual que a inicialização aleatória, a inicialização com $\mathrm{K} 2$ restringe também o número de pais por nó a um máximo de 6 nós.

A Tabela 5.6 mostra os resultados médios de escore, distância SHD e número de gerações do melhor indivíduo obtido por EES-BN (com todos seus blocos ativos) para os dois tipos de inicializações testados. O critério de parada foi o mesmo da seção previa ( 9 injeções infrutíferas ou 300 gerações). Os resultados indicam que a inicialização heurística de EES-BN resulta sempre em uma melhoria dos índices analisados em relação à inicialização aleatória. Essa melhoria é especialmente notória nas redes de maior dimensionalidade (redes estendidas), onde o número de gerações para atingir o critério de parada cai significativamente quando usada a inicialização heurística, ao igual que a distância estrutural SHD. Esse resultado pode ser explicado pelo fato que os indivíduos resultantes de K2 possuem famílias de melhor qualidade do que as famílias dos indivíduos inicializados de forma aleatória, o qual facilita a convergência de EES-BN e também fornece maiores oportunidades de melhoria da qualidade dos indivíduos 
(já que o ponto de inicio é melhor).

Tabela 5.6: Resultados médios do escore (BDeu), numero de gerações e distância SHD do melhor indivíduo obtido por EES-BN com todos seus blocos ativos e duas formas de inicialização: inicialização aleatória e inicialização heurística com K2.

\begin{tabular}{llrrr|rrr}
\hline & & \multicolumn{2}{c}{ Inicialização aleatória } & \multicolumn{3}{c}{ Inicialização heurística com K2 } \\
Rede & Tamanho amostral & Melhor escore & Gerações & SHD & Melhor escore & Gerações & SHD \\
\hline Child & 500 & -6498.5 & 44 & 9.4 & -6493.4 & 32 & 8.1 \\
Child & 1000 & -12728.3 & 55 & 5.3 & -12690.0 & 42 & 3.4 \\
\hline Child5 & 500 & -35129.8 & 79 & 46.0 & -35073.1 & 42 & 38.5 \\
Child5 & 1000 & -66715.3 & 81 & 28.9 & -66619.6 & 40 & 19.3 \\
\hline Insurance & 500 & -7281.2 & 67 & 32.7 & -7215.7 & 44 & 24.9 \\
Insurance & 1000 & -14093.2 & 58 & 27.0 & -13992.1 & 51 & 20.0 \\
\hline Insurance5 & 500 & -41194.4 & 172 & 173.6 & -40912.9 & 105 & 142.3 \\
Insurance5 & 1000 & -78059.7 & 207 & 151.4 & -77358.4 & 134 & 103.1 \\
\hline Alarm & 500 & -5145.1 & 67 & 30.4 & -5096.2 & 62 & 16.9 \\
Alarm & 1000 & -9926.2 & 72 & 20.9 & -9876.5 & 64 & 11.8 \\
\hline Alarm5 & 500 & -31839.8 & 245 & 174.2 & -31715.0 & 149 & 130.9 \\
Alarm5 & 1000 & -61380.6 & 254 & 155.8 & -61194.6 & 193 & 109.1 \\
\hline
\end{tabular}

\subsection{Comparação de EES-BN contra outros algoritmos representa- tivos de aprendizagem estrutural}

Nesta seção é apresentado um estudo comparativo do desempenho de EES-BN contra os seguintes métodos de aprendizagem estrutural de RBs:

GAK2 (Larranaga et al., 1996a): método evolutivo clássico baseado num algoritmo genético para otimizar ordens ancestrais acoplado com a heurística K2 para avaliação das ordens;

- Cooperative Coevolutionary Genetic Algorithm - CCGA (Carvalho, 2011): método recente para aprender RBs evoluindo de forma simultânea e cooperativa populações de ordens ancestrais e populações de esqueletos;

- Greedy Search Hill-climbing com lista Tabu - GS (Chickering e Boutilier, 2002; Teyssier e Koller, 2005): clássico método de aprendizagem de RBs baseado em busca greedy.

Hybrid Max-Min Hill-Climbing - MMHC (Tsamardinos et al., 2006a): método híbrido de aprendizagem baseado em redução do espaço com testes de independências e logo otimização greedy da estrutura. 
A seleção destes métodos foi baseada na sua representatividade na literatura. O método GAK2 foi incluído dado que ele representa vários outros métodos evolutivos de aprendizagem no espaço de ordens, tal como (Hsu et al., 2002; Faulkner, 2007; dos Santos et al., 2010a,b). A implementação usada para GAK2 foi a realizada pelo autor da presente tese, já que não foi encontrada uma implementação pública para este. Os operadores genéticos implementados em GAK2 foram o OX2 (do inglês order-based crossover) para recombinação e o DM (do inglês displacement mutation) para mutação, operadores descritos no artigo original de GAK2 e cujos desempenhos destacaram num estudo comparativo realizado nesse mesmo trabalho. A rotina K2 dentro de GAK2 foi também limitada a 6 pais por nó, tal como os experimentos anteriores.

O método CCGA foi incluído nesta comparação dado que ele é um dos últimos algoritmos evolutivos propostos para aprendizagem estrutural de RBs e que constitui um método representativo no espaço de busca misto de ordens e esqueletos. A implementação usada para CCGA foi a disponibilizada pelos seus autores no site [http://www. cs . uwaterloo. ca/ a3carval/publications.html].

O método GS foi incluído nesta avaliação dada sua relevância na literatura devido a sua simplicidade e efetividade (Teyssier e Koller, 2005). GS tem sido usado em várias aplicações inovadoras (por exemplo, Friedman et al. (2000) e Yu et al. (2004)) e implementado como método de aprendizagem padrão em diversos pacotes de software de RBs (tal como o Bayes Net Toolbox de Murphy (2001) e o Causal Explorer Toolkit de Aliferis et al. (2003)). No presente estudo foi usada a implementação de GS disponível no pacote Causal Explorer, o qual pode ser obtido no site [http://www.dsl-lab.org/causal_explorer].

O método MMHC foi considerado no presente estudo dada sua popularidade e representatividade como método híbrido. No trabalho original foi mostrado empiricamente que MMHC consegue superar o desempenho de vários métodos de aprendizagem estrutural de RBs do estado-da-arte, tal como PC (Spirtes et al., 2000), SC (Friedman et al., 1999), TPDA (Cheng et al., 2002) e GES (Chickering e Boutilier, 2002). A implementação usada para MMHC nesta comparação foi também a disponível no pacote Causal Explorer.

Todos os métodos comparados estão codificados em Matlab ${ }^{\circledR}$ (embora os métodos de GS e MMHC estão disponibilizados como funções protegidas de Matlab ( $p$-codes) e portanto não é possível acessar a seus códigos fontes). Os experimentos foram executados na versão de Matlab R2008a sobre um computador pessoal Intel ${ }^{\circledR}$ Core $^{\mathrm{TM}} 2$ Quad @ 2.83Ghz com 4GB de memória RAM rodando Windows ${ }^{\circledR}$ 7.0. EES-BN foi rodado com todos seus blocos ativados e com 
critério de parada igual aos experimentos anteriores ( 9 injeções infrutíferas ou 300 gerações). O critério de parada configurado para GAK2 e CCGA foi atingir um número de chamadas à função de escore igual a 5 vezes o empregado por EES-BN para convergir. Isso foi feito a fim de verificar se tais métodos conseguem superar a precisão de EES-BN usando esse número aumentado de chamadas à função de escore.

Em cada banco de dados da seção anterior foi realizado o seguinte experimento básico (repetido trinta vezes) com os algoritmos evolutivos (EES-BN, GAK2 e CCGA) :

1. gerar uma população $\mathbf{P}$ de tamanho $w=50$ indivíduos de forma heurística com $\mathrm{K} 2$ (tal como descrito na Seção 5.5);

2. executar EES-BN com $\mathbf{P}$ como população inicial, armazenando no final o escore do melhor indivíduo encontrado, a distância estrutural SHD dele em relação à classe de equivalência verdadeira, o tempo de execução e o número de estatísticas usadas (número de chamadas à função de teste de independência $D e p+$ número de chamadas à função de escore);

3. executar GAK2 e CCGA com $\mathbf{P}$. Usar $\mathbf{P}$ como população inicial de CCGA e as ordens ancestrais de $\mathbf{P}$ como população inicial de GAK2 (dado que este método só trabalha no espaço de ordens). Interromper a execução quando o numero de chamadas à função de escore supera 5 vezes o número de estatísticas usadas por EES-BN (verificação realizada ao final de cada geração). Registrar ao final o escore da melhor estrutura encontrada, a distância SHD dessa estrutura em relação à classe de equivalência verdadeira e o tempo de execução.

A ideia de inicializar todos os algoritmos evolutivos com a mesma população inicial foi para descontar os efeitos da variabilidade da mesma e assim medir unicamente a eficiência de aprendizado desses algoritmos. Os experimentos nos métodos GS e MMHC consistiram em executar eles somente uma vez por cada banco de dados, dada sua natureza determinística (fornecem sempre a mesma resposta). Nenhuma população inicial foi fornecida a GS e MMHC já que tal população é determinada internamente na implementação de Causal Explorer.

As Tabelas 5.7 e 5.8 mostram os resultados médios dos experimentos acima descritos para as medidas de escore e distância SHD respectivamente. O desvio padrão desses resultados é indicado em parênteses. Em relação aos resultados de escore é possível observar uma tendência geral de EES-BN em apresentar os valores mais altos (em negrito) entre todos os métodos, 
Tabela 5.7: Resultados médios de escore (BDeu) das estruturas obtidas por diferentes métodos de aprendizagem estrutural de RBs. Os números em parênteses correspondem aos desvios padrões dos resultados. Os números em negrito indicam os melhores valores na respectiva rede e tamanho amostral.

\begin{tabular}{lllllll}
\hline Rede & Tamanho amostral & EES-BN & GAK2 & CCGA & GS & MMHC \\
\hline Child & 500 & $\mathbf{- 6 4 9 3 . 4}(0.0)$ & $-6527.7(22.8)$ & $-6609.4(36.9)$ & $-6497.3(0.0)$ & $-6500.3(0.0)$ \\
Child & 1000 & $\mathbf{- 1 2 6 9 0 . 0}(0.0)$ & $-12726.1(26.3)$ & $-12922.9(62.5)$ & $\mathbf{- 1 2 6 9 0 . 0}(0.0)$ & $-12692.7(0.0)$ \\
\hline Child5 & 500 & $-35075.3(7.2)$ & $-35501.8(98.2)$ & $-36375.4(74.2)$ & $-34805.1(0.0)$ & $-\mathbf{3 4 6 0 2 . 8}(0.0)$ \\
Child5 & 1000 & $\mathbf{- 6 6 6 1 8 . 4}(4.6)$ & $-68811.0(98.9)$ & $-69445.9(123.8)$ & $-66882.1(0.0)$ & $-67093.9(0.0)$ \\
\hline Insurance & 500 & $\mathbf{- 7 2 1 4 . 1}(3.0)$ & $-7319.1(23.3)$ & $-7445.3(49.9)$ & $-7310.3(0.0)$ & $-7372.1(0.0)$ \\
Insurance & 1000 & $\mathbf{- 1 3 9 8 2 . 5}(6.7)$ & $-14152.3(47.5)$ & $-14335.3(93.9)$ & $-14008.0(0.0)$ & $-14218.2(0.0)$ \\
\hline Insurance5 & 500 & $-40907.9(25.7)$ & $-42561.2(180.9)$ & $-43755.2(140.7)$ & $\mathbf{- 4 0 7 0 6 . 8}(0.0)$ & $-41660.9(0.0)$ \\
Insurance5 & 1000 & $\mathbf{- 7 7 3 5 1 . 7}(99.4)$ & $-81625.6(291.1)$ & $-84083.2(334.2)$ & $-78204.3(0.0)$ & $-79939.3(0.0)$ \\
\hline Alarm & 500 & $\mathbf{- 5 0 9 4 . 6 ( 1 0 . 4 )}$ & $-5204.9(36.4)$ & $-5424.1(52.3)$ & $\mathbf{- 5 0 8 3 . 2}(0.0)$ & $-5150.8(0.0)$ \\
Alarm & 1000 & $\mathbf{- 9 8 7 5 . 0}(11.5)$ & $-10084.5(50.3)$ & $-10356.0(125.1)$ & $-9944.9(0.0)$ & $-9914.5(0.0)$ \\
\hline Alarm5 & 500 & $\mathbf{- 3 1 7 1 3 . 2}(29.2)$ & $-32823.9(67.9)$ & $-34008.1(147.9)$ & $-31793.5(0.0)$ & $-32306.9(0.0)$ \\
Alarm5 & 1000 & $\mathbf{- 6 1 1 9 5 . 7}(55.3)$ & $-63345.0(147.2)$ & $-65508.4(241.4)$ & $-61419.9(0.0)$ & $-61923.5(0.0)$ \\
\hline
\end{tabular}

redes e tamanhos amostrais testados. Os métodos GS e MMHC apresentam valores de escore próximos a EES-BN e em alguns poucos casos superam ele (GS nos bancos de 500 amostras de Alarm e Insurance5 e MMHC nos bancos de 500 amostras da rede Child5). No entanto, ao observar os valores de SHD nesses casos é encontrado que as estruturas aprendidas por EESBN são de maior proximidade à classe de equivalência verdadeira do que os outros métodos. De maneira semelhante, ao comparar os resultados entre GS e MMHC é encontrado que de modo geral MMHC aprende estruturas mais próximas da verdadeira (segundo o índice SHD) do que GS, apesar de que este último oferece maiores valores de escore. É possível inferir portanto a partir desses resultados que a busca da estrutura num espaço restringido, tal como EES-BN e MMHC, tem um efeito positivo na precisão do aprendizado, efeito que não necessariamente se condiz com os resultados de escore em buscas irrestritas. Contudo, EES-BN mostrou em todos os casos a melhor a capacidade em recuperar estruturas mais próximas da estrutura verdadeira (valores em negrito na Tabela 5.8), resultado que é especialmente notório nas redes de maior dimensão.

Os métodos evolutivos GAK2 e CCGA apresentam em média os valores mais baixos em escore e os mais altos em SHD, valores que são marcadamente distantes dos outros métodos. Esses resultados são ainda mais contrastantes ao considerar que tais métodos foram executados desde o mesmo ponto de partida que EES-BN e foram permitidos usar até cinco vezes o número de chamadas estatísticas que EES-BN usa para convergir. 
Tabela 5.8: Resultados médios da distância SHD (em relação à classe de equivalência verdadeira) das estruturas obtidas por diferentes métodos de aprendizagem estrutural de RBs. Os números em parênteses correspondem aos desvios padrões dos resultados. Os números em negrito indicam os melhores valores na respectiva rede e tamanho amostral.

\begin{tabular}{lllllll}
\hline Rede & Tamanho amostral & EES-BN & GAK2 & CCGA & GS & MMHC \\
\hline Child & 500 & $\mathbf{8 . 1}(0.2)$ & $10.0(1.0)$ & 11.6 & $12.0(0.0)$ & $11.0(0.0)$ \\
Child & 1000 & $\mathbf{3 . 4}(0.5)$ & $6.6(1.8)$ & $10.1(2.1)$ & $4.0(0.0)$ & $4.0(0.0)$ \\
\hline Child5 & 500 & $\mathbf{3 8 . 7}(1.7)$ & $82.4(3.3)$ & $75.8(3.8)$ & $66.0(0.0)$ & $41.0(0.0)$ \\
Child5 & 1000 & $\mathbf{1 9 . 3}(0.4)$ & $71.7(5.0)$ & $63.6(4.8)$ & $29.0(0.0)$ & $35.0(0.0)$ \\
\hline Insurance & 500 & $\mathbf{2 4 . 7}(0.7)$ & $33.1(3.6)$ & $37.3(4.0)$ & $32.0(0.0)$ & $32.0(0.0)$ \\
Insurance & 1000 & $\mathbf{1 9 . 3}(0.4)$ & $29.9(4.0)$ & $34.1(3.6)$ & $28.0(0.0)$ & $28.0(0.0)$ \\
\hline Insurance5 & 500 & $\mathbf{1 4 0 . 7}(3.1)$ & $233.1(15.6)$ & $213.3(8.3)$ & $188.0(0.0)$ & $163.0(0.0)$ \\
Insurance5 & 1000 & $\mathbf{1 0 0 . 0}(2.3)$ & $226.6(10.1)$ & $207.3(7.8)$ & $175.0(0.0)$ & $148.0(0.0)$ \\
\hline Alarm & 500 & $\mathbf{1 6 . 6}(2.5)$ & $41.5(4.1)$ & $40.4(3.9)$ & $25.0(0.0)$ & $22.0(0.0)$ \\
Alarm & 1000 & $\mathbf{1 1 . 7}(1.8)$ & $38.9(4.8)$ & $38.0(4.5)$ & $24.0(0.0)$ & $13.0(0.0)$ \\
\hline Alarm5 & 500 & $\mathbf{1 3 0 . 4}(4.4)$ & $291.7(11.0)$ & $214.6(14.8)$ & $224.0(0.0)$ & $146.0(0.0)$ \\
Alarm5 & 1000 & $\mathbf{1 1 0 . 7}(3.5)$ & $275.4(10.1)$ & $216.1(10.8)$ & $198.0(0.0)$ & $126.0(0.0)$ \\
\hline
\end{tabular}

Outro aspecto interessante observado em EES-BN é a sua maior previsibilidade em relação aos outros métodos evolutivos. Isso é observado nos desvios padrões dos resultados de escore e distância SHD, onde EES-BN tende a encontrar estruturas menos variáveis ao longo das repetições dos experimentos. Um exemplo notável disso é encontrado na rede Child nos dois tamanhos amostrais testados, onde EES-BN retorna sempre uma estrutura com o mesmo valor de escore. É observado também que a variabilidade dos índices medidos aumenta com o aumento da dimensão da rede, o qual é compreensível já que a complexidade do espaço de busca aumenta drasticamente nesses casos. No entanto é destacável a contrastante redução da variabilidade de EES-BN em relação aos outros métodos evolutivos estudados.

Em relação aos tempos computacionais, a Tabela 5.9 mostra os resultados médios de tempo de execução dos distintos métodos, redes e tamanhos amostrais testados. Pode ser observado que o método MMHC apresenta os menores valores de tempo de execução entre todos os métodos, o que confirma os notáveis resultados de tempo computacional informados no artigo original (Tsamardinos et al., 2006a) e também a vantagem de usar uma abordagem híbrida. O método GS apresenta os segundos menores tempos de execução nas redes básicas, mas nas redes estendidas o tempo de execução tende a aumentar a uma velocidade superior do que os outros métodos, sendo superado nessas redes por EES-BN (mostrando os segundos melhores tempos) e em alguns casos por CCGA e GAK2. O rápido aumento do tempo de execução de GS com o número de variáveis pode ser compreendido pelo superexponencial aumento do número de op- 
Tabela 5.9: Resultados médios de tempo de execução (em segundos) usados por diferentes métodos de aprendizagem estrutural de RBs. Os números em parênteses correspondem aos desvios padrões dos resultados. Os números em negrito indicam os melhores valores na respectiva rede e tamanho amostral.

\begin{tabular}{lllllll}
\hline Rede & Tamanho amostral & EES-BN & GAK2 & CCGA & GS & MMHC \\
\hline Child & 500 & $10.5(2.1)$ & $21.3(2.6)$ & $20.3(2.1)$ & $3.9(0.0)$ & $\mathbf{3 . 1}(0.0)$ \\
Child & 1000 & $15.2(3.1)$ & $29.5(4.8)$ & $26.4(4.9)$ & $5.7(0.0)$ & $\mathbf{5 . 3}(0.0)$ \\
\hline Child5 & 500 & $81.7(14.8)$ & $239.9(11.4)$ & $101.6(23.8)$ & $107.5(0.0)$ & $\mathbf{2 5 . 0}(0.0)$ \\
Child5 & 1000 & $95.9(11.4)$ & $276.9(12.5)$ & $110.5(13.7)$ & $308.4(0.0)$ & $\mathbf{3 6 . 0}(0.0)$ \\
\hline Insurance & 500 & $18.7(4.2)$ & $50.3(14.0)$ & $46.0(15.0)$ & $6.0(0.0)$ & $\mathbf{4 . 8}(0.0)$ \\
Insurance & 1000 & $21.1(4.6)$ & $46.1(8.7)$ & $41.9(7.0)$ & $12.8(0.0)$ & $\mathbf{9 . 2}(0.0)$ \\
\hline Insurance5 & 500 & $301.2(93.2)$ & $649.9(116.7)$ & $459.7(159.0)$ & $353.1(0.0)$ & $\mathbf{4 8 . 9}(0.0)$ \\
Insurance5 & 1000 & $394.2(84.9)$ & $806.7(155.5)$ & $572.0(157.8)$ & $562.0(0.0)$ & $\mathbf{7 8 . 1}(0.0)$ \\
\hline Alarm & 500 & $33.2(6.0)$ & $69.2(14.9)$ & $59.9(10.3)$ & $13.6(0.0)$ & $\mathbf{6 . 6}(0.0)$ \\
Alarm & 1000 & $39.3(9.4)$ & $88.1(18.4)$ & $73.1(18.3)$ & $18.9(0.0)$ & $\mathbf{7 . 0}(0.0)$ \\
\hline Alarm5 & 500 & $411.0(87.2)$ & $1296.1(188.6)$ & $694.5(246.7)$ & $995.1(0.0)$ & $\mathbf{6 1 . 7}(0.0)$ \\
Alarm5 & 1000 & $601.1(108.3)$ & $1302.8(148.2)$ & $849.8(242.6)$ & $1274.6(0.0)$ & $\mathbf{7 9 . 4}(0.0)$ \\
\hline
\end{tabular}

ções a avaliar em cada movimento do algoritmo, sendo provavelmente o acesso/atualização da lista tabu o principal gargalo desse método. Os tempos computacionais de EES-BN se mostram também competitivos em todos os experimentos, superando notavelmente aos outros métodos evolutivos.

É importante destacar que os resultados de tempo devem ser tomados como indicativos de eficiência temporal e não como evidência absoluta. Isto porque os tempos usados pelos algoritmos evolutivos são fortemente dependentes do critério de parada, o qual foi configurado de forma rigorosa nos experimentos a fim de estudar com maior ênfase os limites de precisão dos algoritmos evolutivos. É possível diminuir os tempos de convergência mediante um relaxamento do critério de parada, mas possivelmente incorrendo em algum detrimento da qualidade das soluções. O balanço tempo/qualidade fica portanto a critério do utilizador e da aplicação abordada. Já nos métodos MMHC e GS não é possível manipular esse balanço (não de forma direta) dada a sua natureza determinística. É importante ressaltar também que as implementações usadas de MMHC e GS na presente avaliação foram as disponíveis no pacote Causal Explorer, não obstante, o código fonte desse pacote não é acessível dado que foi liberado como um conjunto de arquivos protegidos de Matlab ( $p$-codes) e portanto não é possível conhecer se todo o pacote foi codificado em Matlab ou se algumas partes dele foram codificadas em alguma outra linguagem de maior desempenho. Se for verdade este último, as comparações de tempo não estariam refletindo fielmente as eficiências temporais desses métodos. 


\section{Capítulo 6}

\section{Aplicações}

Neste capítulo são apresentadas duas aplicação de EES-BN em problemas reais da área de bioinformática. A primeira aplicação, mostrada na Seção 6.1, é num problema de modelagem de iterações entre genes usando dados de expressão gênica obtidos por tecnologias de microarray. Na Seção 6.2 é apresentada a segunda aplicação no problema de modelagem associações entre marcadores genéticos, problema conhecido como desequilíbrio de ligação.

\subsection{Aplicação na modelagem da rede gênica do sistema de regula- ção do ciclo celular da levadura (Saccharomyces cerevisiae)}

Um dos objetivos centrais em biologia molecular é compreender como os diversos genes de um organismo interagem entre si para produzir uma função ou característica fenotípica. As técnicas de DNA microarray (Stekel, 2003) têm sido a principal ferramenta tecnológica usada nas últimas duas décadas para avançar nesse objetivo.

Brevemente, um microarray (também conhecido como DNA-chip) consiste de um arranjo de moléculas de DNA (oligonucleotídeos, fragmentos de DNA genômico ou cDNA (DNA complementar)) que são colocadas em diminutos pontos (spots) de uma superfície sólida (usualmente uma lâmina de vidro ou uma película fina de silício), formando uma organização em grade pré-definida. Os microarrays são usados para detetar a presença e abundância de ácidos nucleicos (como o RNA mensageiro (mRNA) codificado pelos genes) provenientes de amos-

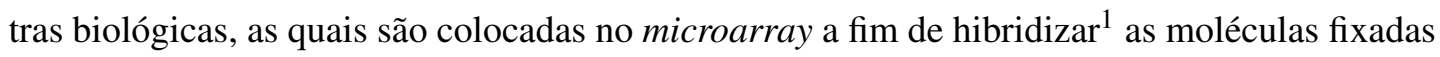

\footnotetext{
${ }^{1}$ A hibridização no contexto de microarrays é o processo de uma molécula de DNA ou RNA estabelecer ->
} 
nele. A detecção da abundância é possível já que as amostras são "rotuladas"com químicos fluorescentes (sensíveis à luz ultravioleta ou radiação). Uma vez que o microarray é hibridizado e lavado das moléculas que não conseguiram se ligar ao mesmo é realizado um processo de "leitura"do microarray. Nesse processo, o microarray é colocado num scanner o qual usa um feixe de luz para estimular o microarray e medir a intensidade de fluorescência dos spots hibridizados pela amostra e consequentemente a abundância dos ácidos nucleicos na amostra. $\mathrm{O}$ resultado da técnica de microarray é normalmente uma imagem digital com cada spot representando um gene em particular e cuja intensidade é proporcional à quantidade relativa do mRNA (também chamado transcript) sendo transcrito por esse gene na amostra, o que indiretamente representa o nível de expressão do gene (Stekel, 2003).

Mediante o uso de microarrays é possível inferir hoje em dia a expressão de milhares de genes de um organismo dado de forma simultânea. Uma constatação notável dessa possibilidade é o repositório público Gene Expression Omnibus - $G E O^{2}$, o qual contem atualmente mais de 30000 conjuntos de dados obtidos com técnicas de microarray de uma grande diversidade de organismos e com finalidades diversas, desde a identificação de redes de regulação gênica de funções celulares até a compreensão das bases gênicas de determinadas doenças.

Um dos organismos eucarióticos que tem sido frequentemente usado como organismo modelo nas pesquisas de biologia e biologia molecular é a levedura (Saccharomyces cerevisiae). $\mathrm{Na}$ literatura recente é possível encontrar uma grande quantidade de artigos revelando diversas iterações a nível gênico-molecular desse organismo (uma revisão extensiva pode ser encontrada em (Botstein e Fink, 2011)), tendo-se nos dias de hoje certo consenso nas iterações de vários genes. A enciclopédia de genes e genomas de Kyoto - $\mathrm{KEGG}^{3}$ (do inglês Kyoto Encyclopedia of Genes and Genomes), um sistema referencial de conhecimento de alto nível que integra, sumariza e depura informação molecular de múltiplas fontes, mostra por exemplo mapas detalhados de várias funções sistêmicas importantes da levedura a nível genômico.

Motivados por essa relativa disponibilidade de conhecimento molecular da levedura, é que ele foi escolhido para testar o método proposto EES-BN na sua capacidade de reconstruir redes biologicamente sensíveis. A função biológica escolhida é a regulação do ciclo celular (também chamado de cell-cycle pathway), função que tem sido alvo de diversas pesquisas, tal como Amon et al. (1994), Spellman et al. (1998), Li et al. (2004) e Bahler (2005). Os dados usados

\footnotetext{
-> uma ligação com outra molécula da mesma natureza por complementaridade de bases.

${ }^{2}$ http://www.ncbi.nlm.nih.gov/geo/

${ }^{3}$ http: // www.kegg . jp
} 
para esta aplicação foram tomados do trabalho original de Spellman et al. (1998), os quais estão livremente disponíveis no site http: / / genome-www. stanford.edu/cellcycle. Esses dados consistem de 76 medições de microarrays de levedura, cada medição estimando a expressão de 6177 genes (especificamente, 6177 mRNAs transcritos pelas sequências codificantes dos respectivos genes, também conhecidos como ORFs (do inglês open reading frame)). As medições correspondem a seis series temporais de culturas de levedura, as quais foram obtidas mediante uma captura inicial delas em um mesmo ponto do ciclo celular (usando diferentes formas de sincronização) e logo deixadas a evoluir nas suas fases celulares, medindo a cada certo intervalo de tempo a expressão dos genes. No trabalho de Spellman et al. (1998) foram identificados 800 genes cuja expressão é afetada pelas fases do ciclo celular (a determinação desse conjunto foi feita com técnicas de correlação e análise de periodicidade). Apesar dessa grande quantidade de genes identificados com expressão sensível ao ciclo celular, a enciclopédia KEGG somente reporta 125 genes (no momento da escrita da presente tese) provados biologicamente agindo na regulação do cell-cycle pathway. Dada essa divergência, na presente aplicação foram considerados para análise aqueles genes que estão na interseção dos dois conjuntos, ou seja, os genes que foram provados estar envolvidos na regulação do ciclo celular da levedura e que também apresentam um mínimo de sensibilidade da sua expressão gênica com relação ao ciclo celular no banco de dados escolhido. Em total foram encontrados 50 genes satisfazendo esse critério, os quais são mostrados na Figura 6.1. Com esta aplicação é pretendido testar o potencial do método proposto EES-BN em recuperar iterações gênicas com base biológica estabelecida a partir do banco de poucas amostras escolhido (característica comum dos bancos de dados de microarray).

\section{Pré-processamento dos dados:}

A matriz de dados considerada na presente análise é formada por 76 linhas (microarrays que constituem as observações ou amostras do banco de dados) e 50 colunas (genes que constituem as variáveis medidas), extraída da matriz original de Spellman et al. (1998). Os valores estão em escala logarítmica (em base 2) e normalizados por médias das colunas, assim um valor de 1 para uma determinada amostra e gene indica que esse gene tem uma expressão duas maior que a expressão média do gene em todas as amostras. Vários elementos da matriz de dados têm valores faltantes (usual em dados de microarray devido a fatores laboratoriais e de medição). Especificamente, as amostras cdc28_130 e cdc28_140 apresentavam valores faltantes em mais de $25 \%$ dos genes selecionados, razão pela qual foram descon- 
sideradas da análise. A fim de não descartar mais amostras, os valores faltantes no resto dos dados (52 elementos da matriz) foram imputados usando o algoritmo BPCA (do inglês Bayesian principal component analysis) (Oba et al., 2003), algoritmo que foi desenvolvido para imputar dados de expressão gênica e que tem apresentado uma alta aceitação na literatura. A implementação usada para BPCA foi a disponibilizada por seus autores no site http://hawaii.sys.i.kyoto-u.ac.jp/ oba/tools, a qual está codificada em Matlab. Os parâmetros usados para BPCA foram os predefinidos nessa implementação (100 épocas e precisão menor a 1e-4).

Uma vez que os dados foram completados, eles foram submetidos a um processo de discretização. Esse processo consiste em atribuir cada elemento da matriz de dados a três categorias possíveis (tal como sugerido por Friedman et al. (2000) e Wang et al. (2007)):

。 sobre-expressão: quando o valor log-normalizado de expressão é maior a 0.5 ( $\sqrt{2}$ vezes maior que o valor de referência);

- normal: quando o valor log-normalizado de expressão esta entre - 0.5 e 0.5 ; e

- sub-expressão: quando o valor log-normalizado de expressão é menor que -0.5 ( $\sqrt{2}$ vezes menor que o valor referência).

Após obter a matriz discretizada $D$ (tamanho 74 x 50) foram geradas 100 versões bootstrap dela, $D_{1}, D_{2}, \ldots, D_{100}$, usando reamostragem com reposição, tal como sugerido em (Friedman et al., 1999, 2000). A função bootstrp do Statistics Toolbox ${ }^{T M}$ de Matlab foi usada para realizar a operação de reamostragem. A ideia de gerar várias versões boostrap do banco de dados original foi para poder inferir a robustez das relações aprendidas, como descrito abaixo.

\section{Aprendendo estruturas robustas com EES-BN}

EES-BN foi executado em cada versão bootstrap $D_{i}$ como banco de dados de entrada. Os parâmetros configurados para EES-BN em todas as execuções foram:

- critério de parada: 13 injeções de diversidade seguidas sem sucesso ou 800 gerações (o que ocorrer primeiro);

- tamanho da população: $w=50$;

- tamanho da subpopulação de doadores para MergePop: $s=2$;

- máximo número de pais por nó na inicialização com K2: $u=3$; 
- parâmetros do bloco de injeção de diversidade: $r_{\min }=0.1 \mathrm{w}, r_{\max }=0.5 \mathrm{w}, r_{\text {inc }}=$ $0.1 w$ e $\Delta=0$

De cada execução de EES-BN sobre $D_{i}$ é obtido um corespondente DAG $D a g_{i}$, onde os nós representam os genes analisados e as arestas as relações de dependência encontradas entre os genes. Dado que os dados usados são puramente observacionais, não existe razão para diferenciar DAGs da mesma classe de equivalência (Friedman et al., 2000). Assim, cada $D a g_{i}$ é transformado em uma representação CPDAG, $C p d a g_{i}$, que codifica a classe de equivalência à que $\operatorname{Dag}_{i}$ pertence. Tal transformação é realizada com o procedimento LABEL-EDGES descrito por Chickering (2002).

Com todas as 100 estruturas CPDAGs obtidas foi aplicado o seguinte procedimento para sintetizar todos os CPDAGs em uma única estrutura de grafo $S_{b s t r}$, chamada de estrutura robusta:

1. inicializar $S_{b s t r}$ como um grafo desconexo (sem arestas) e com nós representando aos genes;

2. colocar em $S_{b s t r}$ toda aresta dirigida de $C p d a g_{i}$ (para todo $i$ ) rotulando cada uma dessas arestas com o número de CPDAGs em que ela aparece;

3. colocar em $S_{b s t r}$ as duas arestas dirigidas (de sentidos opostos) que definem cada aresta não dirigida de $C p d a g_{i}$ (para todo $i$ ). Ao momento de colocar cada uma dessas arestas em $S_{b s t r}$ é atualizado o rotulo da mesma adicionando 0.5 ao valor atual do rotulo;

4. remover de $S_{b s t r}$ todo par de arestas $x \rightarrow y$ e $y \leftarrow x$ cuja soma dos seus rótulos (frequências bootstrap) é menor que um valor th (limiar de confiança);

5. remover de $S_{b s t r}$ toda aresta $x \rightarrow y$ cujo rótulo é menor que duas vezes o rótulo da aresta $y \rightarrow x$.

O grafo $S_{b s t r}$ constitui uma tentativa de representar visualmente as relações mais estáveis ao longo do processo de bootstrap. É considerado que tais relações são originadas do processo biológico subjacente. No trabalho de Friedman et al. (2000) foi encontrado que as relações encontradas com um limiar confiança acima de $40 \%$ aprendidas no processo boostrap são maiormente relações não aleatórias. Baseados nesse resultado, neste trabalho foi estabelecido th $=40$ como limiar confiança na construção da estrutura robusta. 


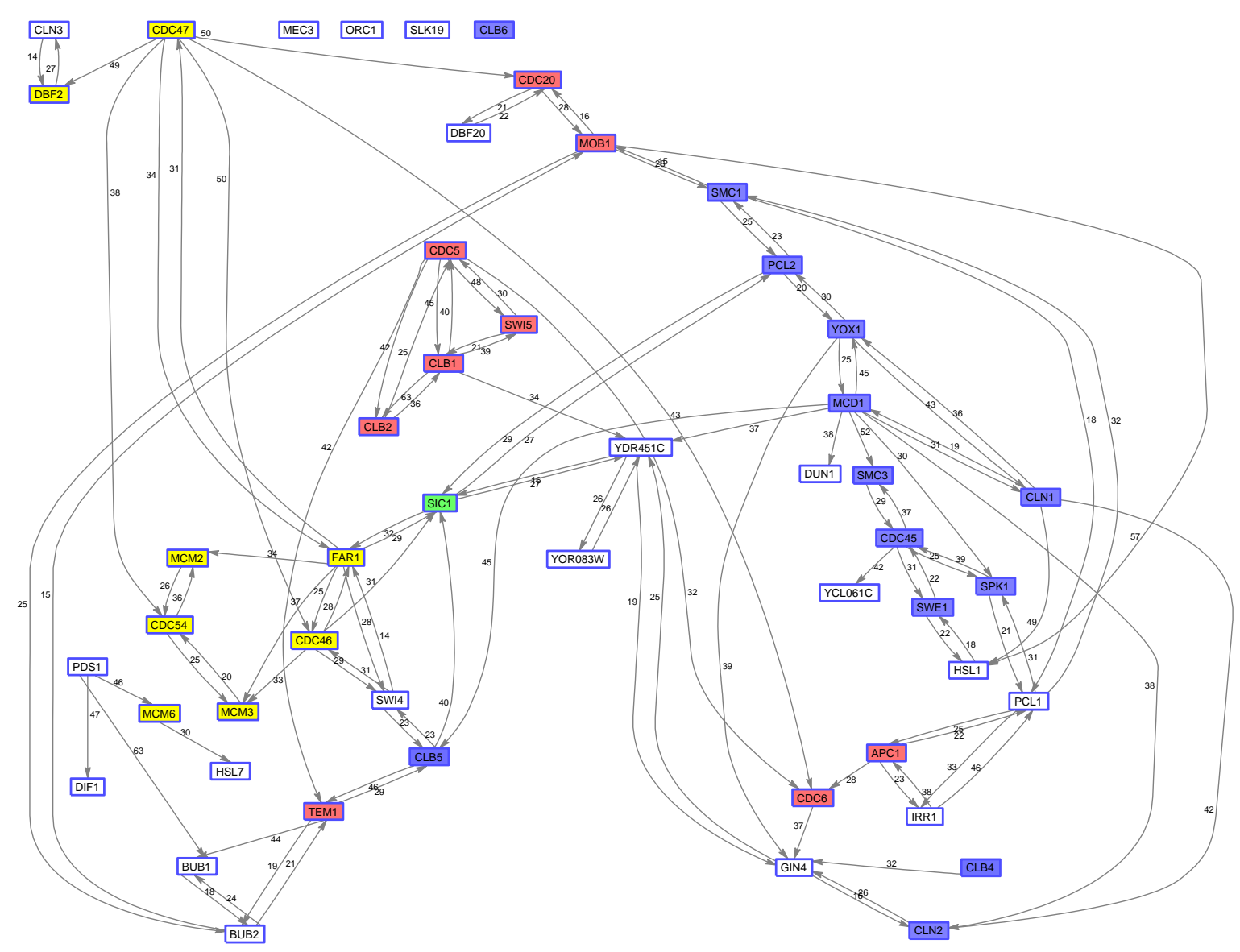

Figura 6.1: Estrutura robusta obtida com o processo bootstrap num banco de dados de microarray de 50 genes escolhidos do estudo do ciclo celular de levedura (Spellman et al., 1998) e que foram biologicamente validados (na enciclopédia KEGG) pertencendo ao cell-cycle pathway. O número de repetições bootstrap foi de 100 e o limiar mínimo de confiança das relações intergênicas para a construção desta estrutura foi de $40 \%$. Os rótulos das arestas indicam o número de CPDAGs em que elas aparecem no processo bootstrap. Os pares de genes com uma única aresta representam relações com uma direção dominante (direção que aparece duas vezes mais frequente que a direção contrária). Os nós foram corados segundo os grupos encontrados no trabalho original de Spellman et al. (1998): MCM (amarelo), CLB2 (vermelho), CLN2 (azul) e SIC1 (verde). Os nós sem cores correspondem a genes que não foram atribuídos a nenhum grupo no trabalho de Spellman et al.

A Figura 6.1 mostra a estrutura robusta resultante $S_{b s t r}$ do procedimento descrito acima. Cada execução bootstrap tomou em média 188 segundos (desvio padrão de 38 seg) e 430 gera- 
ções (desvio padrão de 89). Várias das relações encontradas em $S_{b s t r}$ têm sido biologicamente verificadas e reportadas na literatura. Um exemplo disso é a relação dos genes FAR1 e SIC1, os quais foram encontrados interagindo como inibidores CDK (do inglês cyclin-dependent kinase) (Kumuthini et al., 2007). Uma outra relação interessante, previamente verificada (Spellman et al., 1998), é a que envolve os genes CLN1 and CLN2, os quais atuam colaborativamente na produção de proteínas "cyclins"que controlam a progressão das células na fase G1 e também interagem com o gene YOX1 nessa fase.

A fim de contrastar as relações encontrados em $S_{b s t r}$ com os resultados da análise de agrupamentos realizada por Spellman et al. (1998) (os autores do banco de dados usado) é que o grafo $S_{b s t r}$ na Figura 6.1 foi colorido conforme tais agrupamentos. Os genes considerados no presente análise abrangem 4 grupos dos sete originalmente identificados por Spellman et al. Esses grupos são MCM (amarelo), CLB2 (vermelho), CLN2 (azul) e SIC1 (verde). É possível observar na figura que a quantidade de arestas relacionando genes do mesmo grupo é significantemente maior do que a quantidade de arestas entre genes de diferentes grupos. Esse resultado sugere que o particionamento dos genes encontrado na análise de Spellman et al. é suportado pela maior quantidade de relações intra-grupo reveladas pelas RBs aprendidas. As relações entre genes de diferentes grupos, que os métodos de agrupamento não conseguem mostrar, foram também encontradas tendo significância biológica. Por exemplo, a relação dos genes FAR1 - SIC1 foi descrita em (Kumuthini et al., 2007).

É observado também em $S_{b s t r}$ que algumas relações tendem a ter uma direcionalidade dominante ao longo do processo bootstrap. Friedman et al. (2000) sugeriu que os genes que tendem a ser maiormente geradores de arestas (nós raízes) são indicativos de genes essenciais envolvidos em processos chaves do funcionamento celular. Para testar essa hipótese e, portanto, a utilidade da direcionalidade predominante de algumas relações aprendidas, foi utilizada a métrica de dominância de Friedman et al. (2000), a qual mede quão dominante (ou quão perto de ser um nó raiz) é um determinado gene na ordem ancestral da estrutura. A medida de dominância para um gene $x\left(D S_{x}\right)$ é definida como (Friedman et al., 2000):

$$
D S_{x}=\sum_{y, F(x \rightarrow y)>t h} F(x \rightarrow y)^{k}
$$

onde $F(x \rightarrow y)$ denota a fração de estruturas CPDAGs no processo bootstrap em que $x$ é ancestral de $y$ (onde a ancestralidade é definida sobre caminhos puramente dirigidos), $k$ é uma constante para realçar relações de ordem altamente frequentes, e th é um limiar para descartar 
relações de ordem irrelevantes ou de pouca frequência.

A Tabela 6.1 mostra os dez genes com o maior escore de dominância (em ordem decrescente). Os parâmetros usados para o cálculo do escore de dominância dessa tabela foram $k=2$ e $t h=40 \%$; no entanto foi notado que esses genes tendem a prevalecer dominantes com diferentes configurações de parâmetros do escore de dominância. A maioria dos genes dominantes da tabela são encontrados estando diretamente envolvidos no controle do ciclo celular da levedura (Chen et al., 2004). Alguns deles, como MCD1, CDC5, CDC47 e SPK1, são letais se sofrem mutações de nulidade (Spellman et al., 1998). Os resultados da Tabela 6.1 foram comparados com a lista dos 10 genes dominantes de Friedman et al. (2000), encontrando-se uma concordância de 40\% (genes MCD1, CDC5, CLN1, YOX1), apesar de que a análise aqui apresentada foi realizada num conjunto de genes significativamente menor.

Tabela 6.1: Lista dos dez genes com os maiores valores do escore de dominância obtidos com EES-BN num processo boostrap com dados de microarray de 50 genes relacionados ao ciclo celular da levedura.

\begin{tabular}{lcl}
\hline Gene & Escore de dominância & Descrição do gene \\
\hline MCD1 & 25.74 & Mitotic chromosome determinant. Null mutation is lethal. \\
CDC5 & 19.18 & Cell cycle control. Null mutation is lethal. \\
CDC47 & 17.10 & Required in initiation of chromosomal replication. Null mutation is lethal. \\
CLB1 & 16.93 & B-type cyclin. \\
CLN1 & 13.78 & G1 cyclin. \\
YOX1 & 13.55 & Homeodomain protein. \\
PDS1 & 12.96 & Protein involved in the regulation of sister chromatid separation in mitosis. \\
CLB5 & 11.96 & B-type cyclin involved in S-phase initiation. \\
BUB2 & 11.91 & Checkpoint protein required for cell cycle arrest in response to loss of microtubule function. \\
CLB2 & 11.72 & B-type cyclin. \\
SPK1 & 11.22 & Protein kinase with a checkpoint function in S and G2. Null mutation is lethal. \\
\hline
\end{tabular}

\subsection{Aplicação na modelagem de desequilíbrio de ligação}

Antes de definir o problema de desequilíbrio de ligação e a aplicação de EES-BN neste problema, é apresentada a seguir uma breve revisão de termos e conceitos úteis para a compreensão do contexto do problema.

Um loco é um local fixo num cromossomo. Uma marcador genético é um loco que identifica uma região cromossômica que apresenta diferenças entre indivíduos de uma população ou entre diferentes espécies de organismos (também chamado de loco polimórfico). Um marcador SNP (do inglês single nucleotide polimorphism) é um marcador genético que envolve uma única base do DNA. Um alelo de um marcador genético é uma forma alternativa que esse 
marcador pode assumir. Os marcadores SNPs podem assumir 2 alelos possíveis, razão pela que são chamados de marcadores bi-alélicos. Um organismo diplóide é aquele que possui pares de cromossomas homólogos nas suas células somáticas (não gâmetas), um deles herdado do pai e o outro da mãe, assim todo organismo diplóide possui dois genomas e portanto duas cópias de cada gene. Um marcador genético de um organismo diplóide assume dois alelos simultaneamente (um de cada cromossomo homólogo), par que é chamado de genótipo. Por exemplo, um marcador bi-alélico $A$ de um indivíduo diplóide com alelos $\{a 1, a 2\}$ pode assumir três genótipos distintos: $\langle a 1, a 1\rangle,\langle a 1, a 2\rangle,\langle a 2, a 2\rangle$. Quando os alelos de um genótipo são iguais diz-se que o genótipo é homozigótico, caso contrário ele é chamado de genótipo heterozigótico. Dada uma sequência de marcadores genéticos adjacentes num organismo diplóide, define-se como haplótipo ao arranjo de alelos dos marcadores pertencentes ao mesmo cromossomo. Isso implica que todo indivíduo diplóide possui dois haplótipos para qualquer conjunto de marcadores dado. Por exemplo, considere um organismo diplóide com 2 marcadores: $A$ com possíveis alelos $\{a 1, a 2\}$ e $B$ com possíveis alelos $\{b 1, b 2\}$. A Tabela 6.2 mostra os 3 genótipos possíveis para cada marcador (primeira linha e coluna) e as 9 configurações possíveis de haplótipos, cada configuração contendo os dois haplótipos possíveis para um determinado genótipo de $A$ e de $B$. Note-se que quando os dois marcadores possuem genótipos heterozigóticos (célula

Tabela 6.2: Possíveis genótipos (primeira coluna e primeira linha) e haplótipos (demais células) para dois marcadores bi-alélicos $A$ e $B$ de um organismo diplóide.

\begin{tabular}{|c||c|c|c|}
\hline & $\langle\boldsymbol{b} 1, \boldsymbol{b} 1\rangle$ & $\langle\boldsymbol{b} 1, \boldsymbol{b 2}\rangle$ & $\langle\boldsymbol{b 2}, \boldsymbol{b 2}\rangle$ \\
\hline \hline$\langle\boldsymbol{a} 1, \boldsymbol{a} 1\rangle$ & (a1,b1), (a1,b1) & (a1,b1), (a1,b2) & (a1,b2), (a1,b2) \\
\hline$\langle\boldsymbol{a} 1, \boldsymbol{a 2}\rangle$ & (a1,b1), (a2,b1) & $(\mathrm{a} 1, \mathrm{~b} 1),(\mathrm{a} 2, \mathrm{~b} 2)$ ou (a1,b2), (a2,b1) & $(\mathrm{a} 1, \mathrm{~b} 2),(\mathrm{a} 2, \mathrm{~b} 2)$ \\
\hline$\langle\boldsymbol{a} 2, \boldsymbol{a 2}\rangle$ & (a2,b1), (a2,b1) & $(\mathrm{a} 2, \mathrm{~b} 1),(\mathrm{a} 2, \mathrm{~b} 2)$ & $(\mathrm{a} 2, \mathrm{~b} 2),(\mathrm{a} 2, \mathrm{~b} 2)$ \\
\hline
\end{tabular}

central) então existem duas configurações possíveis de haplótipos, ambiguidade que não pode ser resolvida tendo unicamente os genótipos de um indivíduo. O processo de encontrar a configuração correta dos haplótipos de um conjunto de marcadores é chamado de determinação da fase haplotipica ou faseamento (do inglês haplotype phasing). A forma inequívoca de determinar a fase haplótica é por sequenciamento. Também existem técnicas computacionais de aproximação da fase haplótica quando se dispõe de dados de genótipo de uma população de indivíduos (por exemplo, BEAGLE de Browning e Browning (2007)).

O conceito de desequilíbrio de ligação ou sucintamente LD (do inglês Linkage Disequilibrium) é um fenômeno relativo a uma população de indivíduos. Formalmente, considere dois marcadores genéticos multialélicos $A$ e $B$ observados numa determinada população, com o marcador $A$ tendo $k$ alelos possíveis $\left\{a_{1}, \ldots, a_{k}\right\}$ e o marcador $B$ tendo $l$ alelos possíveis 
$\left\{b_{1}, \ldots, b_{l}\right\}$, onde cada alelo $a_{i}$ é observado nessa população com uma frequência $p_{i}$ e o alelo $b_{j}$ é observado com uma frequência populacional $q_{j}$. Se os marcadores $A$ e $B$ são completamente independentes é esperado que cada possível haplótipo $\left(a_{i}, b_{j}\right)$ (para todo $i, j$ ) seja encontrado na população com uma frequência igual a $p_{i j}=p_{i} q_{j}$, em cujo caso os marcadores são ditos estando em equilibrio de ligação; caso contrário diz-se que os marcadores $A$ e $B$ estão em disequilíbrio de ligação ou em LD.

Idealmente, se uma população evolui somente por recombinação e acasalamento puramente aleatório então qualquer LD entre marcadores genéticos dessa população é esperado se dissipar ao longo das gerações seguintes (devido à quebra sucessiva dos haplótipos originais provocada pela recombinação). Não obstante, fatores como migrações, especialização, acasalamento seletivo, mutações, entre outros, fazem com que as populações apresentem padrões de LD diferentes do caso ideal. A identificação desses padrões tem sido o alvo de diversas pesquisas como passo importante para inferir sobre os fatores genéticos subjacentes. Por exemplo, padrões de LD têm sido usados em estudos de diversidade genética de populações (Jombart et al., 2009), mapeamento de doenças genéticas (Mueller, 2004), inferência de filogenias (Grechko, 2002), inferência de historia populacional como migrações (Rannala e Mountain, 1997), expansão e declínio populacional (Luikart et al., 1999), estudos da biologia de recombinação (Pritchard e Przeworski, 2001), entre outros (Luikart et al., 2003; Jones et al., 2009).

Tradicionalmente, a identificação dos padrões de LD de uma população tem sido realizada com base a alguma métrica de $L D$, tal como os coeficientes $r^{2}$ (Hill e Robertson, 1968), $D^{2}$ (Hedrick, 1987) e $D^{\prime}$ (Hedrick, 1987; Zapata, 2000). Tais métricas medem o grau de associação entre marcadores baseados na divergência entre as frequências observadas dos haplótipos da população em relação às frequências hipotéticas desses haplótipos sob a hipótese de não associação. As métricas de LD junto com ferramentas de visualização das mesmas (por exemplo, Haploview ${ }^{4}$ de Barrett et al. (2005)) têm sido a abordagem padrão para determinar os padrões de LD de uma população (Mueller, 2004). No entanto, apesar da praticidade e popularidade desta abordagem, esta se limita a oferecer uma descrição estática e parcial da estrutura de LD dos marcadores analisados (Thomas e Camp, 2004). Numa tentativa de ir além dessa abordagem e de extrair um conhecimento adicional dos dados de genótipos, Thomas e Camp (2004) e Thomas (2005) propuseram modelar LD com redes de Markov, um tipo de modelo gráfico probabilístico que usa grafos não dirigidos como estruturas de modelo.

\footnotetext{
${ }^{4}$ www.broadinstitute.org/haploview
} 
Tabela 6.3: Bancos de dados de haplótipos usados na aplicação de EES-BN para modelar LD. Estes bancos de dados foram obtidos do repositório HapMap (version III, release 2) usando a ferramenta web Genome Browser do mesmo repositório. Somente marcadores SNPs com MAF $>0.03$ foram considerados.

\begin{tabular}{|lllllll|}
\hline Banco de dados & $\begin{array}{l}\text { região } \\
\text { ENCODE }\end{array}$ & Cromossomo & $\begin{array}{l}\text { Segmento genômico } \\
(\mathrm{kpb})\end{array}$ & $\begin{array}{l}\text { População } \\
\text { HapMap }\end{array}$ & SNPs & Haplotipos \\
\hline ENm010_CHB+JPT & ENm010 & $7 \mathrm{p} 15.2$ & $27070-27126$ & CHB+JPT & 15 & 340 \\
ENr131_CEU & ENr131 & $2 \mathrm{q} 37.1$ & $235065-235122$ & CEU & 31 & 234 \\
ENr321_YRI & ENr321 & $8 \mathrm{q} 24.11$ & $118797-118895$ & YRI & 47 & 230 \\
\hline
\end{tabular}

Seguindo na linha de Thomas (2005) de aplicar modelos gráficos probabilísticos para modelar LD, nesta seção é apresentada uma aplicação de redes Bayesianas para esse problema ${ }^{5}$. Para tal fim é usado o algoritmo de aprendizagem estrutural EES-BN proposto neste trabalho. A ideia de usar RBs na modelagem de LD foi baseada na intuitiva interpretabilidade destes modelos e a possibilidade de extrair um conhecimento adicional dos dados a partir da direcionalidade das relações aprendida nas RBs, informação que não é possível obter diretamente com modelos gráficos não dirigidos ou métricas de LD.

\section{Dados:}

Três bancos de dados foram extraídos do repositório HapMap ${ }^{6}$ (Phase III - Release 2) a fim de testar a habilidade de EES-BN em caracterizar LD. O repositório HapMap é um grande esforço internacional do HapMap-Consortium (2003) por genotipar diferentes populações humanas distribuídas ao longo do planeta (atualmente HapMap dispõe de mais de 5 milhões de marcadores SNPs genotipados em onze populações de vários continentes) a fim de facilitar as pesquisas em medicina e farmacologia. Os dados escolhidos para o presente estudo correspondem a segmentos de haplótipos de regiões cromossômicas conhecidas como ENCODE, as quais estão associadas com elementos funcionais do genoma e apresentam uma alta densidade de marcadores genotipados. A Tabela 6.3 descreve os bancos de dados selecionados os quais variam em número de marcadores SNPs, número de haplótipos, localização cromossomal e população de origem, representando assim 3 casos de variada complexidade. Os dados foram obtidos com a ferramenta web Genome Browser (disponível no mesmo repositório HapMap) usando a opção Download Phased Haplotype Data e descartando os marcadores cujo alelo de menor frequência (do inglês minor allele frequency ou MAF) é menor a 0.03, já que esses marcadores são quase invariáveis na população.

\footnotetext{
${ }^{5}$ Resultados preliminares desta aplicação foram reportados em (Villanueva e Maciel, 2010)).

${ }^{6} \mathrm{http}: / /$ hapmap.ncbi.nlm.nih.gov
} 


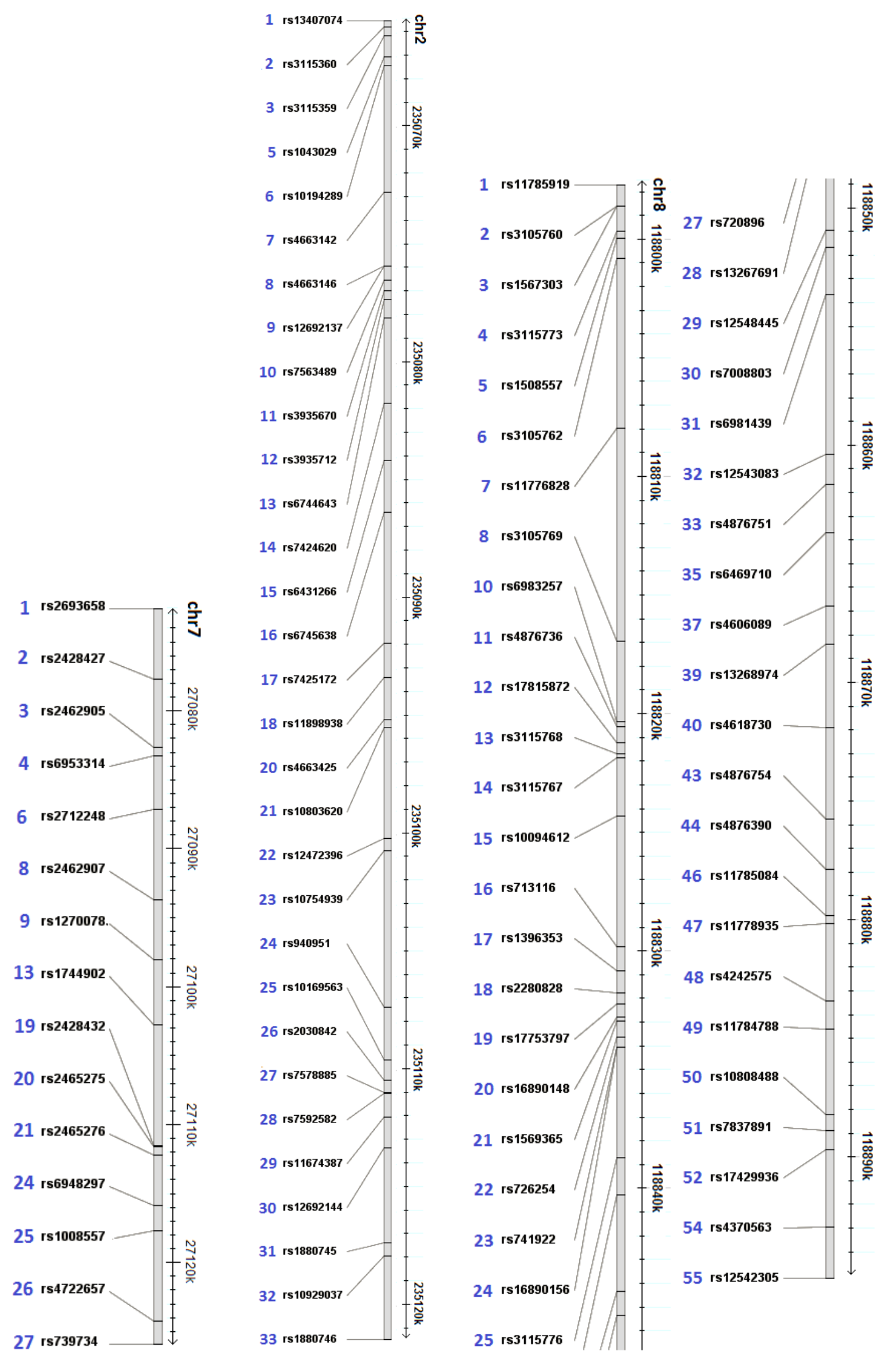
(a) ENm010_CHB+JPT
(b) ENr131_CEU
(c) ENr321_YRI

Figura 6.2: Marcadores genéticos SNPs envolvidos nos haplótipos dos bancos da Tabela 6.3 
A Figura 6.2 mostra os marcadores SNPs integrantes de cada banco de dados e suas localizações nas regiões cromossomais correspondentes. Os números do lado esquerdo dos nomes dos marcadores são códigos atribuídos na presente pesquisa para identificar mais facilmente os marcadores (os números faltantes correspondem aos marcadores removidos por baixo MAF). Como referência são incluídos também na Figura 6.3 os usuais diagramas triangulares de LD. Esses diagramas foram gerados com o aplicativo Haploview usando como métrica de LD o coeficiente $D^{\prime}$ e um esquema de cores padrão (entre mais vermelho maior o valor de $D^{\prime}$ ). Os blocos de LD destacados com triângulos nos diagramas de LD representam regiões de marcadores fortemente associados e foram determinados por Haploview usando a definição de blocos Strong LD Spine ${ }^{7}$ (Barrett et al., 2005).

\section{Modelando LD com EES-BN:}

Cada haplótipo $\boldsymbol{d}_{j}$ do banco de dados é um vector de alelos $\left(d_{j 1}, \ldots, d_{j n}\right)$, o qual é considerado como uma observação ou amostra independente de uma variável aleatória multidimensional $\boldsymbol{X}=\left(X_{1}, \ldots, X_{n}\right)$. Já que os dados considerados são de marcadores SNPs então cada variável $X_{i}$ é uma variável discreta binária representando um dos dois alelos do $i$-ésimo marcador SNP.

Similarmente à aplicação da seção anterior, cada banco de dados $D$ da Tabela 6.3 é usada para gerar 100 versões bootstrap da mesma, $D_{1}, D_{2}, \ldots, D_{100}$, a fim de determinar relações robustas. EES-BN é então executado obre cada versão $D_{i}$ como banco de dados de entrada. Os parâmetros usados para EES-BN foram os mesmos da seção anterior em todas as execuções. Os 100 DAGs devolvidos por EES-BN foram então transformados em representações CPDAGs das suas classes de equivalência. O procedimento LABEL-EDGES de Chickering (2002) foi usado para tal finalidade. Finalmente, as 100 estruturas CPDAGs foram sumarizadas em uma única estrutura robusta $S_{b s t r}$ usando o mesmo procedimento descrito na seção previa.

A Figura 6.4 mostra duas estruturas robustas obtidas para o banco de dados ENm010_CHB+JPT, uma construída com limiar de confiança de $40 \%$ e a outra construída com $60 \%$. Em média, EES-BN usou 14 segundos (desvio padrão de 4 seg.) e 132 gerações (desvio padrão de 18) para aprender o DAG de cada versão bootstrap desse banco de dados. Para contrastar com os resultados da ferramenta Haploview, os nós das estruturas da Figura 6.4 foram corados conforme os dois blocos de LD encontrados nesse banco de dados por Hapliview (Figura 6.3(a)).

\footnotetext{
${ }^{7}$ Strong LD Spine é um critério de definição de blocos LD implementado no aplicativo Haploview onde o primeiro e o último marcador no bloco apresentam um forte LD com todos os outros marcadores intermediários do bloco mas estes não necessariamente apresentam um elevado LD entre sim.
} 


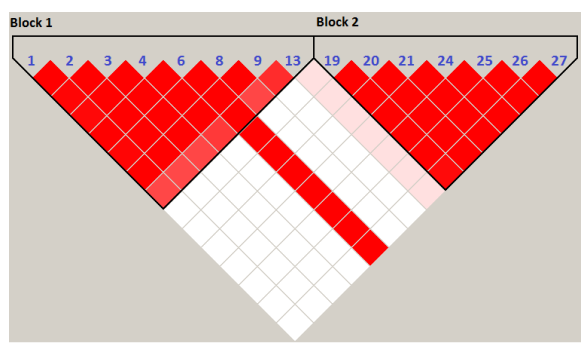

(a) ENm010_CHB+JPT

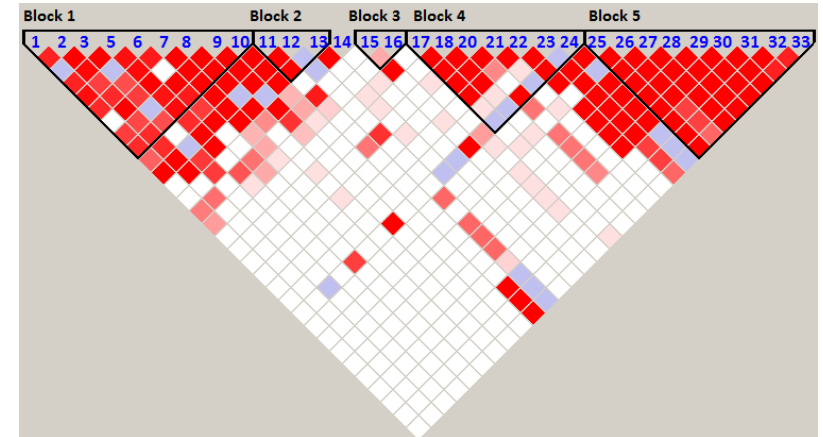

(b) ENr131_CEU

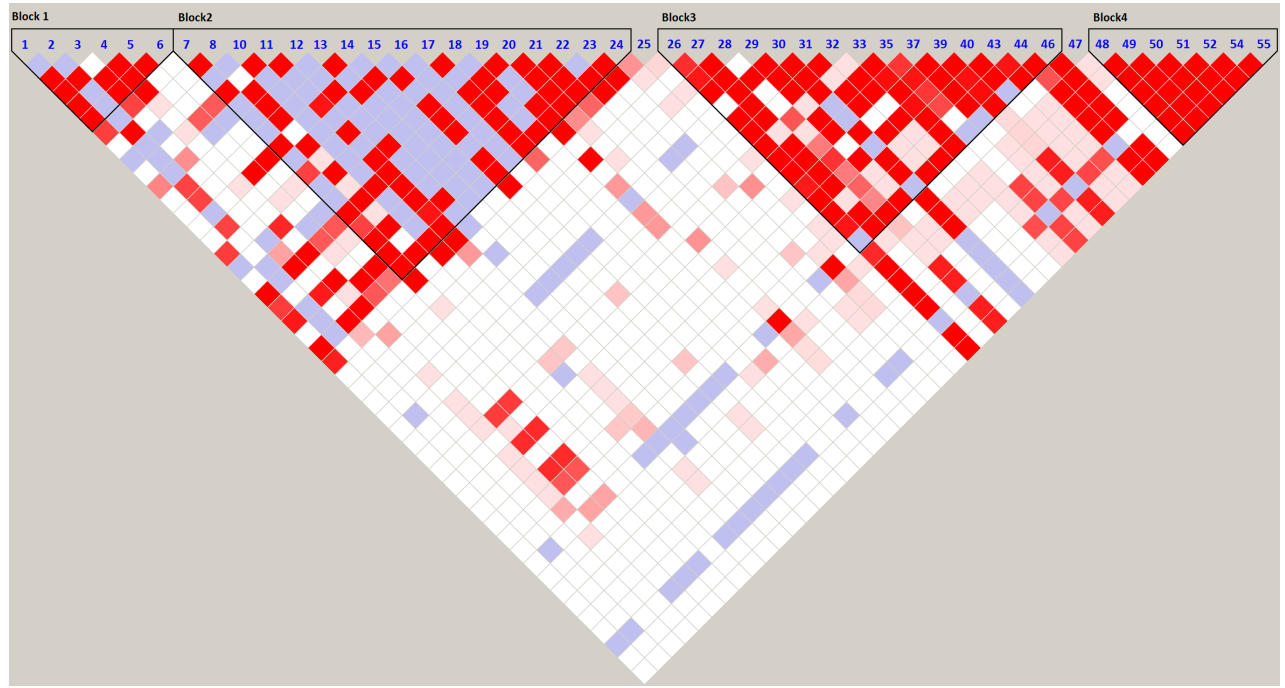

(c) ENr321_YRI

Figura 6.3: Estruturas de LD obtidas com a ferramenta Haploview nos três bancos de haplótipos analisados. Estas estruturas foram obtidas usando a métrica de LD D' e um esquema de cores padrão (cores mais vermelhas indicam maiores valores de D', cor branca indica valor zero de D'). Os blocos de LD destacados com triângulos e rotulados acima do gráfico foram determinados pela mesma ferramenta Haploview usando a definição de bloco Strong LD Spine.

É possível observar na estrutura com limiar de confiança de 40\% (Figura 6.4(a)) que as arestas estão maiormente concentradas entre os nós do mesmo bloco de LD de Haploview. A única aresta ligando nós de distintos blocos é a que relaciona os nós 13 e19. No entanto, tal aresta torna-se essencial para explicar (por caminhos dirigidos) a forte relação observada no diagrama de LD triangular (Figura 6.3(a)) entre cada nó do bloco 2 e o nó 6 do bloco 1. Esse resultado pode ser tomado como um indicativo da capacidade das RBs em modelar com um maior detalhe (que as métricas de LD) as relações subjacentes entre os marcadores genéticos. 


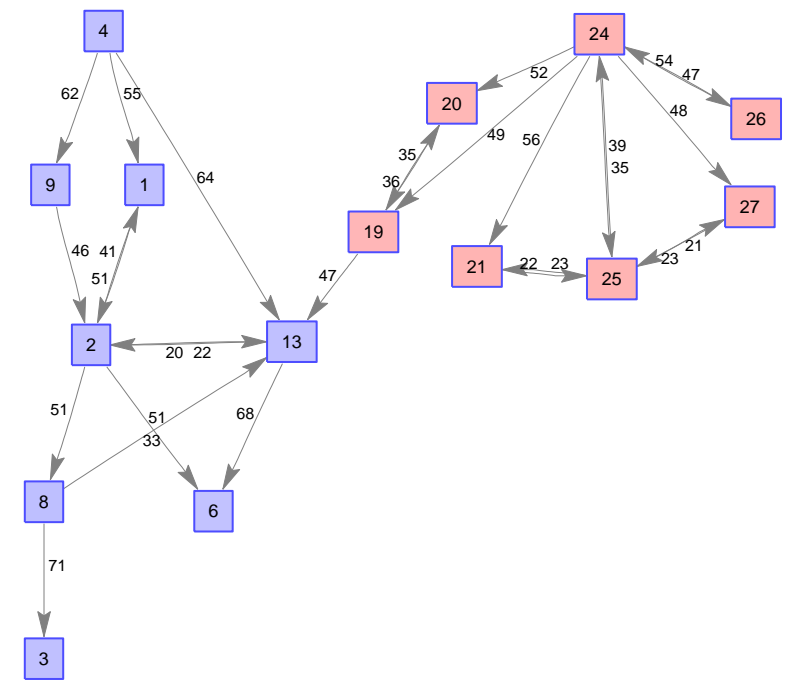

(a) Estrutura robusta com limiar de confiança $t h=40 \%$

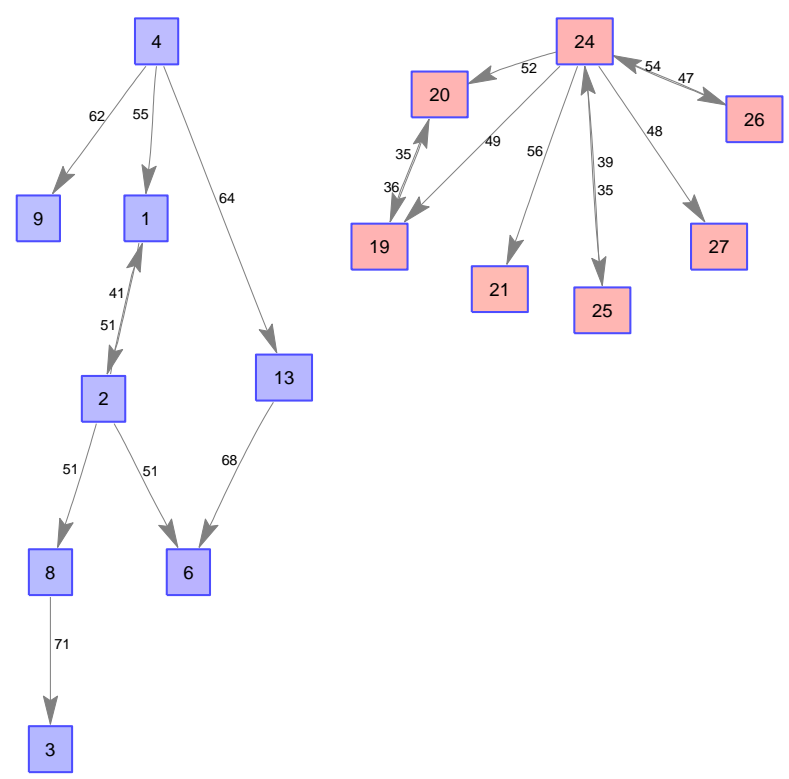

(b) Estrutura robusta com limiar de confiança th $=60 \%$

Figura 6.4: Estruturas robustas aprendidas com EES-BN a partir de versões bootstrap do banco de dados ENm010_CHB+JPT. A estrutura da esquerda (direita) corresponde à estrutura robusta com um limiar de confiança mínimo de 40\% (60\%). 
Ao aumentar o limiar de confiança da estrutura robusta para 60\% (limiar mais rigoroso para aceitar uma relação) é possível observar uma estrutura de relações próxima à estrutura de 40 \% (Figura 6.4(b)) e também uma alta concordância com os blocos de Haploview. Algumas relações diretas ${ }^{8}$ são perdidas (pares $\left.(9,2),(2,13),(8,13),(19,13),(21,25),(25,27)\right)$ fazendo com que os dois blocos fiquem claramente evidenciados.

Um comportamento parecido ao anterior foi observado nas estruturas robustas dos outros dois bancos de dados. A Figura 6.5 mostra para os três bancos de dados e três estruturas robustas aprendidas em cada um deles (com limiares de confiança de $0 \%, 40 \%$ e $60 \%$ ) a distribuição das relações diretas com respeito a dez intervalos do coeficiente $D^{\prime}$. Nos três bancos de dados é notado que uma grande porção das relações diretas capturadas nas estruturas robustas corresponde a relações de alto valor de $D^{\prime}$ (maior a 0.8). A medida que se aumenta o limiar de confiança para construir a estrutura robusta é observado que várias relações diretas desaparecem, especialmente quando se passa de $0 \%$ a $40 \%$ de limiar de confiança e nos intervalos mas baixos de $D^{\prime}$. Esse é um indicativo de que essas relações não são de origem biológico dada sua pouca persistência no processo bootstrap e os valores baixos de $D^{\prime}$. Não obstante, é interessante observar certa tendência a ter um moderado número de relações diretas com baixos valores de $D^{\prime}$ (na faixa de 0.1 a 0.6 ) e que são altamente persistentes no processo bootstrap, inclusive com um limiar de confiança acima de 60\%. Essas relações sugerem associações reais entre marcadores genéticos que a métrica $D^{\prime}$ não consegue detectar, possivelmente porque $D^{\prime}$ está baseada em estatísticas de independência marginal enquanto que a modelagem com RBs usando EES-BN permite estatísticas de ordem superior.

Das estruturas da Figura 6.4 é possível notar que existem certas arestas com uma alta tendência de ter uma direção determinada no processo bootstrap. Por exemplo, os nós 4 e 24 têm certa preponderância a ser originadores de arestas. Para verificar essa tendência e determinar quais são os nós que tendem a ser nós raízes, foi usado o escore de dominância de Friedman et al. (2000) utilizado na aplicação da seção anterior. A Tabela 6.4 mostra a lista dos dez marcadores genéticos com os valores mais altos de escore de dominância para os três bancos de dados. É observado que a maioria desses nós correspondem a marcadores localizados em regiões centrais dos blocos LD de Haploview (Figura 6.3). Essa tendência pode ser entendida considerando os resultados em biologia (Li e Stephens, 2003; Hey, 2004; Myers et al., 2005) que afirmam que a quebra dos cromossomos no processo de recombinação em humanos (e

\footnotetext{
${ }^{8}$ Neste trabalho, considera-se uma relação direta entre um par de nós quando existe uma aresta ligando esses nós em qualquer direção.
} 
também outras espécies) acontece com maior frequência em certas regiões chamadas de $r e$ combination hotspots. Os marcadores genéticos centrais nos blocos de LD são possivelmente os mais distantes desses hotspots e portanto os mais conservados na história populacional. Isso implica que os alelos desses marcadores trazem informações relevantes para a determinação dos alelos dos marcadores que estão por volta deles, sendo assim capturados frequentemente nas RBs como nós originadores de arestas. Um possível uso dessa informação de direcionalidade aprendida pelas RBs poderia ser usada para guiar a seleção de marcadores tags, problema de certa relevância em genética quando se quer genotipar um organismo com uma quantidade reduzida de marcadores (que devem ser os mais informativos da região) por restrições econômicas (Liu e Lin, 2005; Nicolas et al., 2006; Zhang et al., 2009).

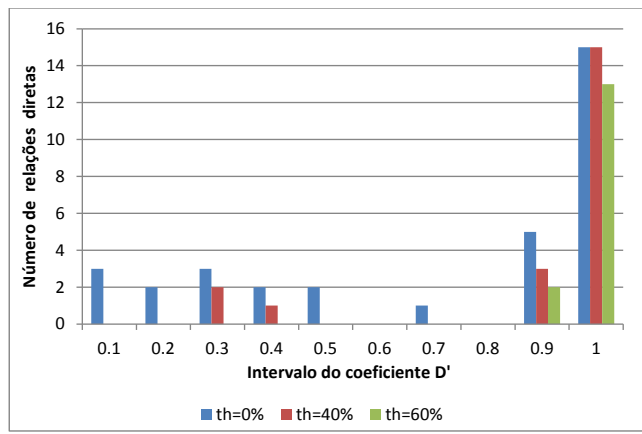

(a) ENm010_CHB+JPT

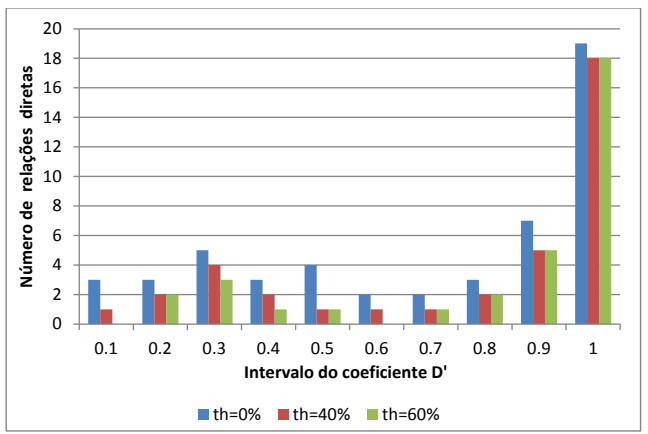

(b) ENr131_CEU

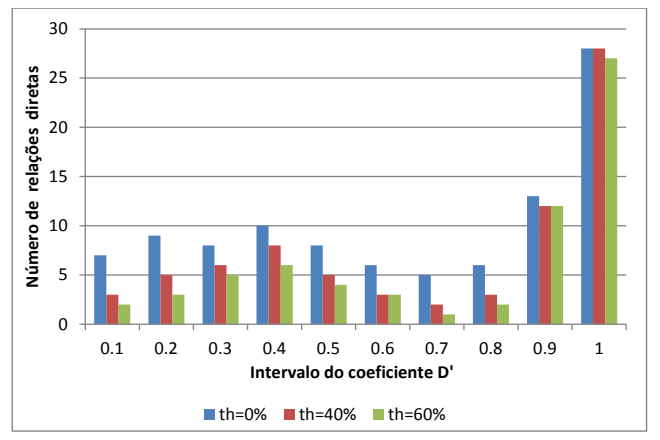

(c) ENr321_YRI

Figura 6.5: Distribuição do número de relações diretas aprendidas nas estruturas robustas com respeito a dez intervalos igualmente espaçados do coeficiente $D^{\prime}$. Cada figura corresponde a um banco de dados da Tabela 6.3 e cada serie a uma das três estruturas robustas aprendidas com limiares de confiança $(t h)$ de $0 \%, 40 \%$ e $60 \%$. Os rótulos do eixo horizontal representam o valor superior do intervalo, assim 0.1 indica o intervalo [0,0.1[ 
Tabela 6.4: Lista dos dez marcadores genéticos com os maiores valores do escore de dominância obtidos nos bancos de dados de haplótipos da Tabela 6.3.

\begin{tabular}{cr|cr|cr}
\multicolumn{2}{c}{ ENm010_CHB+JPT } & \multicolumn{2}{c}{ ENr131_CEU } & \multicolumn{2}{c}{ ENr321_YRI } \\
Marcador & Escore & Marcador & Escore & Marcador & Escore \\
\hline 4 & 0.59 & 5 & 3.23 & 51 & 17.64 \\
24 & 0.58 & 12 & 3.08 & 52 & 15.59 \\
2 & 0.31 & 30 & 2.69 & 33 & 14.34 \\
9 & 0.27 & 8 & 2.23 & 12 & 9.05 \\
8 & 0.20 & 20 & 1.76 & 4 & 8.92 \\
19 & 0.18 & 29 & 1.45 & 35 & 7.15 \\
13 & 0.17 & 21 & 1.42 & 39 & 6.79 \\
- & - & 10 & 1.29 & 18 & 5.77 \\
- & - & 7 & 1.28 & 3 & 5.59 \\
- & - & 22 & 1.06 & 11 & 5.18
\end{tabular}




\section{Capítulo 7}

\section{Conclusões}

Na presente tese foi abordado o problema da aprendizagem estrutural de redes Bayesianas a partir de conjuntos de dados. Para tal fim foi proposto o sistema evolutivo EES-BN, desenvolvido sob o requisito de maximização da precisão e eficiência computacional do processo de aprendizagem. Um híbrido de duas etapas de aprendizagem foi concebido para EES-BN: uma primeira etapa de estimativa de superestrutura que possibilita a redução do espaço de busca, e uma segunda etapa de busca genética que evolui estruturas de modelo no espaço demarcado pela superestrutura estimada.

Para a primeira etapa foram desenvolvidos dois métodos alternativos de estimação de superestruturas, o método Opt01SS e o método OptHPC, ambos baseados em testes de independência condicional. A avaliação experimental desses métodos junto com outros métodos relevantes da literatura para estimação de superestruturas mostrou que tanto Opt01SS como OptHPC são capazes de aprender superestruturas com um equilíbrio sensibilidade-especificidade claramente mais favorável para o esquema de aprendizagem híbrida de EES-BN do que os outros métodos analisados. Adicionalmente, o custo computacional de Opt01SS foi encontrado sendo um dos melhores entre os métodos estudados, requerendo uma reduzida quantidade de testes de independência para aprender as superestruturas. Já o método OptHPC mostrou custos computacionais intermediários, usando em média em torno de 30\% dos testes de independência que seu método matriz HPC usa para aprender superestruturas da mesma precisão.

Para a etapa evolutiva de EES-BN, foi desenvolvido o operador MergePop que generaliza o operador Merge (Wong e Leung, 2004) para admitir vários progenitores na criação dos indivíduos filhos. A análise experimental sobre MergePop mostrou que esse operador con- 
segue gerar populações filhas de qualidade (escore) marcadamente superior do que o operador Merge, resultado que se torna mais notório ao aumentar o tamanho da população progenitora. No entanto, foi notado que com o aumento do tamanho da população progenitora cresce também o tempo computacional para a criação da prole. Os resultados sugeriram que mantendo o tamanho da população progenitora baixo ( 2 ou 3 indivíduos) é possível ter um aceitável balanço efetividade-custo para o operador MergePop.

A análise experimental do desempenho dos blocos principais da etapa evolutiva de EES-BN mostrou a relevância relativa de cada bloco em melhorar a eficiência e precisão da aprendizagem. O bloco de recombinação mostrou sua capacidade de levantar rapidamente o escore da população no inicio da evolução e no momento que um novo indivíduo com blocos construtivos promissores é introduzido na população. O bloco de mutação mostrou sua capacidade de refinar o escore populacional fazendo pequenas alterações de baixo custo computacional nos indivíduos da mesma. O bloco de injeção de diversidade mostrou-se essencial em destravar a população da estagnação. Foi analisada também a influência da inicialização em EES-BN, encontrando-se que uma inicialização da população com a heurística K2 influi positivamente na aprendizagem de melhores soluções e na diminuição do tempo de convergência.

O desempenho de EES-BN foi comparado contra quatro métodos representativos de aprendizagem estrutural, dois evolutivos (CCGA e GAK2) e dois não evolutivos (GS e MMHC), a maioria com implementações publicas disponíveis. Os resultados mostraram que EES-BN é capaz de recuperar estruturas de modelo significativamente mais próximas da estrutura verdadeira do que os outros métodos estudados, resultado que se torna ainda mais evidente nas redes de maior dimensão. EES-BN mostrou-se também superior aos outros métodos evolutivos em relação aos tempos computacionais de aprendizagem. Comparado com os métodos não evolutivos, EES-BN mostrou a tendência de usar tempos computacionais menores do que o método tradicional GS nas redes de alta dimensionalidade, oferecendo nesses casos os segundos melhores tempos depois do método MMHC. No entanto, é possível diminuir os tempos de aprendizagem de EES-BN relaxando o critério de parada, o qual foi configurado de forma rigorosa nos testes realizados.

As aplicações de EES-BN apresentadas na presente tese mostraram a habilidade de EESBN em recuperar relações de significância biológica. Na primeira aplicação, com um banco dados de expressão gênica de poucas amostras, foi observada uma alta concordância entre arestas persistentes em estruturas aprendidas de versões bootstrap dos dados e iterações gênicas já 
descritas na literatura. Foi verificado também que os genes com a tendência de ser nós raízes no processo bootstrap são de forma geral genes de alta relevância no processo biológico-molecular analisado, comprovando resultados da literatura sobre a utilidade da RBs na modelagem de redes gênicas (Friedman et al., 2000; Husmeier, 2003; Werhli et al., 2006).

Na segunda aplicação sobre modelagem de desequilíbrio de ligação (LD) foi observada também uma alta coincidência dos padrões de relações inter-marcadores encontrados com EESBN (através de um processo bootstrap) e os blocos de LD obtidos com técnicas tradicionais. Uma grande parte das arestas que foram persistentes no processo bootstrap foram verificadas tendo valores altos da métrica clássica de desequilíbrio $D^{\prime}$. No entanto, foi notado que uma fração das arestas bootstrap-persistentes representavam valores baixos de $D^{\prime}$, o que pode ser um indicativo de relações biológicas interessantes que a métrica $D^{\prime}$ não foi capaz de capturar, precisando-se de uma validação biológica dessa observação. Os resultados também mostraram a utilidade da direcionalidade aprendida das RBs no problema de LD, encontrando-se que os marcadores genéticos mais conservados na população tendem a ser aprendidos como nós originadores de arestas. Essa propriedade poderia ser explorada, por exemplo, no problema de seleção de marcadores informativos (problema conhecido como SNP tagging (Nicolas et al., 2006) ) quando se tem a necessidade de genotipar um organismo sob restrições econômicas

\subsection{Contribuições e Publicações}

Em síntese, as maiores contribuições da presente tese foram as seguintes:

1. Opt01SS e OptHPC, novos métodos para estimar superestruturas com ênfase na sensibilidade e eficiência computacional da aprendizagem. Estas contribuições são uteis, não somente no contexto de EES-BN, mas nos contextos mais gerais de aprendizagem híbrida e aprendizagem exata de redes Bayesianas. Como apontado por Perrier et al. (2008) e logo por Kojima et al. (2010), existe uma grande necessidade de desenvolvimento de métodos eficientes para aprender superestruturas, já que da qualidade delas dependem vários sistemas de aprendizagem, tanto híbridos como exatos. No entanto, a literatura não tem acompanhado essa necessidade, sendo que a maioria dos métodos existentes foram maiormente desenvolvidos para aprender o esqueleto exato da RB ou a adjacência de um nó alvo, problemas que apresentam requerimentos diferentes dos implicados na aprendizagem de superestruturas. Nesse sentido, os métodos desenvolvidos 
Opt01SS e OptHPC constituem um esforço por diminuir a lacuna existente.

O método OptHPC foi publicado nos proceedings da International Conference on Pattern Recognition Applications and Methods - ICPRAM 2012 (Villanueva e Maciel, 2012c). O método Opt01SS foi aceito para publicação no jornal Neurocomputing (aceitação em 06 de setembro de 2012).

2. EES-BN, um sistema evolutivo híbrido eficiente para aprender estruturas de redes Bayesianas. A literatura de aprendizagem estrutural de RBs tem já mais de duas décadas desde a formalização das RBs por Pearl (1988). Atualmente pode-se observar certa maturidade na área, sendo que certas metodologias de aprendizagem têm atingido níveis difíceis de ser superados. Tal é o caso dos métodos GS e MMHC, que por sua precisão e eficiência computacional têm sido integrados em diversos pacotes software de RBs e usadas frequentemente em várias áreas de aplicação. Por outro lado, na última década vem-se observando um interesse crescente por abordagens evolutivas de aprendizagem estrutural, interesse que está maiormente baseado na promessa da computação evolutiva em fazer buscas mais abrangentes. No entanto, apesar da existência de uma significativa quantidade de propostas evolutivas para a aprendizagem estrutural, a maioria dessas contribuições focam-se em algum (ou alguns poucos) aspecto específico da aprendizagem evolutiva, tal como os operadores de busca, a representação, o espaço de busca, entre outros. É difícil encontrar até agora sistemas evolutivos que otimizem a maior parte dos aspectos evolutivos e que mostrem uma clara melhoria em relação aos métodos estabelecidos como GS e MMHC. O sistema proposto na presente tese, EES$\mathrm{BN}$, foi desenvolvido justamente para ir ao encontro desses objetivos e contribuir assim com o avanço do estado da arte. Os resultados de EES-BN foram promissores e várias peças dele poderiam ser usadas ou melhoradas para construir sistemas de aprendizagem mais avançados. Destacam-se, por exemplo, o operador de recombinação MergePop que mostrou uma elevada capacidade em reconstituir rapidamente bons blocos construtivos espalhados na população, o bloco de injeção de diversidade que mostrou ser efetivo em destravar a população de estagnação, e a fase de redução do espaço de busca com superestruturas que consegue aliviar eficientemente a tarefa de busca.

Foi elaborado um artigo descrevendo o sistema EES-BN e sua aplicação na modelagem de redes de iterações gênicas, o qual foi submetido para o jornal IEEE Transactions on Evolutionary Computation (submissão em 28 de agosto de 2012). 
3. Aplicação de redes Bayesianas na modelagem de LD. Esta contribuição introduz a metodologia das RBs na modelagem do desequilíbrio de ligação (LD), problema de alta relevância em genética e bioinformática. As metodologias clássicas para abordar este problema estão baseadas em medidas de desequilíbrio e ferramentas de visualização das mesmas. No entanto, tal abordagem está limitada a oferecer uma visão estática e parcial da estrutura de LD. Algumas tentativas de fornecer uma visão mais detalhada dos padrões de LD têm sido descritas por Thomas e Camp (2004) e Thomas (2005), introduzindo as redes de Markov para esse problema. Continuando nessa linha de modelar LD com modelos gráficos probabilísticos, na presente tese foi testado o potencial das RBs em descrever a estrutura de LD. Os resultados foram promissores, encontrando-se que as RBs aprendidas com EES-BN conseguem caracterizar LD com um nível de detalhe maior do que a abordagem clássica e também que a direcionalidade das mesmas pode fornecer informações interessantes que a abordagem previa com redes de Markov não é capaz de capturar.

A contribuição da aplicação de redes Bayesianas na modelagem de LD foi publicada no jornal Bioinformatics (Villanueva e Maciel, 2010).

\subsection{Limitações e sugestões de trabalhos futuros}

Um ponto que poderia ser melhorado em EES-BN é a configuração do tamanho da população de doadores no bloco de recombinação com MergePop. Os resultados mostraram que o escore dos filhos e o tempo computacional empregado por esse operador são função do tamanho da população de doadores, encontrando-se nos bancos analisados um aceitável equilíbrio com um tamanho de 2 ou 3 doadores. No entanto, em situações de bancos de dados com vastas quantidades de amostras (não testados neste trabalho) talvez seria preferível maiores tamanhos da população doadora, apesar do aumento do esforço computacional do operador. Isto porque com um tamanho maior da população doadora o número de gerações para convergir seria diminuído e, portanto, diminuiria também o número de chamadas à função de escore, que pelo geral, tem um custo computacional exponencial no número de amostras. Já os indivíduos criados com MergePop não precisam de avaliação. Um esquema auto-ajustável poderia ser projetado para determinar automaticamente o tamanho da população doadora conforme as propriedades do banco de dados ingressado. 
Uma outra ideia que poderia melhorar o desempenho de EES-BN é na forma de escolher a população doadora para MergePop. Na implementação atual de EES-BN essa seleção é realizada de forma aleatória. Não obstante, se tal seleção fosse realizada maximizando a diversidade das famílias nos indivíduos doadores talvez se teria uma maior probabilidade de encontrar melhores famílias, e portanto melhores filhos. Um esquema eficiente de verificação de diversidade seria necessário na implementação dessa ideia.

Um outro ponto interessante que poderia ser explorado é no bloco de injeção de diversidade. Na implementação atual de EES-BN os indivíduos injetados são criados aleatoriamente (impondo um máximo número de pais por nó). Algumas outras formas de criação poderiam ser testadas de tal forma que se garanta que os indivíduos injetados sejam diferentes da população atual. Uma ideia seria observar todas as ordens ancestrais dos indivíduos da população atual para depois inverte-las e otimiza-las com K2, resultando assim em estruturas com direções de arestas completamente novas. Seria necessário verificar se o custo computacional maior gerado pela introdução de $\mathrm{K} 2$ nesse bloco seria compensado com um ganho em escore na solução final.

Uma ideia que poderia ser interessante explorar é a adaptação de EES-BN para o aprendizado de redes Bayesianas dinâmicas - DBN (Husmeier, 2003), as quais são modelos que podem representar diretamente relações de realimentação de processos temporais, frequentemente observadas em sistemas biológicos. Como indicado por Murphy (2002), uma DBN pode ser tratada como uma RB normal com restrições nas direções das arestas (não são permitidas arestas dirigidas conectando variáveis do tempo $t$ para variáveis do tempo $t-1, i=1,2, \ldots$ ). Nesse sentido, a etapa de aprendizagem da superestrutura pode ser modificada ou generalizada para acomodar essas restrições de direcionalidade. Seria interessante ver se a efetividade de EES-BN poderia ser extrapolada para o caso de DBNs.

A paralelização de EES-BN é outra proposta de pesquisa com grande potencial para aumentar a usabilidade do sistema proposto. Uma ideia simples de paralelizar EES-BN é particionar o conjunto de variáveis em vários subconjuntos, aprender de forma paralela uma RB em cada subconjunto e então realizar o processo de reconstrução da estrutura completa, tal como sugerido por Li et al. (2008). Uma paralelização eficiente de EES-BN poderia, por exemplo, abrir possibilidades de modelar grandes redes gênicas envolvendo milhares de genes (senão todos os genes de um organismo), fornecendo assim modelos que podem ser usados em simulações e inferências com uma alta proximidade ao processo biológico subjacente. 


\section{Bibliografia}

Abramson, B., Brown, J., Edwards, W., Murphy, A., e Winkler, R. L. (1996). Hailfinder: A Bayesian system for forecasting severe weather. International Journal of Forecasting, 12(1):57-71.

Acid, S. e De Campos, L. (2000). Learning right sized belief networks by means of a hybrid methodology. In Zighed, D., Komorowski, J., e Zytkow, J. (Eds.), Principles of Data Mining and Knowledge Discovery, vol. 1910 of Lecture Notes in Computer Science, pp. 309-315. Springer Berlin / Heidelberg.

Aliferis, C. F., Tsamardinos, I., Statnikov, A. R., e Brown, L. E. (2003). Causal Explorer: A Causal Probabilistic Network Learning Toolkit for Biomedical Discovery. In Valafar, F., Valafar, H., Valafar, F., e Valafar, H. (Eds.), Proceedings of the International Conference on Mathematics and Engineering Techniques in Medicine and Biological Scienes, METMBS '03, pp. 371-376.

Amon, A., Irniger, S., e Nasmyth, K. (1994). Closing the Cell-Cycle Circle in Yeast - G2 Cyclin Proteolysis Initiated at Mitosis Persists until the Activation of G1 Cyclins in The Next Cycle. Cell, 77(7):1037-1050.

Ash, R. B. (2008). Basic Probability Theory. Dover Publications.

Bahler, J. (2005). Cell-cycle control of gene expression in budding and fission yeast. Annual Review of Genetics, 39:69-94.

Barrett, J., Fry, B., Maller, J., e Daly, M. (2005). Haploview: analysis and visualization of LD and haplotype maps. Bioinformatics, 21(2):263-265.

Beinlich, I. A., Suermondt, H. J., Chavez, R. M., e Cooper, G. F. (1989). The ALARM Monitoring System: A Case Study with Two Probabilistic Inference Techniques for Be- 
lief Networks. In Hunter, J., Cookson, J., e Wyatt, J. (Eds.), Second European Conference on Artificial Intelligence in Medicine, vol. 38, pp. 247-256. Springer-Verlag.

Ben-Gal, I., Shani, A., Gohr, A., Grau, J., Arviv, S., Shmilovici, A., Posch, S., e Grosse, I. (2005). Identification of transcription factor binding sites with variable-order Bayesian networks. BIOINFORMATICS, 21(11):2657-2666.

Binder, J., Koller, D., Russell, S., e Kanazawa, K. (1997). Adaptive probabilistic networks with hidden variables. Machine Learning, 29(2-3):213-244.

Botstein, D. e Fink, G. R. (2011). Yeast: An Experimental Organism for 21st Century Biology. Genetics, 189(3):695-704.

Bouckaert, R. R. (1993). Probalistic network construction using the minimum description length principle. In Proceedings of the European Conference on Symbolic and Quantitative Approaches to Reasoning and Uncertainty, vol. 747 of Lecture Notes in Computer Science, pp. 41-48. Springer-Verlag.

Browning, S. R. e Browning, B. L. (2007). Rapid and accurate haplotype phasing and missingdata inference for whole-genome association studies by use of localized haplotype clustering. American Journal of Human Genetics, 81(5):1084-1097.

Campos, L. D. e Huete, J. (2000a). Approximating causal orderings for Bayesian networks using genetic algorithms and simulated annealing. In Proceedings of the International Conference on Information Processing and Management of Uncertainty in Knowledge-based Systems (IPMU'00), pp. 333-340.

Campos, L. D. e Huete, J. (2000b). A new approach for learning belief networks using independence criteria. International Journal of Approximate Reasoning, 24:11-37.

Campos, L. M. d., Fernández-Luna, J. M., e Puerta, J. M. (2002). Local search methods for learning bayesian networks using a modified neighborhood in the space of dags. In Proceedings of the 8th Ibero-American Conference on AI: Advances in Artificial Intelligence - IBERAMIA 2002, vol. 2527 of Lecture Notes in Computer Science, pp. 182-192.

Carvalho, A. (2011). A cooperative coevolutionary genetic algorithm for learning bayesian network structures. In Proceedings of the 13th annual conference on Genetic and evolutionary computation, GECCO '11, pp. 1131-1138. 
Castelo, R. e Kocka, T. (2004). On inclusion-driven learning of Bayesian networks. Journal of Machine Learning Research, 4(4):527-574.

Chang, P.-C., Huang, W.-H., e Ting, C.-J. (2010). Dynamic diversity control in genetic algorithm for mining unsearched solution space in TSP problems. Expert Systems with Applications, 37(3):1863-1878.

Charitos, T., van der Gaag, L., Visscher, S., Schurink, K., e Lucas, P. (2009). A dynamic bayesian network for diagnosing ventilator-associated pneumonia in icu patients. Expert Systems with Applications, 36(2 PART 1):1249-1258.

Chen, K., Calzone, L., Csikasz-Nagy, A., Cross, F., Novak, B., e Tyson, J. (2004). Integrative analysis of cell cycle control in budding yeast. Molecular Biology of the Cell, 15(8):38413862.

Cheng, J., Greiner, R., Kelly, J., Bell, D., e Liu, W. (2002). Learning bayesian networks from data: an information-theory based approach. Artificial Intelligence, 137:43-90.

Chickering, D. (2002). Learning equivalence classes of Bayesian-network structures. Journal of Machine Learning Research, 2(3):445-498.

Chickering, D., Heckerman, D., e Meek, C. (2004). Large-sample learning of Bayesian networks is NP-hard. Journal of Machine Learning Research, 5:1287-1330.

Chickering, D. e Meek, C. (2006). On the incompatibility of faithfulness and monotone DAG faithfulness. ARTIFICIAL INTELLIGENCE, 170(8-9):653-666.

Chickering, D. M. e Boutilier, C. (2002). Optimal structure identification with greedy search. Journal of Machine Learning Research, 3:507-554.

Chickering, D. M., Geiger, D., e Heckerman, D. (1995). Learning Bayesian networks: Search methods and experimental results. In Proceedings of the Fifth International Workshop on Artificial Intelligence and Statistics, pp. 112-128.

Cooper, G. F. e Herskovits, E. A. (1992). A bayesian method for the induction of probabilistic networks from data. Machine Learning, 9(4):309 - 347.

Cooper, L. (2000). Strategic marketing planning for radically new products. Journal of Marketing, 64(1):1-16. 
Cotta, C. e Muruzabal, J. (2002). Towards a more efficient evolutionary induction of bayesian networks. In Parallel Problem Solving from Nature VII, pp. 730-739.

Cowell, R. G., Lauritzen, S. L., David, A. P., e Spiegelhalter, D. J. (1999). Probabilistic Networks and Expert Systems. Springer-Verlag, Secaucus, NJ, USA, 1st ed.

Daly, R. e Shen, Q. (2009). Learning bayesian network equivalence classes with ant colony optimization. Journal of Artificial Intelligence Research, 35:391-447.

Daly, R., Shen, Q., e Aitken, S. (2011). Learning Bayesian networks: approaches and issues. Knowledge Engineering Review, 26(2):99-157.

Dasgupta, D. e Michalewicz, Z. (Eds.) (1997). Evolutionary Algorithms in Engineering Applications. Springer,.

Dash, D. e Druzdzel, M. J. (1999). A hybrid anytime algorithm for the construction of causal models from sparse data. In Proceedings of the fifteenth international conference on uncertainty in artificial intelligence, pp. 142-149. Morgan Kaufmann.

de Campos, L. M., Fernández-Luna, J. M., e Puerta, J. M. (2003). An iterated local search algorithm for learning bayesian networks with restarts based on conditional independence tests. Int. J. Intell. Syst., 18(2):221-235.

de Campos, L. M., Fernández-Luna, J. M., Gámez, J. A., e Puerta, J. M. (2002). Ant colony optimization for learning bayesian networks. International Journal of Approximate Reasoning, 31(3):291 - 311 .

De Morais, S. e Aussem, A. (2010). An efficient and scalable algorithm for local bayesian network structure discovery. In Proceedings of the 2010 ECML/PKDD, pp. 164-179.

Delaplace, A., Brouard, T., e Cardot, H. (2007). Two evolutionary methods for learning Bayesian network structures. In Wang, Y and Cheung, YM and Liu, H (Ed.), Computational Intelligence and Security, vol. 4456 of Lecture Notes in Artificial Intelligence, pp. 288-297.

dos Santos, E., Hruschka, E., e Ebecken, N. (2010a). Evolutionary Algorithm Using Random Multi-point Crossover Operator for Learning Bayesian Network Structures. In Machine Learning and Applications (ICMLA), 2010 Ninth International Conference on, pp. 430 435. 
dos Santos, E., Hruschka, E., Hruschka, E., e Ebecken, N. (2010b). A Distance-Based Mutation Operator for learning Bayesian Network structures using Evolutionary Algorithms. In IEEE Congress on Evolutionary Computation (CEC), pp. $1-8$.

Faulkner, E. (2007). K2GA: Heuristically Guided Evolution of Bayesian Network Structures from Data. In Computational Intelligence and Data Mining, 2007. CIDM 2007. IEEE Symposium on, pp. 18 -25.

Friedman, N., Goldszmidt, M., e Wyner, A. (1999). Data Analysis with Bayesian Networks: A Bootstrap Approach. In Proceedings of the Fifteenth Conference on Uncertainty in Artificial Intelligence (UAI'99), pp. 196-205.

Friedman, N., Linial, M., Nachman, I., e Pe'er, D. (2000). Using Bayesian networks to analyze expression data. J. of Comput. Bio., 7(3-4):601-620.

Fu, S. e Desmarais, M. (2008). Tradeoff analysis of different Markov blanket local learning approaches. In Washio, T. and Suzuki, E. and Ting, K.M. and Inokuchi, A. (Ed.), Advances in Knowledge Discovery and Data Mining, Proceedings, vol. 5012 of Lecture Notes in Artificial Intelligence, pp. 562-571.

Gou, K. X., Jun, G. X., e Zhao, Z. (2007). Learning bayesian network structure from distributed homogeneous data. In Proceedings of the Eighth ACIS International Conference on Software Engineering, Artificial Intelligence, Networking, and Parallel/Distributed Computing - Volume 03, SNPD ’07, pp. 250-254. IEEE Computer Society.

Grechko, V. (2002). Using molecular dna markers in phylogeny and systematics. Genetika, 38(8):1013-1033.

Gross, J. L. e Yellen, J. (2005). Graph Theory and its Applications. Chapman and Hall/CRC Press, second ed.

HapMap-Consortium, T. I. (2003). The International HapMap Project. Nature, 426(6968):789_ 796.

Harwood, S. e Scheines, R. (2002). Genetic algorithm search over causal models. Technical report, Carnegie Mellon University, Dept. of Philosophy.

Heckerman, D., Geiger, D., e Chickering, D. (1995). Learning Bayesian Networks The combination of Knowledge an Statistical data. Machine Learning, 20(3):197-243. 
Hedrick, P. (1987). Gametic Disequilibrium Measures - Procees with Caution. Genetics, 117(2):331-341.

Heng, X.-C., Qin, Z., Wang, X.-H., e Shao, L.-P. (2006). Research on learning bayesian networks by particle swarm optimization. Information Technology Journal, 5(3):540-545.

Hey, J. (2004). What's so hot about recombination hotspots? PLOS Biology, 2(6):730-733.

Hill, W. G. e Robertson, A. (1968). Linkage disequilibrium in finite populations . Theoretical and Applied Genetics, 38(6):226-231.

Hsu, W. H., Guo, H., Perry, B. B., e Stilson, J. A. (2002). A permutation genetic algorithm for variable ordering in learning bayesian networks from data. In Proceedings of the Genetic and Evolutionary Computation Conference (GECCO-2002, pp. 383-390. Morgan Kaufmann.

Husmeier, D. (2003). Reverse engineering of genetic networks with Bayesian networks. Biochemical Society Transactions, 31(6):1516-1518.

Hwang, K. B., Lee, J. W., Chung, S.-W., e Zhang, B.-T. (2002). Construction of large-scale bayesian networks by local to global search. In Proceedings of the 7th Pacific Rim International Conference on Artificial Intelligence: Trends in Artificial Intelligence, PRICAI '02, pp. $375-384$.

Jansen, R., Yu, H., Greenbaum, D., Kluger, Y., Krogan, N., Chung, S., Emili, A., Snyder, M., Greenblatt, J., e Gerstein, M. (2003). A Bayesian networks approach for predicting protein-protein interactions from genomic data. Science, 302(5644):449-453.

Janzura, M. e Nielsen, J. (2006). A simulated annealing-based method for learning bayesian networks from statistical data: Research articles. Int. J. Intell. Syst., 21(3):335-348.

Jia, H., Liu, D., Chen, J., e Guan, J. (2008). Learning Markov equivalence classes of Bayesian Network with immune genetic algorithm. In 3rd IEEE Conference on Industrial Electronics and Applications ICIEA 2008, pp. 197 -202.

Jia, H., Liu, D., Chen, J., e Liu, X. (2007). A hybrid approach for learning Markov Equivalence Classes of Bayesian Network. In Zhang, Z. and Siekmann, J. (Ed.), Knowledge Science, Engineering and Managment, vol. 4798 of Lecture Notes in Artificial Intelligence, pp. 611616. 
Jombart, T., Pontier, D., e Dufour, A.-B. (2009). Genetic markers in the playground of multivariate analysis. Heredity, 102(4):330-341.

Jones, N., Ougham, H., Thomas, H., e Pasakinskiene, I. (2009). Markers and mapping revisited: finding your gene. New Phytologist, 183(4):935-966.

Kalisch, M. e Bühlmann, P. (2007). Estimating High-Dimensional Directed Acyclic Graphs with the PC-Algorithm. Journal of Machine Learning Research, 8:613-636.

Khanteymoori, A. R., Menhaj, M. B., e Homayounpour, M. M. (2011). Structure Learning in Bayesian Networks Using Asexual Reproduction Optimization. Etril Journal, 33(1):39-49.

Kim, K.-J., Yoo, J.-O., e Cho, S.-B. (2005). Robust Inference of Bayesian Networks Using Speciated Evolution and Ensemble. In Foundations of Intelligent Systems, vol. 3488 of Lecture Notes in Computer Science, pp. 185-232.

Kirkos, E., Spathis, C., e Manolopoulos, Y. (2007). Data mining techniques for the detection of fraudulent financial statements. Expert Systems with Applications, 32(4):995-1003.

Kjaerulff, U. B. e Madsen, A. L. (2008). Bayesian Networks and Influence Diagrams: A Guide to Construction and Analysis. Springer Publishing Company, primeira ed.

Koivisto, M. e Sood, K. (2004). Exact Bayesian structure discovery in Bayesian networks. Journal of Machine Learning Research, 5:549-573.

Kojima, K., Perrier, E., Imoto, S., e Miyano, S. (2010). Optimal search on clustered structural constraint for learning bayesian network structure. Journal of Machine Learning Research, $11: 285-310$.

Kumuthini, J., Jouffe, L., e Bessant, C. (2007). A novel graph optimisation algorithm for the extraction of gene regulatory networks from temporal microarray data. In Hochreiter, $\mathrm{S}$ and Wagner, R (Ed.), Bioinformatics Research and Development, Proceedings, vol. 4414 of Lecture Notes in Computer Science, pp. 28-37.

Larranaga, P., Kuijpers, C., Murga, R., e Yurramendi, Y. (1996a). Learning Bayesian network structures by searching for the best ordering with genetic algorithms. Systems, Man and Cybernetics, Part A: Systems and Humans, IEEE Transactions on, 26(4):487 -493. 
Larranaga, P., Kuijpers, C. M. H., Murga, R., Inza, I., e Dizdarevic, S. (1999). Genetic algorithms for the travelling salesman problem: A review of representations and operators. Artificial Intelligence Review, 13:129-170.

Larranaga, P., Poza, M., Yurramendi, Y., Murga, R., e Kuijpers, C. (1996b). Structure learning of bayesian networks by genetic algorithms: a performance analysis of control parameters. Pattern Analysis and Machine Intelligence, IEEE Transactions on, 18(9):912 -926.

Lee, E., Park, Y., e Shin, J. (2009). Large engineering project risk management using a bayesian belief network. Expert Systems with Applications, 36(3 PART 2):5880-5887.

Lee, S., Son, Y.-J., e Jin, J. (2008). Decision field theory extensions for behavior modeling in dynamic environment using Bayesian belief network. Information Sciences, 178(10):22972314.

Li, F., Long, T., Lu, Y., Ouyang, Q., e Tang, C. (2004). The yeast cell-cycle network is robustly designed. Proceedings of the National Academy of Sciences of the United States of America , 101(14):4781-4786.

Li, N. e Stephens, M. (2003). Modeling linkage disequilibrium and identifying recombination hotspots using single-nucleotide polymorphism data. Genetics, 165(4):2213-2233.

Li, W., Liu, W., e Yue, K. (2008). Recovering the Global Structure from Multiple Local Bayesian Networks. International Journal on Artificial Intelligence Tools, 17(6):1067-1088.

Liu, F., Tian, F., e Zhu, Q. (2007). An improved greedy bayesian network learning algorithm on limited data. In de Sá, J., Alexandre, L., Duch, W., e Mandic, D. (Eds.), Artificial Neural Networks - ICANN 2007, vol. 4668 of Lecture Notes in Computer Science, pp. 49-57.

Liu, Z. e Lin, S. (2005). Multilocus LD measure and tagging SNP selection with generalized mutual information. Genetic Epidemiology, 29(4):353-364.

Lucas, P., van der Gaag, L., e Abu-Hanna, A. (2004). Bayesian networks in biomedicine and health-care. Artificial Intelligence in Medicine, 30(3):201-214.

Luikart, G., Cornuet, J., e Allendorf, F. (1999). Temporal changes in allele frequencies provide estimates of population bottleneck size. Conservation Biology, 13(3):523-530. 
Luikart, G., England, P., Tallmon, D., Jordan, S., e Taberlet, P. (2003). The power and promise of population genomics: From genotyping to genome typing. Nature Reviews Genetics, 4(12):981-994.

Marcot, B., Holthausen, R., Raphael, M., Rowland, M., e Wisdom, M. (2001). Using Bayesian belief networks to evaluate fish and wildlife population viability under land management alternatives from an environmental impact statement. Forest Ecology and Management, 153(1-3, SI):29-42.

Margaritis, D. e Thrun, S. (2000). Bayesian network induction via local neighborhoods. In Advances in Neural Information Processing Systems, vol. 12, pp. 505-511.

Mueller, J. (2004). Linkage disequilibrium for different scales and applications. Briefings in Bioinformatics, 5(4):355-364.

Murphy, K. (2002). Dynamic Bayesian Networks: Representation, Inference and Learning. Tese de Doutorado, Computer Science Division. University of California., Berkeley, US.

Murphy, K. P. (2001). The bayes net toolbox for matlab. Computing Science and Statistics, 33:2001.

Muruzabal, J. e Cotta, C. (2004). A primer on the evolution of equivalence classes of BayesianNetwork structures. In Parallel Problem Solving from Nature VIII., vol. 3242 of Lecture Notes in Computer Science, pp. 612-621.

Muruzabal, J. e Cotta, C. (2007). A study on the evolution of Bayesian network graph structures. In Advances in Probabilistic Graphical Models, vol. 213 of Studies in Fuzziness and Soft Computing, pp. 193-213.

Myers, S., Bottolo, L., Freeman, C., McVean, G., e Donnelly, P. (2005). A fine-scale map of recombination rates and hotspots across the human genome. Science, 310(5746):321-324.

Neapolitan, R. (2003). Learning Bayesian networks. Prentice Hall.

Nicolas, P., Sun, F., e Li, L. M. (2006). A model-based approach to selection of tag SNPs. BMC Bioinformatics, 7.

Nikovski, D. (2000). Constructing Bayesian networks for medical diagnosis from incomplete and partially correct statistics. IEEE Transactions on Knowledge and Data Engineering, 12(4):509-516. 
Oba, S., Sato, M., Takemasa, I., Monden, M., Matsubara, K., e Ishii, S. (2003). A Bayesian missing value estimation method for gene expression profile data. Bioinformatics, 19(16):20882096.

Ott, S., Imoto, S., e Miyano, S. (2004). Finding optimal models for small gene networks. In Pacific Symposium on Biocomputing, pp. 557-567.

Park, H.-S. e Cho, S.-B. (2012). Evolutionary attribute ordering in bayesian networks for predicting the metabolic syndrome. Expert Systems with Applications, 39(4):4240-4249.

Parviainen, P. e Koivisto, M. (2009). Exact structure discovery in Bayesian networks with less space. In Proceedings of the Twenty-Fifth Conference on Uncertainty in Artificial Intelligence (UAI'09), pp. 436-443.

Peña, J. M. (2001). On Unsupervised Learning of Bayesian Networks and Conditional Gaussian Networks. Tese de Doutorado, Department of Computer Science. University of the Basque Country., Donostia, San Sebastián.

Pearl, J. (1988). Prob. Reas. in intelligent systems. Morgan Kaufmann.

Pearl, J. (2009). Causality: Models, Reasoning, and Inference. Cambridge University Press, 2nd edition ed.

Pena, J., Nilsson, R., Bjorkegren, J., e Tegner, J. (2007). Towards scalable and data efficient learning of Markov boundaries. International Journal of Approximate Reasoning, 45(2):211232.

Perrier, E., Imoto, S., e Miyano, S. (2008). Finding Optimal Bayesian Network Given a SuperStructure. Journal of Machine Learning Research, 9:2251-2286.

Pourret, O., Nam, P., Naïm, P., Marcot, B., e Na?m, P. (2008). Bayesian Networks: A Practical Guide to Applications. John Wiley \& Sons.

Pritchard, J. e Przeworski, M. (2001). Linkage disequilibrium in humans: Models and data. American Journal of Human Genetics, 69(1):1-14.

Rannala, B. e Mountain, J. (1997). Detecting immigration by using multilocus genotypes. Proceedings of the National Academy of Sciences of the United States of America, 94(17):91979201. 
Robinson, R. (1977). Counting unlabeled acyclic digraphs. In Little, C. (Ed.), Combinatorial Mathematics V, vol. 622 of Lecture Notes in Mathematics, pp. 28-43.

Sahin, F. e Devasia, A. (2007). Distributed Particle Swarm Optimization for Structural Bayesian Network Learning. In Felix T.S. Chan and Manoj Kumar Tiwari (Ed.), Swarm Intelligence, Focus on Ant and Particle Swarm Optimization, pp. 505-532. I-Tech Education and Publishing.

Segal, E., Pe'er, D., Regev, A., Koller, D., e Friedman, N. (2005). Learning module networks. Journal of Machine Learning Research, 6:557-588.

Shimodaira, H. (1996). A new genetic algorithm using large mutation rates and populationelitist selection (GALME). In Eighth IEEE International Conference on Tools with Artificial Intelligence, Proceedings, pp. 25-32.

Shimodaira, H. (2001). Methods for reinitializing the population to improve the performance of a diversity-control-oriented genetic algorithm. IEICE Transactions on Information and Systems, E84D(12):1745-1755.

Singh, M. e Valtorta, M. (1995). Construction of Bayesian Network Structures from Data: a Brief Survey and an Efficient Algorithm. International Journal of Approximate Reasoning, 12(2):111-131.

Spellman, P., Sherlock, G., Zhang, M., Iyer, V., Anders, K., Eisen, M., Brown, P., Botstein, D., e Futcher, B. (1998). Comprehensive identification of cell cycle-regulated genes of the yeast Saccharomyces cerevisiae by microarray hybridization. Molecular Biology of the Cell, 9(12):3273-3297.

Spirtes, P., Glymour, C., e Scheines, R. (1991). From probability to causality. Philosophical Studies: An International Journal for Philosophy in the Analytic Tradition, 64(1):1-36.

Spirtes, P., Glymour, C., e Scheines, R. (2000). Causation, prediction, and search. The MIT Press, Cambridge, second ed.

Srinivas, M. e Patnaik, L. (1994). Genetic Algorithms - A Survey. Computer, 27(6):17-26.

Steck, H. (2000). On the use of skeletons when learning in bayesian networks. In Proceedings of the 16th Conference on Uncertainty in Artificial Intelligence, UAI '00, pp. 558-565. 
Steck, H. e Jaakkola, T. (2002). On the dirichlet prior and bayesian regularization. In Advances in Neural Inf. Proces. Systems, vol. 15, pp. 697-704.

Steck, H. e Tresp, V. (1999). Bayesian belief network for data mining. In Proceedings of the second DMDW, pp. 145-154.

Stefano, C., Fontanella, F., Marrocco, C., e Freca, A. (2010). A hybrid evolutionary algorithm for bayesian networks learning: An application to classifier combination. In Applications of Evolutionary Computation, vol. 6024 of Lecture Notes in Computer Science, pp. 221-230. Springer Berlin Heidelberg.

Stekel, D. (2003). Microarray Bioinformatics. Cambridge University Press, New York, USA, 1 st ed.

Tamada, Y., Imoto, S., Araki, H., Nagasaki, M., Print, C., Charnock-Jones, D., e Miyano, S. (2011a). Estimating genome-wide gene networks using nonparametric bayesian network models on massively parallel computers. IEEE/ACM Trans. Comput. Biol. Bioinformatics, 8:683-697.

Tamada, Y., Imoto, S., e Miyano, S. (2011b). Parallel algorithm for learning optimal bayesian network structure. Journal of Machine Learning Research, 12:2437-2459.

Teyssier, M. e Koller, D. (2005). Ordering-based Search: A Simple and Effective Algorithm for Learning Bayesian Networks. In Proceedings of the Twenty-first Conference on Uncertainty in AI (UAI), pp. 584-590, Edinburgh, Scottland, UK.

Thomas, A. (2005). Characterizing allelic associations from unphased diploid data by graphical modeling. Genetic Epidemiology, 29(1):23-35.

Thomas, A. e Camp, N. (2004). Graphical modeling of the joint distribution of alleles at associated loci. American Journal of Human Genetics, 74(6):1088-1101.

Tian, F., Zhang, Y., Wang, Z., e Huang, H. (2007). Learning Bayesian Networks Using Evolutionary Algorithm and a Variant of MDL Score. In Knowledge-Based Intelligent Information and Engineering Systems, vol. 4694 of Lecture Notes in Computer Science, pp. 166-173.

Tsamardinos, I., Aliferis, C., e Statnikov, E. (2003). Algorithms for Large Scale Markov Blanket Discovery. In Proceedings of the 16th International FLAIRS Conference, St, pp. 376-380. 
Tsamardinos, I., Brown, L., e Aliferis, C. (2006a). The max-min hill-climbing Bayesian network structure learning algorithm. Machine Learning, 65(1):31-78.

Tsamardinos, I., Statnikov, A., Brown, L., e Aliferis, C. (2006b). Generating Realistic Large Bayesian Networks by Tiling. In Proceedings of the 19th International FLAIRS Conference, pp. 592-597.

Uusitalo, L. (2007). Advantages and challenges of Bayesian networks in environmental modelling. Ecological Modeling, 203(3-4):312-318.

van Dijk, S. e Thierens, D. (2004). On the use of a non-redundant encoding for learning Bayesian networks from data with a GA. In Parallel Problem Solving from Nature - PPSN VIII, vol. 3242 of Lecture Notes in Computer Science, pp. 141-150.

van Dijk, S., Thierens, D., e van der Gaag, L. (2003). Building a ga from design principles for learning bayesian networks. In Genetic and Evolutionary Computation - GECCO 2003, vol. 2723 of Lecture Notes in Computer Science, pp. 886-897.

Villanueva, E. e Maciel, C. (2012a). An efficient evolutionary system for learning bayesian network structures and its application to gene expression data. Submetido ao journal IEEE Transactions on Evolutionary Computation.

Villanueva, E. e Maciel, C. (2012b). Efficient methods for learning bayesian network superstructures. Aceito para publicação no journal Neurocomputing.

Villanueva, E. e Maciel, C. (2012c). Optimized algorithm for learning bayesian network superstructures. In Proceedings of the International Conference on Pattern Recognition Applications and Methods - ICPRAM 2012, pp. 217-222.

Villanueva, E. e Maciel, C. D. (2010). Modeling associations between genetic markers using Bayesian networks. Bioinformatics, 26(18):i632-i637.

Wang, M., Chen, Z., e Cloutier, S. (2007). A hybrid Bayesian network learning method for constructing gene networks. Computational Biology and Chemistry, 31(5-6):361-372.

Wang, T., Touchman, J. W., e Xue, G. (2004). Applying two-level simulated annealing on bayesian structure learning to infer genetic networks. In In Proceedings of the IEEE Computational Systems Bioinformatics Conference, pp. 647-648. 
Werhli, A. V., Grzegorczyk, M., e Husmeier, D. (2006). Comparative evaluation of reverse engineering gene regulatory networks with relevance networks, graphical gaussian models and bayesian networks. Bioinformatics, 22(20):2523-2531.

Wong, M. e Leung, K. (2004). An efficient data mining method for learning Bayesian networks using an evolutionary algorithm-based hybrid approach. IEEE Trans. on Evol. Comput., 8(4):378-404.

Wong, M. L., Lam, W., e Leung, K. S. (1999). Using evolutionary programming and minimum description length principle for data mining of bayesian networks. Pattern Analysis and Machine Intelligence, IEEE Transactions on, 21(2):174 -178.

Xie, X. e Geng, Z. (2008). A recursive method for structural learning of directed acyclic graphs. J. Mach. Learn. Res., 9:459-483.

Xing-Chen, H., Zheng, Q., Lei, T., e Li-Ping, S. (2007). Learning bayesian network structures with discrete particle swarm optimization algorithm. In Foundations of Computational Intelligence, 2007. FOCI 2007. IEEE Symposium on, pp. 47 -52.

Ye, S., Cai, H., e Sun, R. (2008). An algorithm for bayesian networks structure learning based on simulated annealing with mdl restriction. In Natural Computation, 2008. ICNC '08. Fourth International Conference on, vol. 3, pp. $72-76$.

Yehezkel, R. e Lerner, B. (2009). Bayesian Network Structure Learning by Recursive Autonomy Identification. Journal of Machine Learning Research, 10:1527-1570.

Yu, J., Smith, V., Wang, P., Hartemink, A., e Jarvis, E. (2004). Advances to Bayesian network inference for generating causal networks from observational biological data. Bioinformatics, 20(18):3594-3603.

Zapata, C. (2000). The D' measure of overall gametic disequilibrium between pairs of multiallelic loci. Evolution, 54(5):1809-1812.

Zhang, L., Liu, J., e Deng, H.-W. (2009). A multilocus linkage disequilibrium measure based on mutual information theory and its applications. Genetica, 137(3):355-364. 